\title{
Auto-aggressive CXCR6(+) CD8 T cells cause liver immune pathology in NASH
}

Citation for published version (APA):

Dudek, M., Pfister, D., Donakonda, S., Filpe, P., Schneider, A., Laschinger, M., Hartmann, D., Hueser, N., Meiser, P., Bayerl, F., Inverso, D., Wigger, J., Sebode, M., Oellinger, R., Rad, R., Hegenbarth, S., Anton, M., Guillot, A., Bowman, A., ... Knolle, P. A. (2021). Auto-aggressive CXCR6(+) CD8 T cells cause liver immune pathology in NASH. Nature, 592(7854). https://doi.org/10.1038/s41586-021-03233-8

Document status and date:

Published: 15/04/2021

DOI:

10.1038/s41586-021-03233-8

Document Version:

Publisher's PDF, also known as Version of record

Document license:

Taverne

Please check the document version of this publication:

- A submitted manuscript is the version of the article upon submission and before peer-review. There can be important differences between the submitted version and the official published version of record.

People interested in the research are advised to contact the author for the final version of the publication, or visit the DOI to the publisher's website.

- The final author version and the galley proof are versions of the publication after peer review.

- The final published version features the final layout of the paper including the volume, issue and page numbers.

Link to publication

\footnotetext{
General rights rights.

- You may freely distribute the URL identifying the publication in the public portal. please follow below link for the End User Agreement:

www.umlib.nl/taverne-license

Take down policy

If you believe that this document breaches copyright please contact us at:

repository@maastrichtuniversity.nl

providing details and we will investigate your claim.
}

Copyright and moral rights for the publications made accessible in the public portal are retained by the authors and/or other copyright owners and it is a condition of accessing publications that users recognise and abide by the legal requirements associated with these

- Users may download and print one copy of any publication from the public portal for the purpose of private study or research.

- You may not further distribute the material or use it for any profit-making activity or commercial gain

If the publication is distributed under the terms of Article $25 \mathrm{fa}$ of the Dutch Copyright Act, indicated by the "Taverne" license above, 


\section{Auto-aggressive $\mathrm{CXCR6}^{+} \mathrm{CD8}$ T cells cause liver immune pathology in NASH}

https://doi.org/10.1038/s41586-021-03233-8

Received: 17 February 2020

Accepted: 12 January 2021

Published online: 24 March 2021

Check for updates

\author{
Michael Dudek', Dominik Pfister ${ }^{2}$, Sainitin Donakonda ${ }^{1,3}$, Pamela Filpe ${ }^{4}$, Annika Schneider', $^{1}$ \\ Melanie Laschinger ${ }^{5}$, Daniel Hartmann ${ }^{5}$, Norbert Hüser ${ }^{5}$, Philippa Meiser ${ }^{1}$, Felix Bayerl', \\ Donato Inverso ${ }^{6,7}$, Jennifer Wigger ${ }^{4}$, Marcial Sebode ${ }^{4}$, Rupert Öllinger ${ }^{8}$, Roland Rad $^{8}$, \\ Silke Hegenbarth', Martina Anton ${ }^{1}$, Adrien Guillot $^{9}$, Andrew Bowman ${ }^{10}$, Danijela Heide ${ }^{2}$, \\ Florian Müller ${ }^{2}$, Pierluigi Ramadori' ${ }^{2}$, Valentina Leone ${ }^{11,12}$, Cristina Garcia-Caceres ${ }^{13}$, \\ Tim Gruber ${ }^{13}$, Gabriel Seifert ${ }^{14}$, Agnieszka M. Kabat ${ }^{15}$, Jan-Philipp Mallm ${ }^{16}$, Simon Reider ${ }^{17,18}$, \\ Maria Effenberger ${ }^{17}$, Susanne Roth ${ }^{19}$, Adrian T. Billeter ${ }^{19}$, Beat Müller-Stich ${ }^{19}$, \\ Edward J. Pearce ${ }^{15}$, Friedrich Koch-Nolte ${ }^{20}$, Rafael Käser ${ }^{21}$, Herbert Tilg ${ }^{17}$, Robert Thimme ${ }^{21}$, \\ Tobias Boettler ${ }^{21}$, Frank Tacke ${ }^{9}$, Jean-Francois Dufour ${ }^{22}$, Dirk Haller ${ }^{23}$, Peter J. Murray ${ }^{1,24}$, \\ Ron Heeren ${ }^{10}$, Dietmar Zehn ${ }^{25}$, Jan P. Böttcher ${ }^{1}$, Mathias Heikenwälder ${ }^{2}$ \& Percy A. Knolle ${ }^{1,3,25 凶}$
}

Nonalcoholic steatohepatitis (NASH) is a manifestation of systemic metabolic disease related to obesity, and causes liver disease and cancer $^{1,2}$. The accumulation of metabolites leads to cell stress and inflammation in the liver ${ }^{3}$, but mechanistic understandings of liver damage in NASH are incomplete. Here, using a preclinical mouse model that displays key features of human NASH (hereafter, NASH mice), we found an indispensable role for $T$ cells in liver immunopathology. We detected the hepatic accumulation of CD8 T cells with phenotypes that combined tissue residency (CXCR6) with effector (granzyme) and exhaustion (PD1) characteristics. Liver CXCR6 ${ }^{+}$ CD8 T cells were characterized by low activity of the FOXO1 transcription factor, and were abundant in NASH mice and in patients with NASH. Mechanistically, IL-15 induced FOXO1 downregulation and CXCR6 upregulation, which together rendered liver-resident $\mathrm{CXCR}^{+} \mathrm{CD} 8 \mathrm{~T}$ cells susceptible to metabolic stimuli (including acetate and extracellular ATP) and collectively triggered auto-aggression. $\mathrm{CXCR6}^{+} \mathrm{CD} 8 \mathrm{~T}$ cells from the livers of NASH mice or of patients with NASH had similar transcriptional signatures, and showed auto-aggressive killing of cells in an MHC-class-I-independent fashion after signalling through $\mathrm{P} 2 \mathrm{X} 7$ purinergic receptors. This killing by auto-aggressive CD8 T cells fundamentally differed from that by antigen-specific cells, which mechanistically distinguishes auto-aggressive and protective T cell immunity.
Preclinical mouse models-which reflect key findings in patients with $\mathrm{NASH}$, including obesity, insulin resistance, metabolic disturbance, low-grade inflammation and liver cancer ${ }^{1}-$ are suitable for studying the pathogenesis of NASH. Mice fed a choline-deficient, high-fat diet (CD-HFD) or a Western diet for 9-12 months show these features of NASH, alongside with changes in the immune cell populations of the liver ${ }^{4-7}$.

\section{Liver CXCR6 ${ }^{+}$CD8 T cells in NASH}

The development of NASH features in mice fed a CD-HFD requires conventional $T$ cells, as shown by the fact that serum alanine aminotransferases and liver histology in mice that lack the genes that encode T cell receptor (TCR) $\beta$ and TCR $\delta\left(T c r b^{-/-} T_{c r d}{ }^{-1-}\right.$ mice) were normal (Fig.1a-c),

${ }^{1}$ Institute of Molecular Immunology and Experimental Oncology, School of Medicine, Technical University of Munich (TUM), Munich, Germany. ${ }^{2}$ Institute of Chronic Inflammation and Cancer,

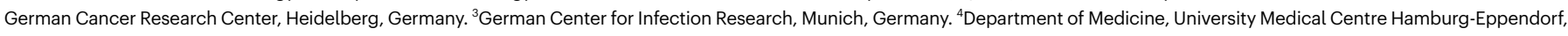
Hamburg, Germany. ${ }^{5}$ Department of Surgery, University Hospital München rechts der Isar, TUM, Munich, Germany. ${ }^{6}$ Division of Vascular Oncology and Metastasis, German Cancer

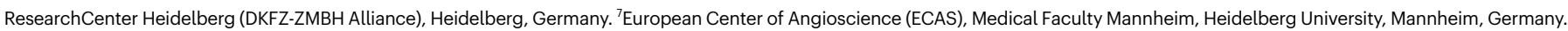
${ }^{8}$ Institute of Molecular Oncology and Functional Genomics, TUM, Munich, Germany. ${ }^{9}$ Department of Hepatology and Gastroenterology, Charité Universitätsmedizin, Berlin, Germany.

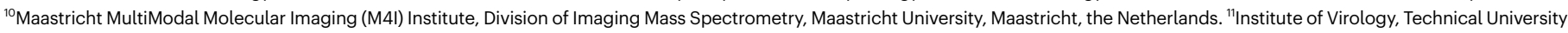

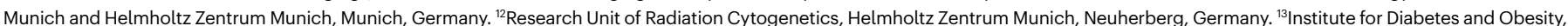

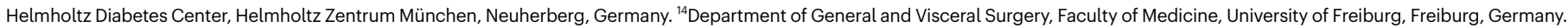

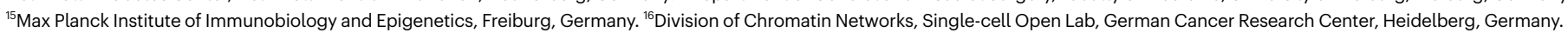
${ }^{17}$ Department of Internal Medicine I, Gastroenterology, Hepatology, Endocrinology and Metabolism, Medical University Innsbruck, Innsbruck, Austria. ${ }^{18} \mathrm{Christian}$ Doppler Labor for Mucosal Immunology, Innsbruck, Austria. ${ }^{19}$ Department of General, Visceral and Transplantation Surgery, Heidelberg University, Heidelberg, Germany. ${ }^{20}$ Institute of Immunology, University Medical

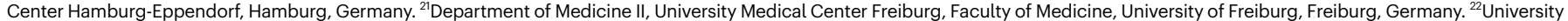
Clinic for Visceral Surgery and Medicine, Inselspital, University of Bern, Bern, Switzerland. ${ }^{23}$ Chair of Nutrition and Immunology, School of Life Sciences Weihenstephan, TUM, Freising, Germany. ${ }^{24}$ Max Planck Institute for Biochemistry, Martinsried, Germany. ${ }^{25}$ Division of Animal Physiology and Immunology, School of Life Sciences Weihenstephan, TUM, Freising, Germany.

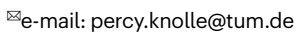



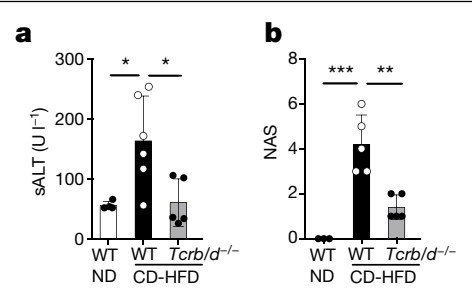

d

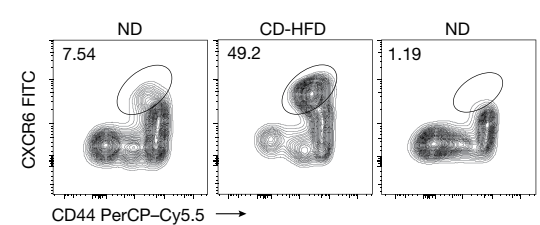

f

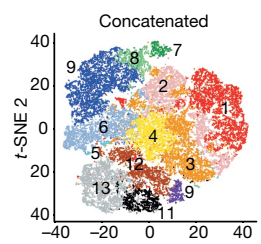

$t$-SNE $1 \longrightarrow$

(1) $\mathrm{CX} \frac{\mathrm{CD} 8^{+} T \text { cells }}{\mathrm{CR}^{+} \mathrm{GzmB} \mathrm{B}^{+} \mathrm{PD} 1^{\text {high }}}$

(2) $\mathrm{CXCR6}^{+} \mathrm{GzmB}-\mathrm{PD} 1^{\text {high }}$
(3) $\mathrm{CXCR6}{ }^{+} \mathrm{GzmB} \mathrm{C}^{-} \mathrm{PD} 1^{\text {int }}$

(4) CXCR6-GzmB-PD1-

(5) CXCR6-GzmB-PD1 high
(6) CXCR6-GzmB-PD1 int
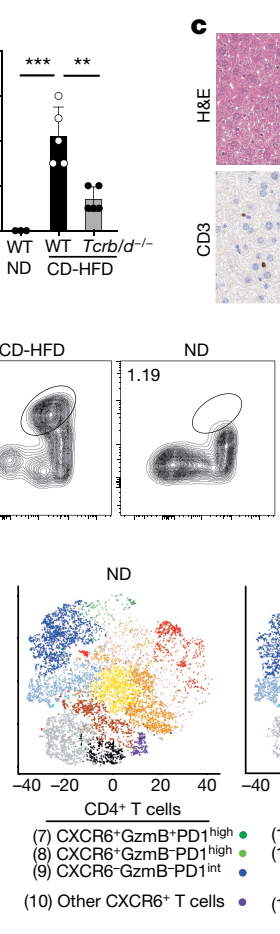

ND
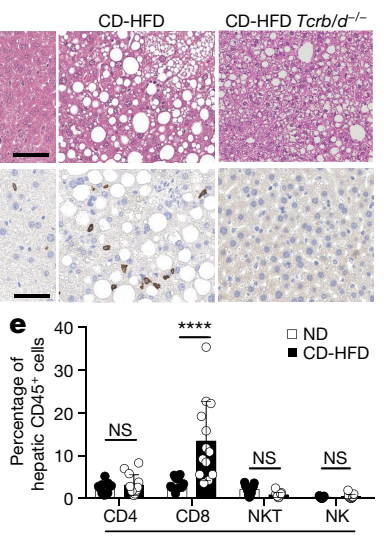

s

CD-HFD

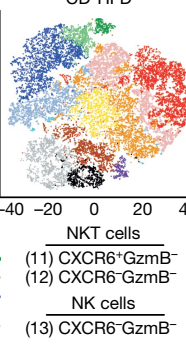

g

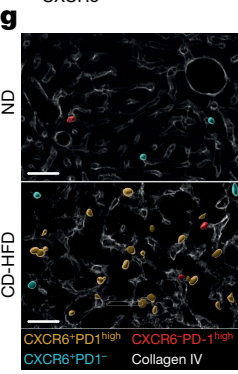

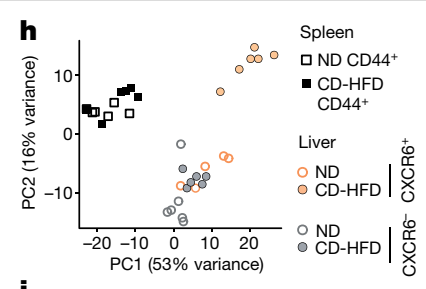

i CD-HFD: CXCR6 ${ }^{+}$vs CXCR6-
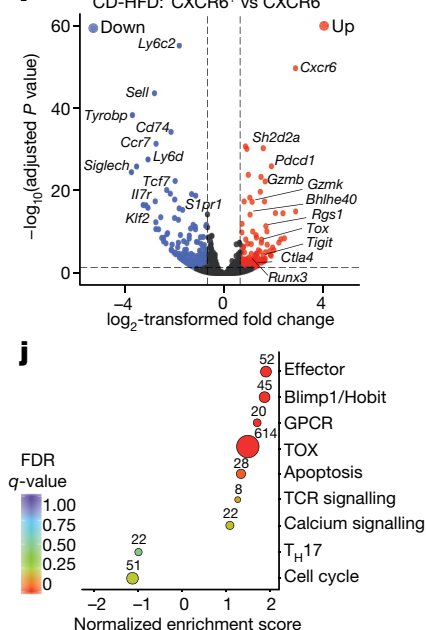

Fig. 1 | CD8 T cells in NASH mice have a unique pathogenic profile. $a-c$, Serum alanine aminotransferases (sALT) (a), nonalcoholic fatty liver disease (NAFLD) activity score (NAS) (b) and liver immunohistochemistry (c) in $T c r b^{-/-} T_{c r d}{ }^{-/}\left(T c r b / d^{-1-}\right)$ mice $(n=5)$ compared to wild-type (WT) littermates $(n=4)$ after six months of feeding a CD-HFD. Two independent experiments. Scale bar, $100 \mu \mathrm{m}$. H\&E, haematoxylin and eosin; ND, normal diet.d, Hepatic (left and middle) and splenic (right) $\mathrm{CXCR6}{ }^{+} \mathrm{CD} 44^{+} \mathrm{CD} 8 \mathrm{~T}$ cells. e, Frequencies of hepatic lymphocyte populations in mice fed a normal diet $(n=11)$ and NASH mice $(n=13)$. Two independent experiments. NK, natural killer cells; NKT, natural killer T cells. f, Phenograph-based analysis of hepatic lymphocytes $(n=5) . t$-SNE, $t$-distributed stochastic neighbour embedding. $\mathbf{g}$, Representative microscopic image of liver CD8 T cells depicting 3D cell objects. Scale bar, $50 \mu \mathrm{m} . \mathbf{h}-\mathbf{j}$, Principal component (PC) analysis (h), volcano plot analysis (i) and GSEA (j) of differentially expressed genes from hepatic CD $44^{+} \mathrm{CXCR} 6^{+} \mathrm{CD} 8$ T cells compared to $\mathrm{CD} 44^{+} \mathrm{CXCR} 6^{-} \mathrm{CD} 8 \mathrm{~T}$ cells and splenic CD $44^{+} \mathrm{CD} 8 \mathrm{~T}$ cells isolated from mice fed a normal diet $(n=3)$ or a CD-HFD $(n=3)$. Technical duplicates. FDR, false discovery rate. $\operatorname{Exact} P(\mathbf{a}, \mathbf{b}, \mathbf{e})$ and $n(\mathbf{e})$ values are presented in Source Data. ${ }^{*} P<0.05,{ }^{* *} P<0.01,{ }^{* * *} P<0.001,{ }^{* * * *} P<0.0001$; NS, not significant. One-way analysis of variance (ANOVA) with Tukey's (a, b), and two-way ANOVA with Sidak's (e), multiple comparison test. In a, b, e data are mean \pm s.e.m., errors are shown as s.d. whereas $\mathrm{Ja1}^{-/-}$(which contain a knockout of the Tcra-J gene cluster) or $C d 1 d^{-/-}$mice (Cd1d is also known as Cd1d1) - which lack T cells with invariant $T$ cell receptors and natural killer T cells-developed features of NASH (Extended Data Fig. 1). Furthermore, $\mathrm{Tcrb}^{-1-} \mathrm{Tcrd}^{-1-}$ mice fed a CD-HFD were not obese and liver steatosis was reduced (as compared to wild-type mice) (Fig. 1c, Extended Data Fig. 1), which collectively implicates T cells in the development of obesity, steatosis and NASH.

We phenotyped T cells, which revealed an increase of hepatic CD8 T cells in NASH mice that express the chemokine receptor CXCR6 (a marker of liver-resident CD8 T cells) but not CD49a, CX ${ }_{3}$ CR1 or KLRG1 (Fig. 1d, e, Extended Data Fig. 1), which characterize tissue-resident memory, effector memory or short-lived effector cells, respectively ${ }^{8-12}$. High numbers of hepatic CXCR6 ${ }^{+} \mathrm{CD} 8 \mathrm{~T}$ cells in NASH mice were distributed throughout the liver and co-expressed markers associated with exhaustion (PD1), effector function (GzmB, TNF and IFN $\gamma$ ) and apoptosis, but not Ki67 or BCL2 (which are markers of proliferation or survival) (Fig. 1f, g, Extended Data Fig. 1). An increase in the numbers of hepatic CXCR6 $^{+}$PD $1^{\text {high }}$ CD8 T cells was a general feature of liver immune pathology driven by obesity, from a modest increase in the livers of mice fed a high-fat diet to a high increase in mice fed a Western diet or in obese, hyperphagic leptin-deficient $o b / o b$ mice (Extended Data Fig. 2). The phenotype of hepatic CXCR6 ${ }^{+} \mathrm{CD} 8 \mathrm{~T}$ cells we observed is not compatible with current classifications into liver-resident memory $T$ cells or exhausted T cells ${ }^{8,13-15}$, which led us to characterize these cells in more depth.

Our genome-wide transcriptome analysis revealed a clear separation of hepatic $\mathrm{CXCR}^{+}{ }^{+}$from $\mathrm{CXCR}^{-} \mathrm{CD} 8 \mathrm{~T}$ cells in NASH mice, as compared to $\mathrm{CXCR6}^{+}$and $\mathrm{CXCR}{ }^{-} \mathrm{CD} 8 \mathrm{~T}$ cells in the livers of healthy mice or splenic CD8 T cells (Fig. 1 h). In liver $\mathrm{CXCR}^{+} \mathrm{CD} 8 \mathrm{~T}$ cells from NASH mice, we found a higher expression of genes relevant for effector function (those encoding granzymes, as well as Bhlhe4O) and exhaustion ( $P d c d 1$ and $T o x$ ), as well as the expression of genes indicative of tissue residency (for example, S1pr1, Klf2 and Rgs1) (Fig. 1i, Extended Data Fig. 3, Supplementary Table 1). We confirmed this using gene-set enrichment analysis (GSEA), which identified an enrichment of genes associated with $T$ cell effector function and activation, exhaustion and tissue residency, without enrichment for genes dependent on Thelper 17 cells or IL-17 (Fig. 1j, Extended Data Fig.3), which have previously been associated with immune pathology during infection ${ }^{16}$. Consistent with a short half-life of hepatic CXCR6 ${ }^{+}$ CD8 T cells in NASH, apoptosis-related (but not cell-cycle-related) genes were enriched (Fig. 1j, Supplementary Table 2). Together, this characterized hepatic CXCR6 ${ }^{+}$CD8 T cells in NASH as short-lived tissue-resident effector cells that receive concurrent activation and regulatory signals, and raised the question of how they were generated.

\section{IL-15 induces hepatic CXCR6 ${ }^{+}$CD8 T cells}

Our transcriptome profiling of hepatic $\mathrm{CXCR}^{+} \mathrm{CD} 8 \mathrm{~T}$ cells did not show evidence for cardinal transcription factors that are required for the development of effector CD8 T cells, such as BLIMP1, EOMES or T-BET ${ }^{17}$ (Extended Data Fig. 3). Using 'Binding Analysis for Regulation of Transcription' (BART) program ${ }^{18}$, we identified 42 potentially relevant transcription factors, which-together with an in silico analysis that 


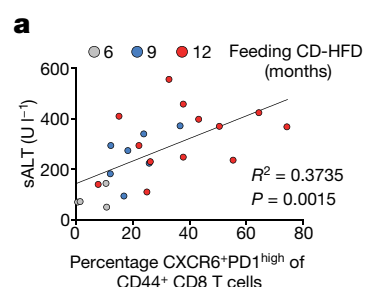

$\mathbf{f}$

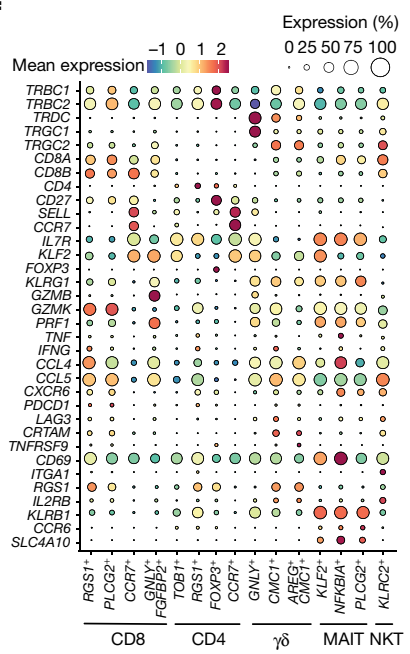

b

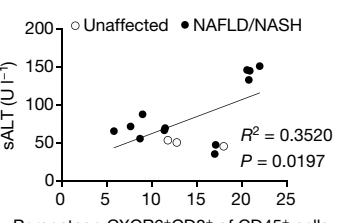

Percentage $\mathrm{CXCR} 6^{+} \mathrm{CD} 8^{+}$of $\mathrm{CD} 45^{+}$cells

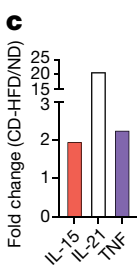

$\mathbf{g}$

g
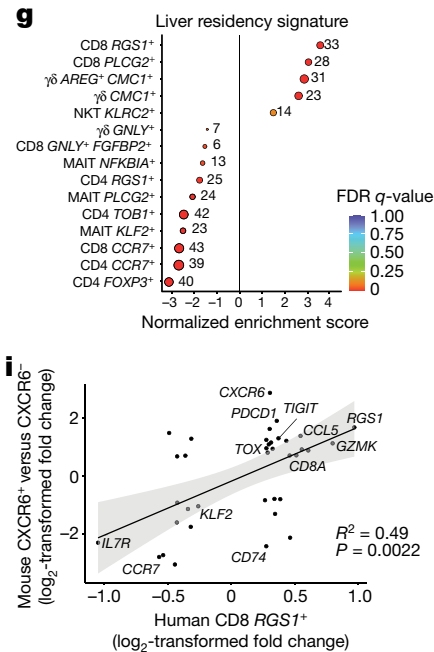

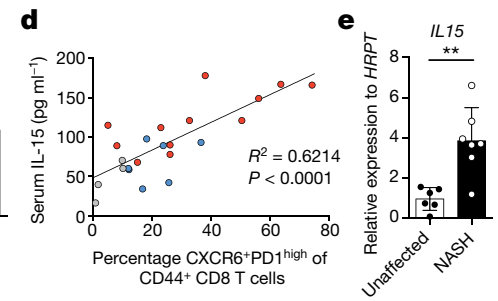

h
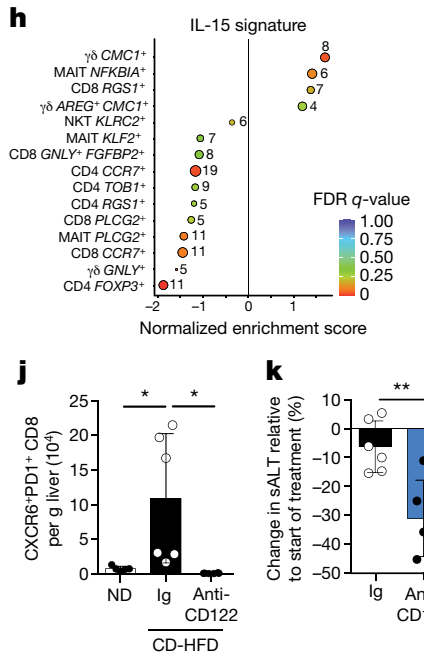

$\mathbf{k}$

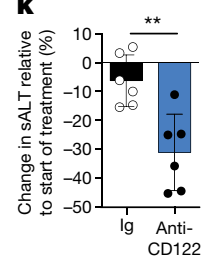

Fig. 2 High similarity between hepatic CXCR6 ${ }^{+}$PD1 ${ }^{\text {high }}$ CD8 T cells in NASH mice and patients with NASH. $a, b$, Correlation of hepatic $C X C R 6^{+} \mathrm{CD} 8 \mathrm{~T}$ cells with sALT in NASH mice (a) and patients with NASH (compared with unaffected individuals) (b). c, Fold change in serum cytokine levels. d, Correlation of mouse CXCR6 ${ }^{+}$PD $1^{\text {high }}$ CD8 T cells with serum levels of IL-15. Four independent experiments. e, Hepatic expression of $I L 15$ expression in patients with NASH. f, Dot-plot heat map, showing expression and cellular detection rate of selected cluster marker genes in hepatic T cells of patients with steatosis $(n=4)$ or NASH $(n=3)$. MAIT, mucosal-associated invariant T cells. $\mathbf{g}, \mathbf{h}$, GSEA from differentially expressed genes of single-cell RNA-sequencing (RNA-seq) data from hepatic $\mathrm{CD}^{+} \mathrm{T}$ cells from patients with NASH, using gene sets for liver residency ${ }^{33}$ and IL-15 stimulation ${ }^{34}$. $\mathbf{i}$, Similarity of RNA-seq datasets from $\mathrm{CXCR6}^{+}$compared to CXCR6 ${ }^{-} \mathrm{CD} 8 \mathrm{~T}$ cells of NASH mice with human $\mathrm{CD} 8 \mathrm{RGS1}^{+}$ cells from patients with NASH. The solid line is the linear regression, and the grey area shows the $95 \%$ confidence intervals. j, k, Hepatic CXCR6 ${ }^{+}$PD $1^{\text {high }}$ CD8 T cells in NASH mice after anti-CD122 application and change in sALT. Exact $P$ values $(\mathbf{e}, \mathbf{j}, \mathbf{k})$ and $n(\mathbf{a}-\mathbf{e}, \mathbf{j}, \mathbf{k})$ values are presented in Source Data. ${ }^{*} P<0.05$, ${ }^{* *} P<0.01$. Coefficient of determination $\left(R^{2}\right)$ and statistical significance ( $P$ value) were determined using Pearson's $(\mathbf{a}, \mathbf{b}, \mathbf{d})$ or Spearman's (i) correlation. One-way ANOVA with Tukey's multiple comparison test $(\mathbf{j})$ and unpaired two-tailed $t$-test $(\mathbf{e}, \mathbf{k})$. In $\mathbf{e}, \mathbf{j}, \mathbf{k}$, data are mean \pm s.e.m., errors are shown as s.d. revealed 21 downstream transcription factors-suggested a key role for the downregulation of FOXO1 in hepatic $\mathrm{CXCR}^{+} \mathrm{CD} 8 \mathrm{~T}$ cells in NASH mice. GSEA confirmed the reduced expression of FOXO1-dependent genes, and reduced levels of FOXO1 protein in hepatic CXCR6 ${ }^{+}$CD8 $T$ cells, but not in CD4 T cells, further corroborated these findings (Extended Data Fig. 3, Supplementary Tables 2, 3). To investigate the relevance of FOXO1 regulation, we performed loss- and gain-of-function experiments. Inhibition of FOXO1 in CXCR6 ${ }^{-}$CD8 T cells caused upregulation of CXCR6, whereas overexpression of FOXO1 in CD8 T cells reduced expression of CXCR6 (Extended Data Fig. 4). Accordingly, levels of FOXO1 in CD8 T cells inversely correlated with percentages of hepatic $\mathrm{CXCR}^{+} \mathrm{CD} 8 \mathrm{~T}$ cells and with liver damage in livers of NASH mice and patients with NASH over the time of NASH development (Extended Data Fig. 4). Increased numbers of mouse and human hepatic CXCR6 ${ }^{+}$ CD8 T cells, as well as increased human-liver CXCR6 expression and CXCR6 mRNA-expressing cells (Fig. 2b, Extended Data Fig. 4), demonstrated that similar hepatic CD8 T cell phenotypes correlated with liver damage in NASH mice and patients with NASH.

We screened for cytokines to identify mediators that downregulate FOXO1 in T cells, and detected increased levels of IL-15, IL-21 and TNF serum protein and liver mRNA in NASH mice (Fig. 2c, Extended Data Fig. 5). IL-15 signalling causes phosphorylation of FOXO1 for nuclear export and proteasomal degradation of cytosolic FOXO1 ${ }^{19,20}$, and has previously been associated with the development of $\mathrm{NASH}^{21}$. Upon treatment with IL-15 in vitro, mouse and human CD8 T cells downregulated
FOXO1 and upregulated CXCR6, PD1, GzmB and CD69 (Extended Data Fig. 5). Of note, the expression of CXCR6 induced by IL-15 was further increased by IL-21 (Extended Data Fig. 5). Levels of serum IL-15 correlated with the frequency of hepatic CXCR $6{ }^{+} \mathrm{PD} 1^{\text {high }} \mathrm{CD} 8 \mathrm{~T}$ cells, as well as the extent of liver damage and FOXO1 expression not only in NASH mice but also in patients with NASH (Fig. 2d, e, Extended Data Fig. 5), which together indicates a key role for IL-15 in NASH.

To further translate the findings from preclinical models into human disease, we isolated $T$ cells from the livers of patients with steatosis or NASH and performed single-cell RNA sequencing (RNA-seq). We detected seven distinct hepatic CD8 T cell clusters, among which $\mathrm{CD} 8 \mathrm{RGS1^{+ }}$ cells were increased in the liver of patients with NASH and co-expressed high amounts of $C X C R 6, P D C D 1$ and genes encoding granzymes and low levels of $K L F 2$; in GSEA, this cluster of cells showed liver-residency and IL-15 signatures (Fig. 2f-h, Extended Data Fig. 6, Supplementary Tables 4-8). We also found $R G S 1^{+} \mathrm{CD} 8$ cells in the fat tissue of patients with NASH (Extended Data Fig. 6, Supplementary Tables 9, 10). Importantly, the key gene signatures of hepatic CXCR6 ${ }^{+} \mathrm{CD} 8 \mathrm{~T}$ cells from NASH mice were also present in hepatic $R G S 1^{+} \mathrm{CD} 8 \mathrm{~T}$ cells, but not in $\mathrm{GNLY}^{+} \mathrm{FGFBP2} 2^{+} \mathrm{CD} 8 \mathrm{~T}$ cells, from patients with NASH (Fig. 2i, Extended Data Fig. 6, Supplementary Table 11), which suggests similar functionality of CD8 T cells in NASH mice and patients with NASH. Upon exposure to IL-15, CD8 T cells downregulated CD122 (which is required for IL-15 signalling ${ }^{22}$ ), consistent with $\mathrm{CXCR}^{-}{ }^{-}$, but not $\mathrm{CXCR}^{+}, \mathrm{CD} 8$ T cells expressing CD122 (Extended Data Fig. 7); this suggested that 


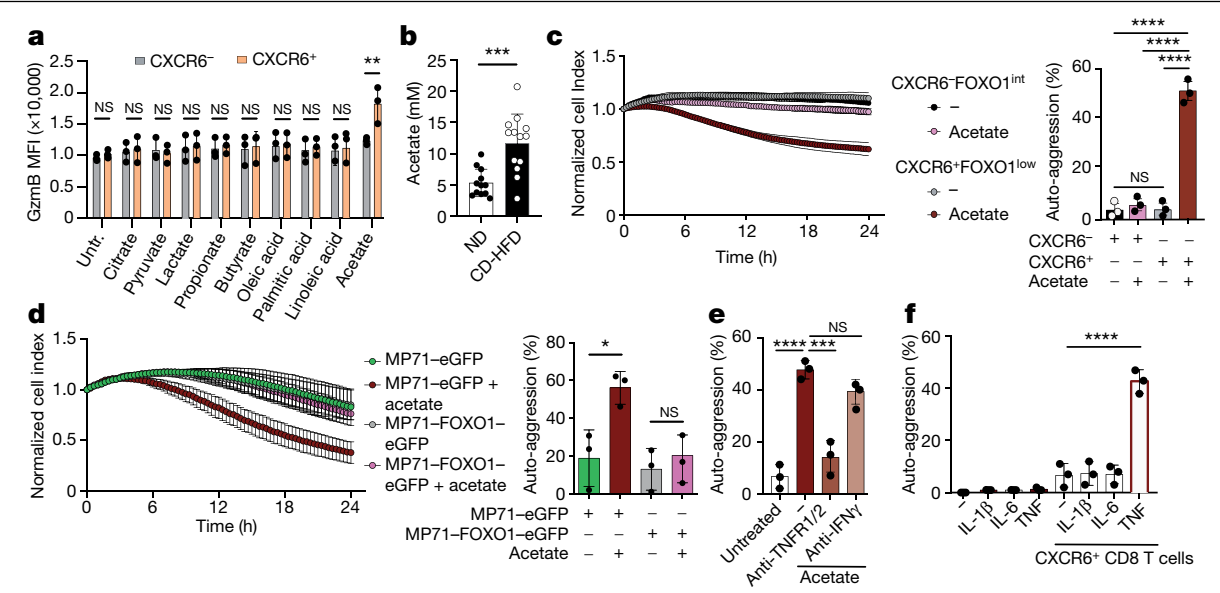

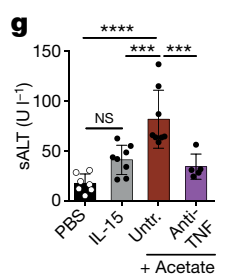
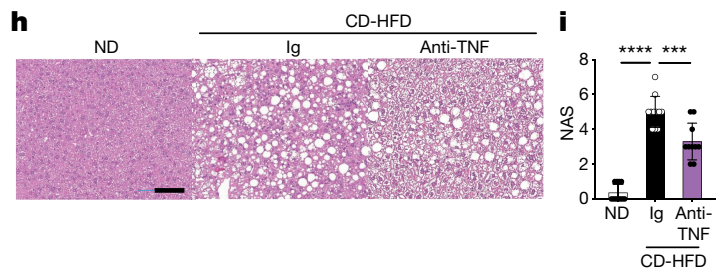

j

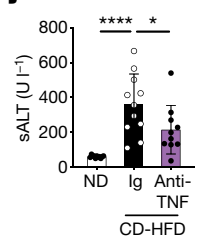

Fig. 3 | Acetate exposure enables $\mathrm{CXCR6}^{+} \mathrm{CD8} \mathrm{T}$ cells to become auto-aggressive. a, GzmB expression in IL-15-stimulated CD8 T cells exposed to metabolites $(n=3)$. Untr., untreated. $\mathbf{b}$, Liver acetate levels in mice fed a normal diet $(n=12)$ and NASH mice $(n=13)$. c, d, Auto-aggressive activity of IL-15-treated CXCR6 ${ }^{+} \mathrm{CD} 8 \mathrm{~T}$ cells against hepatocytes in presence of acetate $(15 \mathrm{mM})(n=3)$, or after transduction with pMP71-Foxo1-eGFP $(n=3)$. e,f, Auto-aggressive activity of IL-15-treated, acetate-exposed CXCR6 ${ }^{+}$CD8 T cells in presence of anti-TNFR1 and anti-TNFR2 (anti-TNFR1/2) $\left(10 \mu \mathrm{g} \mathrm{ml}^{-1}\right)$ or anti-IFN $\gamma\left(10 \mu \mathrm{g} \mathrm{ml}^{-1}\right)$, or recombinant cytokines $(n=3)$. g, sALT at day 2 after transfer of IL-15-exposed CD8 T cells and anti-TNF injection $(200 \mu \mathrm{g}$ per

hepatic $\mathrm{CXCR}{ }^{+}{ }^{+} \mathrm{PD} 1^{\text {high }} \mathrm{CD} 8 \mathrm{~T}$ cells originated from $\mathrm{CD} 122$-expressing T cells. In NASH mice treated with anti-CD122 antibodies, only hepatic CXCR6 ${ }^{+} \mathrm{PD} 1^{\text {high }} \mathrm{CD} 8 \mathrm{~T}$ cells (and not $\mathrm{CD} 4 \mathrm{~T}$ cells, $\mathrm{CX}_{3} \mathrm{CR} 1^{+} \mathrm{CD} 8 \mathrm{~T}$ cells or natural killer $T$ cells) were depleted, and this treatment was followed by the amelioration of liver damage (Fig. 2j, k, Extended Data Fig. 7). Of note, the numbers of natural killer cells were also reduced after treatment with anti-CD122, but the number or phenotype of hepatic natural killer cells were not changed in NASH mice (Extended Data Fig. 7). These results suggested a role for IL-15 and CXCR6 ${ }^{+} \mathrm{CD} 8 \mathrm{~T}$ cells in mediating liver damage in NASH.

\section{Auto-aggression by CXCR6 ${ }^{+}$CD8 $\mathrm{T}$ cells}

We next tested whether $\mathrm{CXCR}^{+} \mathrm{CD} 8 \mathrm{~T}$ cells were pathogenic, but-despite high levels of GzmB-they did not kill hepatocytes (Extended Data Fig. 8). Given the disturbance of lipid metabolism in the livers of patients with $\mathrm{NASH}^{2}$, we evaluated the effect of fatty acids on T cell cytotoxicity. Only the short-chain fatty acid acetate further increased expression of GzmB in $\mathrm{CXCR6}^{+} \mathrm{CD} 8 \mathrm{~T}$ cells and promoted the release of TNF, which is consistent with previous reports ${ }^{23,24}$ (Fig. 3a, Extended Data Fig. 8). Levels of hepatic acetate were elevated in NASH mice (Fig. 3b), which may be the result of gut dysbiosis ${ }^{25}$ or of hepatocytes releasing acetate after exposure to fatty acids, and we found enrichment of acetate-induced-but not butyrate-induced-genes ${ }^{23,26}$ in hepatic CXCR6 $^{+}$CD8 T cells from NASH mice (Extended Data Fig. 8, Supplementary Table 12). Notably, sequential application of IL-15 stimulation or FOXO1 inhibition followed by acetate exposure rendered $\mathrm{CXCR} 6^{+} \mathrm{FOXO1}{ }^{\text {low }} \mathrm{CD} 8 \mathrm{~T}$ cells capable of killing hepatocytes (Fig.3d, Extended Data Fig. 8). We term this nonspecific killing activity of CXCR6 ${ }^{+} \mathrm{CD} 8 \mathrm{~T}$ cells 'auto-aggression'. Overexpression of FOXO1 prevented auto-aggression by T cells (Fig.3e, Extended Data Fig. 8), mouse). Two independent experiments. h-j, Liver histology (h), NAS (i) and SALT (j) after anti-TNF application $(200 \mu$ g per mouse twice a week, at 8 weeks) in mice fed a CD-HFD (normal diet, $n=11$; CD-HFD + immunoglobulin, $n=11$; CD-HFD + anti-TNF, $n=10$ ). Three independent experiments in a, c-f. MFI, mean fluorescence intensity. Exact $P$ values $(\mathbf{a}-\mathbf{g}, \mathbf{i}, \mathbf{j})$ and $n(\mathbf{g})$ values are presented in Source Data. ${ }^{*} P<0.05,{ }^{* * *} P<0.001,{ }^{* * * *} P<0.0001$. Two-way ANOVA with Sidak's multiple comparison test (a), one-way ANOVA with Tukey's multiple comparison test $(\mathbf{c}-\mathbf{g}, \mathbf{i}, \mathbf{j})$ and unpaired two-tailed $t$-test $(\mathbf{b})$. In $\mathbf{a}-\mathbf{g}, \mathbf{i}, \mathbf{j}$, data are mean \pm s.e.m., errors are shown as s.d.

which suggests that low FOXO1 activity rendered T cells responsive to environmental metabolic cues such as acetate. Adoptive transfer of either IL-15-stimulated or FOXO1-inhibited, and then acetate-exposed, CD8 T cells caused liver damage (Extended Data Fig. 8). This raised the question how acetate contributed to auto-aggression by $\mathrm{CXCR6}{ }^{+} \mathrm{CD} 8 \mathrm{~T}$ cells.

Because acetate-exposed CXCR6 ${ }^{+} \mathrm{CD} 8 \mathrm{~T}$ cells did not trigger exocytosis (which is required for the release of GzmB from intracellular stores) and because $\mathrm{Prf1}^{-/-}$mice (which lack perforin to deliver GzmB-containing granules into target cells ${ }^{27}$ ) developed NASH features (Extended Data Fig. 8), we analysed the effect of TNF on auto-aggression. Hepatocytes exposed to TNF upregulated ICAM1, which facilitated close interaction with LFA1-expressing CXCR6 ${ }^{+} \mathrm{CD} 8$ T cells; blockade of LFA1 prevented auto-aggression by T cells in vitro or after adoptive transfer in vivo (Extended Data Fig. 8). Consequently, TNF blockade prevented auto-aggression by T cells in vitro and in vivo, and hepatocyte incubation with TNF (but no other pro-inflammatory cytokines) sufficed to initiate auto-aggression by T cells even without prior exposure to acetate (Fig. 3e-g, Extended Data Fig. 8). Importantly, TNF inhibition for eight weeks in NASH mice reduced liver damage and hepatic steatosis (Fig. $3 \mathrm{~h}-\mathrm{j}$ ), which together indicated a role for TNF in establishing physical contact between auto-aggressive CXCR6 ${ }^{+} \mathrm{CD} 8$ T cells and hepatocytes. In patients with NASH, we also found increased levels of $T N F$ expression that correlated with liver damage (Fig. $3 \mathrm{j}, \mathrm{k}$ ), and this raised the question how pathogenic CD8 T cells were activated to exert auto-aggression.

\section{Execution of CD8 $\mathrm{T}$ cell auto-aggression}

MHC class I expression on hepatocytes was dispensable for auto-aggression by T cells, and anti-PD1 checkpoint inhibition-despite 


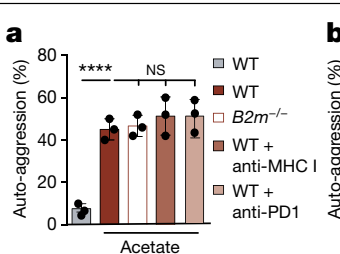

e
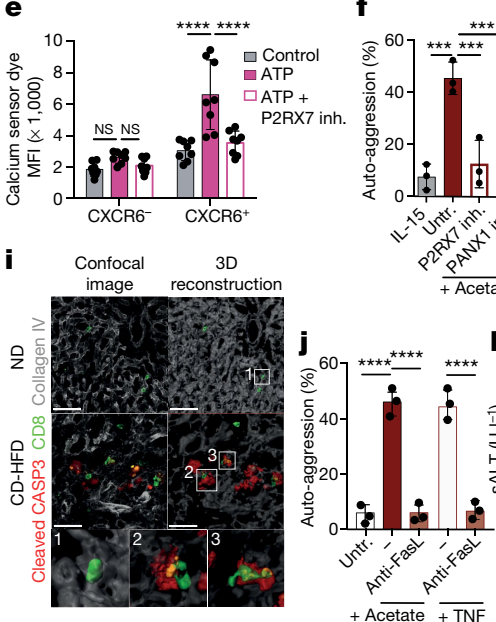

Fig. 4 | Metabolic activation of CXCR6 ${ }^{+}$CD8 T cells for the execution of auto-aggression. a, Auto-aggression by IL-15-treated CXCR6 ${ }^{+} \mathrm{CD} 8 \mathrm{~T}$ cells in the presence or absence of acetate against hepatocytes from wild-type or $B 2 \mathrm{~m}^{-/}$ mice, in presence of anti-MHC class I $\left(10 \mu \mathrm{g} \mathrm{ml}^{-1}\right)$ or anti-PD1 antibodies $(10 \mu \mathrm{g}$ $\left.\mathrm{ml}^{-1}\right)(n=3)$. $\mathbf{b}$ CD8 T cell auto-aggression after inhibition of defined pathways $(n=3) . c$, Increase in intracellular calcium in auto-aggressive CXCR6 ${ }^{+} \mathrm{CD} 8$ T cells $(n=4)$. d, P2RX7 surface expression on CXCR6 ${ }^{+}$CD8 T cells $(n=7)$. e, Calcium influx in ATP-exposed CD8 T cells after P2RX7 inhibition $(n=8)$. $\mathbf{f}, \mathbf{g}$, Effect of P2RX7 or PANX1 inhibition (inh.) on auto-aggression and antigen-specific cytotoxic activity of IL-15-stimulated, acetate-exposed polyclonal or ovalbumin-specific OT1CXCR6 ${ }^{+} \mathrm{CD} 8 \mathrm{~T}$ cells $(n=3)$. h, Auto-aggression by IL-15 (15 $\left.\mathrm{ng} \mathrm{ml}^{-1}\right)$-stimulated human CD8 T cells against allogeneic or autologous primary human hepatocytes $(n=3)$. $\mathbf{i}$, Confocal microscopic analysis and 3D reconstruction of cell surfaces in liver tissues from mice fed a CD-HFD or normal diet (green, CD8 T cells; red, cleaved caspase $3^{+}$hepatocytes; grey, nonparenchymal cells); quantification in Extended Data Fig. $10(n=3)$. Scale bar, $30 \mu \mathrm{m}$.j, Auto-aggression of CXCR6 ${ }^{+}$ CD8 T cells after anti-FasL in vitro $(n=3)$. $\mathbf{k}$, Liver damage after anti-FasL application (100 $\mu$ g per mouse twice a week, for 4 weeks) of mice fed a CD-HFD (normal diet, $n=11$; CD-HFD + immunoglobulin, $n=11$; CD-HFD + anti-FasL, $n=6)$. I, Model for CXCR6 ${ }^{+} \mathrm{CD} 8 \mathrm{~T}$ cell auto-aggression in NASH. Three or more independent experiments in $\mathbf{a}, \mathbf{b}, \mathbf{d}-\mathbf{g}, \mathbf{j}$. Exact $P$ values $(\mathbf{a}, \mathbf{b}, \mathbf{d}, \mathbf{e}-\mathbf{g}, \mathbf{j}, \mathbf{k})$ are presented in source data. ${ }^{*} P<0.05,{ }^{* * *} P<0.001,{ }^{* * * *} P<0.0001$. Two-way ANOVA with Tukey's multiple comparison test (e), one-way ANOVA with Tukey's multiple comparison test (a, $\mathbf{b}, \mathbf{f}, \mathbf{g}, \mathbf{j}, \mathbf{k})$ and unpaired two-tailed $t$-test (b). In a, $\mathbf{b}, \mathbf{d}, \mathbf{e}-\mathbf{g}, \mathbf{j}, \mathbf{k}$, data are mean \pm s.e.m., errors are shown as s.d. a high expression of PD1 by CXCR6 ${ }^{+}$CD8 T cells-did not augment auto-aggression (Fig. 4a). Consistent with this, neither phosphorylation of TCR-downstream signalling kinases nor immunometabolic features of effector function (such as a switch towards glycolysis ${ }^{28}$ ) were observed in auto-aggressive CD8 T cells (Extended Data Fig. 9), which led us to search for other stimuli that triggered $\mathrm{T}$ cell activation in an MHC-independent fashion. Neither inhibition of phospholipase C-nor mitogen-activated kinase-coupled signalling affected $\mathrm{T}$ cell auto-aggression, whereas inhibition of PI3K and calcium signalling abolished auto-aggression by CD8 T cells (Fig. 4b). Notably, incubation with ATP or nicotinamide adenine dinucleotide (NAD) (both of which are ligands for purinergic receptors ${ }^{29}$ )-but not with acetate, TNF, TLR ligands, chemokines or degradation products of ATP-triggered calcium influx into $\mathrm{CXCR}^{+}$ CD8 T cells as a sign of activation (Fig. 4c, Extended Data Fig. 9). ATP was released through pannexin 1(PANX1) (an oligomeric membrane channel complex that is responsible for releasing cytosolic ATP into the extracellular space ${ }^{29,30}$ ) from dying hepatocytes or from hepatocytes cocultured with auto-aggressive CD8 T cells (Extended Data Fig. 9). Imaging using matrix-assisted laser desorption and ionization revealed an increased and uniform presence of fatty acids in the livers of NASH mice in contrast to the multifocal localization of ATP (Extended Data Fig. 9), which is compatible with ATP release at sites at which auto-aggressive CD8 T cells interacted with hepatocytes.

To investigate how extracellular ATP activated CD8 T cells to exert auto-aggression, we searched for purinergic receptors (such as
P2X7) that are expressed on tissue-resident CD8 T cells ${ }^{31,32}$. We found $\mathrm{P} 2 \mathrm{RX} 7$ expression on $\mathrm{CXCR6}^{+} \mathrm{CD} 8 \mathrm{~T}$ cells, which was required for auto-aggressive $\mathrm{CXCR}^{+} \mathrm{CD} 8 \mathrm{~T}$ cells to respond to ATP or NAD and to supernatants from dying hepatocytes (Fig. 4d, e, Extended Data Fig. 9). Consequently, inhibition of P2RX7 or PANX1 prevented auto-aggression by CD8 T cells, whereas the antigen-specific cytotoxicity of CD8 T cells was not affected (Fig. 4f, g, Extended Data Fig. 9). Thus, distinct mechanisms discriminate auto-aggression, which is triggered by increased calcium influx through purinergic signalling via P2RX7 in auto-aggressive $\mathrm{CXCR6}^{+} \mathrm{CD} 8 \mathrm{~T}$ cells, from MHC-class-I-dependent cytotoxicity exerted by antigen-specific CD8 T cells.

Given the high similarity in gene signatures of $\mathrm{CXCR} 6^{+} \mathrm{CD} 8 \mathrm{~T}$ cells in livers of NASH mice and patients with NASH, we examined whether similar mechanisms were involved in auto-aggression by human CD8 T cells. Human CD8 T cells stimulated with IL-15 also showed MHC-class-I-independent auto-aggression, but did not require acetate or TNF to become auto-aggressive (Fig. 4h, Extended Data Fig. 10). Similar to auto-aggression by CD8 T cells in mice, calcium influx was required to trigger auto-aggression by human $\mathrm{CXCR6}^{+} \mathrm{CD} 8 \mathrm{~T}$ cells (Extended Data Fig. 10).

We next characterized the mechanism by which CXCR6 ${ }^{+} \mathrm{CD} 8 \mathrm{~T}$ cells executed auto-aggression. The exposure of $\mathrm{CXCR}^{+} \mathrm{CD} 8 \mathrm{~T}$ cells to ATP led to rapid upregulation of FasL, but not TRAIL, and the death of hepatocytes depended on apoptosis, but not necroptosis; this was supported by the close contact between CD8 T cells and cleaved caspase $3^{+}$ 
hepatocytes in livers from NASH mice (Fig. 4i, Extended Data Fig. 10). Importantly, the blocking of FasL prevented auto-aggression by CD8 $T$ cells in vitro and after adoptive transfer in vivo, and ameliorated liver damage in NASH mice (Fig. 4j, k, Extended Data Fig. 10).

\section{Discussion}

These results reveal that CD8 T cells are rendered auto-aggressive through defined, non-redundant sequential activation steps (Fig. 4l) and provide mechanistic insights into the pathogenesis of immune-mediated metabolic diseases such as NASH. The sequential steps for the generation of auto-aggressive mouse and human CD8 $\mathrm{T}$ cells involve IL-15-driven transcriptional programming followed by metabolic activation to execute auto-aggression. The auto-aggression of CD8 T cells in the liver may be involved in the development of liver cancer in patients with NASH that is driven by chronic liver damage, and may also be responsible for tissue damage in other organs. Our results demonstrate that auto-aggression by CD8 T cells is determined by mechanisms distinct from those of antigen-specific killing through CD8 $\mathrm{T}$ cells, which will help in the design of future immune therapies to avoid immune pathology without compromising the efficacy of antigen-specific $\mathrm{T}$ cell immunity.

\section{Online content}

Any methods, additional references, Nature Research reporting summaries, source data, extended data, supplementary information, acknowledgements, peer review information; details of author contributions and competing interests; and statements of data and code availability are available at https://doi.org/10.1038/s41586-021-03233-8.

1. Roden, M. \& Shulman, G. I. The integrative biology of type 2 diabetes. Nature $5 \mathbf{5 7 6}, 51-60$ (2019).

2. Friedman, S. L., Neuschwander-Tetri, B. A., Rinella, M. \& Sanyal, A. J. Mechanisms of NAFLD development and therapeutic strategies. Nat. Med. 24, 908-922 (2018).

3. Hotamisligil, G. S. Inflammation, metaflammation and immunometabolic disorders. Nature 542, 177-185 (2017).

4. Wolf, M. J. et al. Metabolic activation of intrahepatic CD8+ T cells and NKT cells causes nonalcoholic steatohepatitis and liver cancer via cross-talk with hepatocytes. Cancer Cell 26, 549-564 (2014).

5. Malehmir, M. et al. Platelet GPIba is a mediator and potential interventional target for NASH and subsequent liver cancer. Nat. Med. 25, 641-655 (2019).

6. Clapper, J. R. et al. Diet-induced mouse model of fatty liver disease and nonalcoholic steatohepatitis reflecting clinical disease progression and methods of assessment. Am. J. Physiol. Gastrointest. Liver Physiol. 305, G483-G495 (2013).

7. Ma, C. et al. NAFLD causes selective $C D 4^{+} T$ lymphocyte loss and promotes hepatocarcinogenesis. Nature 531, 253-257 (2016).

8. Fernandez-Ruiz, D. et al. Liver-resident memory $C D 8^{+} T$ cells form a front-line defense against malaria liver-stage infection. Immunity 45, 889-902 (2016).
9. Topham, D. J. \& Reilly, E. C. Tissue-resident memory $C D 8^{+}$T cells: from phenotype to function. Front. Immunol. 9, 515 (2018).

10. Böttcher, J. P. et al. Functional classification of memory $C D 8^{+} T$ cells by $C X 3 C R 1$ expression. Nat. Commun. 6, 8306 (2015)

11. Gerlach, C. et al. The chemokine receptor CX3CR1 defines three antigen-experienced CD8 T cell subsets with distinct roles in immune surveillance and homeostasis. Immunity 45, 1270-1284 (2016)

12. Olson, J. A., McDonald-Hyman, C., Jameson, S. C. \& Hamilton, S. E. Effector-like CD8 ${ }^{+}$ $\mathrm{T}$ cells in the memory population mediate potent protective immunity. Immunity $\mathbf{3 8}$, 1250-1260 (2013).

13. Khan, O. et al. TOX transcriptionally and epigenetically programs $C D 8^{+} \mathrm{T}$ cell exhaustion. Nature 571, 211-218 (2019).

14. Alfei, F. et al. TOX reinforces the phenotype and longevity of exhausted T cells in chronic viral infection. Nature 571, 265-269 (2019).

15. Mackay, L. K. et al. Hobit and Blimp1 instruct a universal transcriptional program of tissue residency in lymphocytes. Science 352, 459-463 (2016).

16. Veldhoen, M. Interleukin 17 is a chief orchestrator of immunity. Nat. Immunol. 18, 612-621 (2017).

17. Man, K. \& Kallies, A. Synchronizing transcriptional control of T cell metabolism and function. Nat. Rev. Immunol. 15, 574-584 (2015).

18. Wang, Z. et al. BART: a transcription factor prediction tool with query gene sets or epigenomic profiles. Bioinformatics 34, 2867-2869 (2018).

19. Leonard, W. J., Lin, J. X. \& O'Shea, J. J. The $\mathrm{Y}_{\mathrm{c}}$ family of cytokines: basic biology to therapeutic ramifications. Immunity 50, 832-850 (2019).

20. Hedrick, S. M. Hess Michelini, R., Doedens, A. L., Goldrath, A. W. \& Stone, E. L. FOXO transcription factors throughout T cell biology. Nat. Rev. Immunol. 12, 649-661 (2012).

21. Cepero-Donates, Y. et al. Interleukin-15-mediated inflammation promotes non-alcoholic fatty liver disease. Cytokine 82, 102-111 (2016).

22. Chirifu, M. et al. Crystal structure of the IL-15-IL-15Ra complex, a cytokine-receptor unit presented in trans. Nat. Immunol. 8, 1001-1007 (2007).

23. Balmer, M. L. et al. Memory $\mathrm{CD} 8^{+} \mathrm{T}$ cells require increased concentrations of acetate induced by stress for optimal function. Immunity 44, 1312-1324 (2016).

24. Qiu, J. et al. Acetate promotes T cell effector function during glucose restriction. Cell Rep. 27, 2063-2074 (2019).

25. Liu, X. et al. Acetate production from glucose and coupling to mitochondrial metabolism in mammals. Cell 175, 502-513 (2018).

26. Bachem, A. et al. Microbiota-derived short-chain fatty acids promote the memory potential of antigen-activated CD8 ${ }^{+}$T cells. Immunity 51, 285-297 (2019).

27. Voskoboinik, I., Whisstock, J. C. \& Trapani, J. A. Perforin and granzymes: function, dysfunction and human pathology. Nat. Rev. Immunol. 15, 388-400 (2015).

28. Chang, C. H. et al. Posttranscriptional control of T cell effector function by aerobic glycolysis. Cell 153, 1239-1251 (2013)

29. Linden, J., Koch-Nolte, F. \& Dahl, G. Purine release, metabolism, and signaling in the inflammatory response. Annu. Rev. Immunol. 37, 325-347 (2019).

30. Chekeni, F. B. et al. Pannexin 1 channels mediate 'find-me' signal release and membrane permeability during apoptosis. Nature 467, 863-867 (2010).

31. Stark, R. et al. $\mathrm{T}_{\mathrm{RM}}$ maintenance is regulated by tissue damage via P2RX7. Sci. Immunol. 3 , eaau1022 (2018)

32. Borges da Silva, $\mathrm{H}$. et al. The purinergic receptor $\mathrm{P} 2 \mathrm{RX} 7$ directs metabolic fitness of long-lived memory CD8 ${ }^{+}$T cells. Nature 559, 264-268 (2018).

33. Zhao, J. et al. Single-cell RNA sequencing reveals the heterogeneity of liver-resident immune cells in human. Cell Discov. 6, 22 (2020).

34. Setoguchi, R. IL-15 boosts the function and migration of human terminally differentiated CD8+ T cells by inducing a unique gene signature. Int. Immunol. 28, 293-305 (2016).

Publisher's note Springer Nature remains neutral with regard to jurisdictional claims in published maps and institutional affiliations.

(c) The Author(s), under exclusive licence to Springer Nature Limited 2021, corrected publication 2021 


\section{Methods}

No statistical methods were used to predetermine sample size. The experiments were not randomized, and investigators were not blinded to allocation during experiments and outcome assessment.

\section{Mice, diets and treatments}

C57BL/6 mice were purchased from Charles River. $\mathrm{H}-2 \mathrm{~K}^{\mathrm{b}}$-restricted TCR transgenic CD45.1 $1^{+}$OT-1 mice were bred and maintained under specific-pathogen-free conditions at the School of Medicine, TUM, according to the guidelines of the Federation of Laboratory Animal Science Association. Mice were housed with a light:dark cycle of $12 \mathrm{~h}$, ambient temperature of $24^{\circ} \mathrm{C}$ and humidity of $55 \%$. Male mice between the ages of 6 and 10 weeks were used, and the number of mice subjected to experiments was chosen on the basis of previous studies ${ }^{4,5}$. Six-week-old

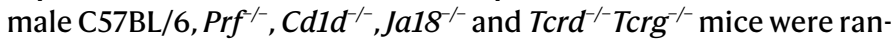
domly fed ad libitum and housed at the at German Cancer Research Center: normal diet, CD-HFD (Research Diets; D05010402), Western diet with trans-fat (Research Diets; D09100301, 40 kcal per cent fat (Primex shortening), $20 \mathrm{kcal}$ per cent fructose, 2\% cholesterol). For interventional studies, mice were fed a CD-HFD for the indicated time and randomly assigned to treatment groups with depleting monoclonal antibodies against CD122 (BioXcell, clone 5H4, no. BE0272,100 $\mu$ g per tmouse), FasL (BioXcell, clone MFL3, no. BE0319, $100 \mu \mathrm{g}$ per mouse) or TNF (BioXcell, clone XT3.11, no. BE0058, $200 \mu \mathrm{g}$ per mouse) every 3 days. At the end of the experiment, mice were killed, and organs and serum were collected for analysis. All mice experiments were authorized by permission of the Regierung of Oberbayern (55.2-1-54-2532-6014) and the animal research committee at the DKFZ (g129/16).

\section{Human specimens}

All experiments with human liver samples for in situ hybridization, isolating lymphocytes, RNA and measuring acetate concentrations were approved by the ethics committee of Hamburg (PV5184 and PV5187), Innsbruck (AN2017-0016369/4.21) and Bern (2020-00852). Single-cell RNA-seq-analysis of $\mathrm{CD}^{+}$lymphocytes from human liver tissue and mesenterial fat tissue was approved by the Medical Ethics Committee of Heidelberg University (S-629/2013) and the Ethics Committee of Freiburg University (544/17). Experiments with liver samples from unaffected participants for isolating primary human hepatocytes were approved by the ethics committee at TUM (232/19S). Liver samples were acquired by mini-laparoscopy-guided liver biopsy or bariatric surgery. All studies were performed in accordance with the regulations of the ethics committee and the ethical guidelines of the World Medical Association (WMA) Declaration of Helsinki. The participants were recruited into the study after they gave written and informed consent.

\section{Immune cell isolation}

For the isolation of splenic immune cells, the spleen was removed and mechanically disrupted, filtered through a $70-\mu \mathrm{m}$ strainer and red blood cells were lysed with a 2-min incubation with ammonium chloride potassium buffer. Spleen cells were washed twice with cold PBS. For isolation of hepatic immune cells, mouse liver was perfused via the portal vein for a minute and subsequently passed through a 100- $\mu \mathrm{m}$ mesh sieve, washed and the cell pellet was resuspended in $8 \mathrm{ml}$ of GBSS containing collagenase IV (1:400, Worthington, no. LS004189) and digested in a rotatory shaker $(240 \mathrm{rpm})$ for $15 \mathrm{~min}$ at $37^{\circ} \mathrm{C}$. The cell suspension was washed and lymphocytes were isolated through Percoll (40/80, GE Healthcare, no. 10607095) density centrifugation (7 acceleration, 1 deceleration, $1,440 \mathrm{~g}$, for $25 \mathrm{~min}$ ). For stimulation of lymphocytes, cells were stimulated with IL-15-IL-15R $\alpha$ and $\left(10 \mathrm{ng} \mathrm{ml}^{-1}\right.$, ThermoFisher, no. 14-8152-80), IL-21 (10 $\mathrm{ng} \mathrm{ml}^{-1}$, Peprotech, no. 210-21), IL-7 (10 $\mathrm{ng} \mathrm{ml}^{-1}$, Peprotech, no. 217-17), IL-2 (10 $\left.\mathrm{ng} \mathrm{ml}^{-1}\right)$, TGF $\beta\left(10 \mathrm{ng} \mathrm{ml}^{-1}\right.$, Peprotech, no. 100-21), IFN $\gamma$ (10 $\mathrm{ng} \mathrm{ml}^{-1}$, Peprotech, no. 315-05), IL-1
(10 ng ml $^{-1}$, Peprotech, no. 211-11B) or TNF (5 ng ml ${ }^{-1}$, ThermoFisher, no. PMC3013) for $18 \mathrm{~h}$ followed by flow cytometry analysis.

For isolation of lymphocytes from kidney, the renal capsula was removed and kidneys were digested by injecting $1 \mathrm{ml}$ PBS containing type IV collagenase ( $1 \mathrm{mg} \mathrm{ml}^{-1}$, Worthington, no. LS004189) and DNase I (50 U ml ${ }^{-1}$, Roche, no. 04716728001). After mechanical dissection, tissue was incubated for $60 \mathrm{~min}$ at $37^{\circ} \mathrm{C}$, the cell suspension was filtered through a $70-\mu \mathrm{m}$ mesh strainer, washed and subjected to Percoll $(40 \% / 80 \%)$ density centrifugation $(1,440 \mathrm{~g}$, for $25 \mathrm{~min})$. For isolation of lymphocytes from mouse skin, ears were cut and the dorsal side was removed from the ventral side. After cutting into small pieces, tissue suspensions were digested with PBS solution containing type IV collagenase $\left(2 \mathrm{mg} \mathrm{ml}^{-1}\right)$ and DNase $\mathrm{I}\left(50 \mathrm{U} \mathrm{ml}^{-1}\right)$ for $60 \mathrm{~min}$ at $37^{\circ} \mathrm{C}$. Cell suspensions were filtered through $70-\mu \mathrm{m}$ mesh, washed and used for analysis. For isolation of lung lymphocytes, both lobes were removed and digested by injecting $1 \mathrm{ml}$ PBS solution containing type IV collagenase $\left(1 \mathrm{mg} \mathrm{ml}^{-1}\right)$ and DNase $\mathrm{I}\left(50 \mathrm{U} \mathrm{ml}^{-1}\right)$. After tearing the lobes apart and removing remaining air by pipetting, the tissue suspension was digested for $30 \mathrm{~min}$ at $37^{\circ} \mathrm{C}$. Finally, the tissue suspension was filtered through a $70-\mu \mathrm{m}$ mesh, washed and subjected to Percoll (40\%/80\%) density centrifugation $(1,440 g, 25 \mathrm{~min})$.

To generate cell suspensions from human liver tissue, tissue was filtered through a $100-\mu \mathrm{m}$ mesh and centrifuged $(400 \mathrm{~g}, 5 \mathrm{~min})$. After cautiously decanting the supernatant, cell pellets were resuspended in medium (RPMI $1640+10 \%$ fetal calf serum (FCS) $+1 \%$ penicillin-streptomycin) and centrifuged before use in experiments.

\section{Isolation of primary mouse hepatocytes}

Mouse livers were perfused via the portal vein for $8 \mathrm{~min}$ with buffer containing $0.12 \mathrm{U} \mathrm{ml}^{-1}$ collagenase (SERVA, no. 17465), were mechanically dissected, filtered through a mesh $(300 \mu \mathrm{m})$ and centrifuged at $50 \mathrm{~g}$ for $2 \mathrm{~min}$ to remove cellular debris. Hepatocytes were washed twice, filtered through a mesh $(100 \mu \mathrm{m})$ and isolated by Percoll $(80 \% / 50 \%)$ gradient centrifugation $(600 \mathrm{~g}, 20 \mathrm{~min})$. Freshly isolated primary mouse hepatocytes were seeded on collagen $\mathrm{R}(0.02 \%$, SERVA, no. 47254.02)coated 96-well E-plates (ACEA Biosciences, no. 2801035.6) in William's E medium (PAN Biotech, no. P04-29050) containing 200 mM glutamine (ThermoFisher, no. 25030081), 1 M HEPES pH 7.4,10,000 $\mathrm{ml}^{-1}$ penicillin-streptomycin (Merck, no. P0781), $50 \mathrm{mg} \mathrm{ml}^{-1}$ gentamycin (Merck, no. G1397), $0.005 \mathrm{ng} \mathrm{ml}^{-1}$ insulin (INSUMAN rapid, Sanofi), $1.6 \%$ DMSO (Merck, no. 472301) and 10\% FCS (PAN Biotech, no. P30-3306). After seeding, the medium was exchanged with a medium containing $1 \%$ FCS, and hepatocytes were maintained until their use in experimental approaches.

\section{Isolation of primary human hepatocytes}

Isolation of primary human hepatocytes was performed as previously described ${ }^{35}$. In brief, liver tissue was perfused via $2-3$ vessels at $37^{\circ} \mathrm{C}$ in a two-step procedure using an EGTA-containing washing buffer followed by a digestion buffer containing $0.05 \%$ collagenase IV (Worthington). Viable hepatocytes were enriched using a Percoll gradient centrifugation and cell viability was determined by Trypan blue dye exclusion. Cells were seeded and cultivated on plates coated with rat tail collagen (collagen R, Serva) in Williams E medium containing insulin-transferrin-selenium, $1.5 \%$ bovine serum albumin, GlutaMAX, non-essential amino acids, $100 \mathrm{U} \mathrm{ml}^{-1}$ penicillin-streptomycin (all supplements from Gibco) in the presence of $10 \%$ FCS for $16 \mathrm{~h}$. Hepatocytes were maintained in medium lacking FCS for 5 days before use in experiments.

\section{Antibodies for flow cytometric analysis}

For mouse studies, the following antibodies were purchased from Thermo Fisher or BioLegend, if not indicated differently: anti-BLIMP1 (5E7; 1:100), anti-BCL2 (100, 1:100), anti-BCL6 (BCL-DWN, 1:100), anti-CD3 (17A2, 1:250), anti-CD4 (PM4-5, 1:250), anti-CD8 (53-6.7, 1:250), anti-CD11a (I217,1:250), anti-CD44 (IM7), 1:250, anti-CD45.1(A20, 
1:250), anti-CD49a (HMa1,1:200), anti-CD54 (ICAM1, YN1/1.7.4,1:250), anti-CD62L (MEL14, 1:250), anti-CD69 (H1.2F3, 1:250), anti-CD107a (LAMP1, eBioD4B, 1:200), anti-CD122 (IL2rb, 5H4, 1:250), anti-CD178 (FasL, MFL3,1:100), anti-CD183 (CXCR3-173,1:250), anti-CD186 (CXCR6, SA051D1, 1:250), anti-CD223 (LAG3, eBioC98B7W, 1:250), anti-CD253 (TRAIL, N2B2, 1:200), anti-CD279 (PD1, 29F.1A12, 1:250), anti-CX3CR1 (SA011F11,1:250), anti-EOMES (Dan11mag, 1:100), anti-FOXO1(C29H4, Cell Signaling, no. 2880S, 1:200), anti-GzmB (GB11,1:100), IFN $\gamma$ (XM61.2, 1:100), anti-Ki67 (SolA15, 1:100), anti-KLRG1 (2F1, 1:200), anti-NK1.1 (PK136, 1:250), anti-P2XR7 (1F11, 1:100), anti-pAKT (SDRNR, 1:100), anti-pZAP70 (h3kobu5, 1:100), anti-pLCK (SRRCHA, 1:100), anti-T-BET (eBio4B10, 1:100), anti-TCRß (H57-597), anti-TNF (MP6-XT22, 1:100) and TOX (TXRX10, 1:100).

For human studies, the following antibodies were used: anti-CD3 (SK7), anti-CD8 (HIT8a), anti-CD45 (HI-30), anti-CD69 (FN50), anti-CD186 (K041E5), anti-GzmB (GB11), and anti-FOXO1 (C29H4).

\section{Flow cytometric analysis of cell phenotype and function}

Cell-surface staining with fluorochrome-labelled antibodies was performed for 30 min at $4{ }^{\circ} \mathrm{C}$ in PBS (ThermoFisher) supplemented with $2 \%$ FCS (Merck). Intracellular cytokine staining was performed using the Transcription Factor Staining Buffer Set (ThermoFisher, no. 00-5523-00) according to the manufacturer's instructions. In brief, liver-associated lymphocytes were incubated with PMA (20 ng ml ${ }^{-1}$, Merck, no. P8139) and Ionomycin (500 $\mathrm{ng} \mathrm{ml}^{-1}$, Merck, no. I0634) for $4-5 \mathrm{~h}$ at $37^{\circ} \mathrm{C}$ in the presence of brefeldin A (1:1,000, ThermoFisher, no. 00-4506-51) and monensin (1:1,000, ThermoFisher, no. 00-4505-51). Cells were labelled with Zombie NIR fixable viability kit (1:1,000, BioLegend, no. 423106) or with eBioscience fixable viability dye eFluor 780 (1:2,000, ThermoFisher, no. 65-0865-18). After cell-surface staining, cells were fixed, permeabilized and stained with flurochrome-labelled antibodies against IFN $\gamma$, TNF and GzmB. Intracellular transcription factor staining was performed using the FOXP3/Transcription Factor Staining Buffer Set (no. 00-5523-00, ThermoFisher). For FOXO1 staining, cells were incubated with the unconjugated primary rabbit anti-mouse antibody overnight at $4{ }^{\circ} \mathrm{C}$ followed by incubation with an Alexa Fluor 488-(Cell Signaling, no. 4412s)- or Alexa Fluor 647- (ThermoFisher, no. A-21244)-conjugated secondary goat anti-rabbit antibody for $1 \mathrm{~h}$. For staining of phosphorylated proteins, cells were fixed and permeabilized in ice-cold methanol (100\%). Flow cytometric analysis was performed using SP6800 (Sony); cells were sorted using SH800 (Sony). Data were analysed with FlowJo software (Tree Star, v.10.8).

To measure intracellular calcium concentration in T cells, the calcium-sensitive dye eF514 (2 mM, ThermoFisher, no. 65-0859-39) was used together with fluorochrome-labelled antibodies and cells were analysed by flow cytometry. Apoptosis in T cells was assessed by flow cytometry using APC- or FITC-labelled annexin V (Apoptosis Detection Kit, BioLegend: no. 640932 and no. 640914) following the manufacturer's instructions.

Phenographic analysis of hepatic T cells in mice fed a normal diet or CD-HFD for 12 months (normal diet, $n=5$; CD-HFD, $n=5$ ) was performed using single .fcs files of cells that were positive for TCR $\beta$ and/or for NK1.1. Further analysis was executed with the R package Cytofkit ${ }^{36}$. The .fcs files were concatenated with the $t$-SNE algorithm. To cluster the populations, we used Rphenograph in Cytofkit with default settings. Annotation of each cluster was performed using expression of the following markers: CD4, CD8, CXCR6, PD1 and GzmB.

\section{Image-stream analysis}

To visualize intracellular localization of FOXO1 protein, stained T cells were analysed using the Amnis ImageStream (Millipore). Similarity score between FOXO1 and propidium iodide (PI) (ThermoFisher, no. $\mathrm{P} 1304 \mathrm{MP}$ ) was calculated using the IDEAS software v.6.2. Similarity score was used to determine nuclear localization of FOXO1 and subsequent mean fluorescence intensity of the protein.

\section{Stimulation of CD8 $\mathrm{T}$ cells in vitro}

One million per ml splenic CD8 T-cells from C57BL/6 mice or from transgenic OT-1 mice were purified by immunomagnetic separation using AutoMACS (Miltenyi Biotec), were activated with plate-bound anti-CD3 $\left(2 \mu \mathrm{g} \mathrm{ml}^{-1}\right)$ in RPMI 1640 medium containing FCS (10\%), L-glutamine $(2 \mathrm{mM})$, penicillin-streptomycin $\left(100 \mathrm{U} \mathrm{ml}^{-1}\right), \beta$-mercaptoethanol $(0.1 \mathrm{mM})$ and IL-2 (100 $\left.\mathrm{U} \mathrm{ml}^{-1}\right)$ for 2 days in 24 -well plates. Cells were removed and transferred to a new plate at a concentration of $10^{6}$ cells per $\mathrm{ml}$ in the presence of TGF $\beta\left(5 \mathrm{ng} \mathrm{ml}^{-1}\right)$ that was shown to be involved in T cell tissue residency ${ }^{37}$. After 2 days, vital cells were isolated through Pancoll density centrifugation $(1,440 \mathrm{~g}, 20 \mathrm{~min})$. Vital CD8 T cells were stimulated with IL-15-IL-15R $\alpha$ (10 $\mathrm{ng} \mathrm{ml}^{-1}$, ThermoFisher, no. 14-8152-80) and TGF $\beta$ ( $5 \mathrm{ng} \mathrm{ml}^{-1}$, Peprotech, no. 100-21) for $24 \mathrm{~h}$ to become highly enriched for $\mathrm{CXCR6}^{+}, \mathrm{GzmB}^{+}$and $\mathrm{CD} 9^{+} \mathrm{T}$ cells. Positively selected human CD8 T cells were stimulated with IL-15 (15 $\mathrm{ng} \mathrm{ml}^{-1}$, Peprotech, no. 200-15) or TGF $\beta$ (25 ng ml ${ }^{-1}$, Peprotech, no. 100-21) as control for 5 days before analysis if not differently indicated. To be consistent in the terminology for IL-15 treatment of mouse and human T cells, we used the term IL-15 instead of IL-15-IL-15R $\alpha$ in the Article. For analysis of ligand-dependent influx of calcium in IL-15-IL-15R $\alpha$-stimulated CXCR6 $^{+}$CD8 T cells, the following molecules were used: LPS (100 ng $\mathrm{ml}^{-1}$, Merck, no. L4524), CpG (10 $\mu \mathrm{g} \mathrm{ml}^{-1}$, Invivogen, no. tlrl-1585), Poly $\mathrm{I}: \mathrm{C}\left(10 \mu \mathrm{g} \mathrm{ml}^{-1}\right.$, Invivogen, no. tlrl-picw), adenosine (1 $\mu \mathrm{M}$, Merck, no. A4036), ATP disodium salt hydrate (200 $\mu \mathrm{M}$, Merck, no. A26209), NAD $\left(10 \mu \mathrm{M}\right.$, Merck, no. NAD100-RO) and recombinant CXCL16 (10 $\mathrm{ng} \mathrm{ml}^{-1}$, Peprotech, no. 250-28). For analysis of metabolite-dependent expression of GzmB in IL-15-IL-15R $\alpha$-stimulated CXCR6 ${ }^{+}$CD8 T cells, the following substances were used (all from Merck): sodium lactate $(5 \mathrm{mM}$, no. 71718$)$, sodium citrate $(5 \mathrm{mM}$, no. PHR1416), sodium pyruvate $(5 \mathrm{mM}$, no. P5280), sodium acetate (15 mM, no. S2889), sodium propionate (0.5 mM, no. P1880), sodium butyrate ( $0.5 \mathrm{mM}$, no. 303410$)$, palmitic acid $(50 \mu \mathrm{M}$, no. P0500), linoleic acid $(100 \mu \mathrm{M}$, no. L1012), oleic acid $(100 \mu \mathrm{M}$, no. 01383). Fatty acids were dissolved in ethanol. Medium $\mathrm{pH}$ values were monitored after adding these substances, but no change in $\mathrm{pH}$ value was detected.

Isolation of human CD8 $\mathrm{T}$ cells from peripheral mononuclear cells CD8 T cells were generated from blood of healthy, voluntary donors after they gave written and informed consent. This study was approved by a vote from the ethics committee of the University Hospital München rechts der Isar. Blood was mixed with PBS (1:1) and loaded on Pancoll (PAN Biotech, no. P04-601000) to isolate peripheral blood mononuclear cells through centrifugation $(1,400 \mathrm{~g}, 25 \mathrm{~min})$. Cells were washed, counted and mixed with human anti-CD8 magnetic beads (Miltenyi Biotec, no.130-045-201) and subjected to immunomagnetic separation before use in experiments.

\section{CD8 T cell cytotoxicity assay}

Measurement of the dynamics of CD8 T cell cytotoxicity against primary mouse or human hepatocytes over time was performed with the impedance-based technology using an xCelligence RTCA MP device (ACEA Biosciences). In brief, after isolation, primary mouse or human hepatocytes were seeded in Xcelligence plates $\left(10^{4}\right.$ cells per well) and on day 2 (after hepatocytes reached confluency and a maximum cell index) $3 \times 10^{4} \mathrm{CD} 8 \mathrm{~T}$ cells were added. As indicated in the figures, acetate, recombinant cytokines, blocking antibodies or specific inhibitors were added. The following reagents were used: TNF (ThermoFisher, no. PMC3013), IL-6 (Miltenyi Biotec, no. 130-094-065), IL-1ß (Peprotech, no. 211-11B), pannexin I inhibitor (probenecid, Merck, no. P8761, $100 \mu \mathrm{M}$ ), P2RX7 inhibitor (A-438079 hydrochloride, Cayman Chemical, no. 14580, $25 \mu \mathrm{M})$, PLC $\gamma$ inhibitor (edelfosine, Tocris, no. 3022, $10 \mu \mathrm{M}$ ), EGTA (Merck, no. E3889, 2 mM), ERK inhibitor (U0126, Merck, no. 662005, 100 nM), PI3K inhibitor (wortmannin, Merck, no. W1628, $10 \mathrm{nM}$ ), calcineurin inhibitor (cyclosporin A, Merck, no. C3662, 
$1 \mu \mathrm{M}$ ), anti-LFA1 (mouse: BioXcell, M17/4, BE0006, $10 \mu \mathrm{g} \mathrm{ml}^{-1}$; human: BioLegend, $10 \mathrm{\mu g} \mathrm{ml}^{-1}$ ), anti-mouse $\mathrm{MHCl}$ (BioXcell, M1/42.3.9.8, no. BE0077, $10 \mu \mathrm{g} \mathrm{ml}^{-1}$ ), anti-mouse PD1 (BioXcell, RMP1-14, no. BE0146, $10 \mu \mathrm{g} \mathrm{ml}^{-1}$ ), anti-mouse TNFR1 (BioLegend, 55R-593, no. 113102, $10 \mu \mathrm{g}$ $\mathrm{ml}^{-1}$ ), anti-mouse TNFR2 (BioLegend, TR75-32.4, no. 113202, $10 \mu \mathrm{g} \mathrm{ml}^{-1}$ ), anti-human TNF (BioLegend, MAb11, no. 502901), anti-mouse IFN $\gamma$ (BioLegend, XMG1.2, no. 505801,10 $\mathrm{g} \mathrm{m} \mathrm{m}^{-1}$ ), anti-FasL (mouse: BioXcell, MFL3, no. BE0319, $10 \mu \mathrm{g} \mathrm{ml}^{-1}$; human: BioLegend, NOK-1, no. 306415, $10 \mu \mathrm{g} \mathrm{ml}^{-1}$ ) and anti-human NKG2D (BioLegend, 1D11, no. 320813,10 $\mu \mathrm{g}$ $\left.\mathrm{ml}^{-1}\right)$. Hepatocytes treated with respective reagents alone were used for measurement of baseline values. Measured electrical impedance is shown as cell index and normalized to the time point of starting the coculture of $\mathrm{T}$ cells with hepatocytes. The cell index at $24 \mathrm{~h}$ after start of coculture was used to calculate the efficacy of hepatocyte killing. Percentage of killing was calculated by subtracting the cell index values from controls (hepatocytes alone or with respective substances).

Cytotoxicity measurement of human CD8 T cells against human K562 cells (ATCC, CCL-243) was performed by labelling target cells with CFSE $(1 \mu \mathrm{M}$, ThermoFisher, no. C34554) and incubating with effector cells in different effector-to target ratios for $24 \mathrm{~h}$. Dead $\mathrm{K} 562$ cells in coculture with CD8 T cells were detected by flow cytometry and percentage was calculated to $\mathrm{K} 562$ cells alone.

\section{Adoptive transfer of auto-aggressive CD8 T cells into C57BL/6 mice}

$\mathrm{CXCR6}^{+} \mathrm{CD} 8 \mathrm{~T}$ cells from $\mathrm{C} 57 \mathrm{BL} / 6$ mice were differentiated and stimulated with IL-15-IL-15R $\alpha\left(10 \mathrm{ng} \mathrm{ml}^{-1}\right)$ as described in 'Stimulation of CD8 T cells in vitro', followed by exposure to sodium acetate $(15 \mathrm{mM}$, Merck) for $24 \mathrm{~h}$. CD8 T cells were washed and adoptively transferred $\left(4 \times 10^{6}\right.$ cells per mouse) into mice in combination with antibodies against either TNF (200 $\mu$ g per mouse, BioXcell, clone XT3.11, no. BE0058), LFA1 (100 $\mu$ g per mouse, BioXcell, clone M17/4, no. BE0006), FasL (100 $\mu \mathrm{g}$ per mouse, BioXcell, clone MFL3, no. BE0319) or P2XR7 (50 $\mu \mathrm{g}$ per mouse, 13A7). sALT was determined two days after transfer.

\section{Extracellular flux analysis}

Extracellular acidification rates were measured in XF medium (no. 03334-100, Agilent, non-buffered RPMI 1640 containing $2 \mathrm{mM}$ L-glutamine, and $1 \mathrm{mM}$ sodium pyruvate) under basal conditions and in response to $10 \mathrm{mM}$ glucose (Merck, no. G7021), $2 \mu \mathrm{M}$ oligomycin (Merck, no. 75351) and 50 mM 2-deoxy-D-glucose (Merck, no. D8375) using a 96-well XF Extracellular Flux Analyzer with Analyzer Software v.1.4.2 (Agilent).

\section{Retroviral infection and overexpression of FOXO1}

Mouse FOXO1-eGFP was amplified from a GFP-Foxo1 plasmid using the following primers Foxo1 fw_SLIC: 5' CTCCAAGCTCACTTACAGGC GAGTCACCATGGCCGAGGCG3'; eGFPrev_SLIC:5' GCGGTAAGATGCTCG AATTCTTTACTTGTA CAGCTCGTCC 3' (underlining denotes restriction enzyme sites for KpnI and EcoRI)). GFP-Foxo1 was a gift from D. Accilli (Addgene plasmid no. 17551; https://www.addgene.org/17551/; RRIDAddgene_17551). Foxo1-eGFP was inserted into pMP71 retroviral vector by sequence and ligation independent cloning ${ }^{38}$ to generate pMP71-Foxo1-eGFP.Specifically, the eGFP of pMP71-eGFP was deleted by NotI + EcoRI restriction enzyme digestion and the PCR fragment was inserted. pMP71-Foxo1-GFP and control pMP71-eGFP containing only GFP were used for retroviral transduction of activated CD8 T cells: on day 1, the retroviral packaging cell line Plat-Eco (Cell Biolabs, no. RV-101) was transfected using Lipofectamine 3000 (ThermoFisher, no. L3000001) according to the manufacturer's instructions. On the same day, splenic CD8 T cells from C57BL/6J mice were isolated and stimulated with plate-bound anti-CD3 and anti-CD28 antibodies $\left(5 \mathrm{ng} \mathrm{ml}^{-1}\right)$ in RPMI 1640 medium containing FCS (10\%), L-glutamine $(2 \mathrm{mM})$, penicillin-streptomycin $\left(100 \mathrm{U} \mathrm{ml}^{-1}\right), \beta$-mercaptoethanol $(0.1 \mathrm{mM})$ and IL-2 $\left(300 \mathrm{U} \mathrm{ml}^{-1}\right)$. On day 3 , viral supernatant was transferred to retronectin-coated 12 -well plates $\left(20 \mathrm{ng} \mathrm{ml}^{-1}\right.$, TaKaRa, no. T100A/B), and spun at $1,000 \mathrm{~g}$ for $120 \mathrm{~min}$ at $37^{\circ} \mathrm{C}$. Activated CD8 $T$ cells were loaded on centrifuged viral supernatant and this process was repeated on the next day. Transduced T cells were cultured for two days, adding fresh medium with IL-2 $\left(300 \mathrm{U} \mathrm{ml}^{-1}\right)$ on day 1 after transduction. CXCR6, FOXO1 and GzmB expression were determined in $\mathrm{GFP}^{+} \mathrm{CD} 8 \mathrm{~T}$ cells, allowing us to differentiate between $\mathrm{T}$ cells that overexpressed FOXO1.

For CD8 T cell cytotoxicity experiments against primary mouse hepatocytes with Xcelligence device, transduced GFP ${ }^{+}$CD8 T cells were sorted by fluorescence-activated cell sorting on day 1 after transduction. On day 2 after transduction, sorted and transduced CD8 T cells were stimulated with IL-15-IL-15R $\alpha\left(10 \mathrm{ng} \mathrm{ml}^{-1}\right)$ and exposed to acetate $(15 \mathrm{mM})$ overnight and added to primary hepatocytes at an effector-to-target ratio of 3:1. After $24 \mathrm{~h}$ of coculture, auto-aggression was calculated as described in 'CD8 T cell cytotoxicity assay'.

\section{Measurement of serum parameters}

Serum was obtained by cardial puncture after mice were killed, and sALT levels were measured with the Reflotronplus system (Roche). Detection of cytokine concentrations in serum was performed with a 23-plex bead array (Bio-Rad, no. M60009RDPD) or an enzyme-linked immunosorbent assay for IL-15 (Peprotech, no. 900-K188) or IL-21 (Peprotech, no. 900-K368).

\section{Fluorescent-linked immunospot (fluorospot) assay}

One hundred thousand in vitro-differentiated CXCR6 ${ }^{+} \mathrm{CD} 8 \mathrm{~T}$ cells were incubated for $24 \mathrm{~h}$ in the presence of TGF $\beta\left(5 \mathrm{ng} \mathrm{ml}^{-1}\right)$, IL-15-IL-15R $\alpha$ $\left(10 \mathrm{ng} \mathrm{ml}^{-1}\right)$ and sodium acetate $(15 \mathrm{mM})$ on TNF- and IFN $\gamma$-coated 96-well plates. For antigen-specific stimulation, medium was supplemented with $1 \mathrm{nM}$ SIINFEKL for the last four hours followed by detection of TNF- and IFN $\gamma$-secreting $\mathrm{CXCR6}^{+} \mathrm{CD} 8 \mathrm{~T}$ cells, according to the manufacturer's instructions (Immunospot, no. mT2001F, no. mT02, no. mT11). Counting of TNF- and IFN $\gamma$-producing CXCR6 ${ }^{+}$CD8 T cells was performed with Immunospot's S6 ULTIMATE Analyzer and Immunospot Software (CTL Immunospot 5.4 Professional DC Software).

\section{Confocal microscopy of primary cells in vitro}

Thirty thousand hepatocytes were seeded on collagen-coated sterile 12 -well silicone chamber slides (Ibidi, no. 81201) and $1 \times 10^{5} \mathrm{CXCR6}^{+}$ CD8 T cells were added with medium containing TGF $\beta\left(5 \mathrm{ng} \mathrm{ml}^{-1}\right), \mathrm{IL}-15-$ IL-15R $\alpha\left(10 \mathrm{ng} \mathrm{ml}^{-1}\right)$ and sodium acetate $(15 \mathrm{mM})$. After $18 \mathrm{~h}$ of coculture, cells were fixed with $4 \%$ PFA, washed with PBS and were stained with ICAM1-PE (1:200), LFA1-Alexa Fluor 647 (1:200) and DAPI (1:2,000, Merck, no. 10236276001). Stained sections were mounted in Mowiol and analysed on an inverted TCS SP8 confocal microscope (Leica) for tiled imaging using a HC PL APO CS2 $40 \times / 1.30$ NA or a HCPL APO CORR CS2 $63 \times / 1.30$ NA objective. Tiled $x-y$ stacks were acquired with $0.5-\mu \mathrm{m}$ $z$-spacing to provide 3D image volumes of 7-11- $\mu \mathrm{m}$ depth. Confocal image analysis was performed using Imaris software (v.9.5, Bitplane) on maximum projections of 10 large $z$-plane sections. Automated analyses using the IMARIS surface generation tool were used to reconstruct surface objects for T cells and hepatocytes based on LFA1 and ICAM1 staining. Distances between surface objects were calculated on the basis of positional information using the IMARIS Shortest Distance Statistics tool.

\section{Confocal microscopy and 3D reconstruction of liver tissue}

Thirty-micrometre paraffin sections were cut on a HM355S microtome (ThermoFisher) and adhered to Superfrost Plus slides (ThermoFisher). Antigen retrieval was performed in 1 mM EDTA pH9 0.05\% Tween-20 at $100^{\circ} \mathrm{C}$ for $20 \mathrm{~min}$. Sections were then permeabilized and blocked in PBS containing $0.3 \%$ Triton X-100 (Sigma-Aldrich) and $10 \%$ FBS followed by staining in the same blocking buffer. The following primary antibodies were used for staining: rat anti-mouse CD8 (4SM15, ThermoFisher), 
rabbit anti-mouse cleaved caspase 3(D3E9, Cell Signaling Technology), goat anti-mouse collagen IV-a1 (polyclonal, Novus Biologicals). The following secondary antibodies were used for staining: Alexa Fluor 488 chicken anti-rat IgG $(\mathrm{H}+\mathrm{L})$, Alexa Fluor 568 chicken anti-rabbit IgG $(\mathrm{H}+\mathrm{L})$ and Alexa Fluor 647 donkey anti-goat $\operatorname{IgG}(\mathrm{H}+\mathrm{L})$, (ThermoFisher).

Stained slides were mounted with Fluorsave (Merck Millipore) and images were acquired on an inverted Leica microscope (TCS STED CW SP8, Leica Microsystems) with a motorized stage for tiled imaging. To minimize fluorophore spectral spill over, we used the Leica sequential laser excitation and detection modality. The bleed-through among sequential fluorophore emission was removed by applying simple compensation correction algorithms to the acquired images. The semiautomatic surface-rendering module in IMARIS (Bitplane) was used to create $3 \mathrm{D}$ volumetric surface objects corresponding either to individual cells or to the liver vascular system. Signal thresholds were determined using the IMARIS Surface Creation module, which provides automatic threshold identification and value-based visual surface thresholds around the positively stained objects. The semiautomatic channel colocalization module in Imaris (Bitplane) was used to detect and reconstruct surface contact areas between CD8 T cells and cleaved-caspase-3-positive hepatocytes.

For confocal imaging of CXCR6 in the liver, livers were perfused with $2.5 \mathrm{ml}$ Antigenfix solution (Diapath) via the portal vein, excised and fixed for $4 \mathrm{~h}$ in $1 \mathrm{ml}$ Antigenfix. Fixed liver lobes were embedded in Tissue-Tek O.C.T. compound (Sakura Finetek) and frozen at $-80^{\circ} \mathrm{C}$ before 50- $\mu \mathrm{m}$ cryosections were cut. Liver sections were permeabilized and blocked with $0.1 \mathrm{M}$ Tris (AppliChem) containing 1\% BSA, 0.3\% Triton X-100 (Gebru Biotechnik), 1\% normal mouse serum (Sigma) for $2 \mathrm{~h}$. Sections were stained in blocking buffer with anti-CD3 (Biolegend, clone 17A2), anti-CD8 (eBioscience, clone 53-6.7), anti-CXCR6 (Sony, clone SA051D1), anti-PD-1 (R\&D Systems, polyclonal) and anti-collagen IV (Abcam, polyclonal). Unconjugated primary antibodies were stained with the following secondary antibodies overnight: donkey anti-rabbit IgG (Biolegend, clone Poly4064) and donkey anti-goat IgG (Jackson Immunology, polyclonal). Stained sections were mounted in Mowiol and analysed on an inverted TCS SP8 confocal microscope (Leica) for tiled imaging using a HCPL APOCS2 $20 \times / 0.75$ IMM objective. Tiled $x-y$ stacks were acquired with $1-\mu \mathrm{m} z$-spacing to provide $3 \mathrm{D}$ image volumes of $15-\mu \mathrm{m}$ depth. Three-dimensional image analysis was performed using IMARIS 9.5 software (Bitplane) following adaptive image deconvolution using the Leica TCS SP8 LIGHTNING tool. The IMARIS surface generation tool was used to reconstruct 3D surfaces for $\mathrm{CD}^{+} \mathrm{CD} 8 \mathrm{~T}$ cells, $\mathrm{T}$ cell subsets were identified based on mean voxel intensities for CXCR6 and PD1.

\section{Multiplex immunohistochemistry}

Sequential immunostaining was performed on 2 - $\mu \mathrm{m}$-thick formalin-fixed paraffin-embedded (FFPE) mouse liver sections, as previously described ${ }^{5}$. Heat-mediated antigen retrieval was performed in citrate buffer (ThermoFisher). Antibody elution was performed between each staining cycle using a 2-mercaptoethanol, SDS buffer. Primary antibodies used: anti-PD1 (1/200, R\&D Systems, no. AF1021), anti-CD8a (1/200, ThermoFisher no. 14-0808-82), anti- $\alpha$ SMA (1/200, Agilent no. M085129-2), anti-IBA1 (1/1,000, EMD Millipore no. MABN92) and anti-CK19 (1/200, DSHB no. TROMA-III). TROMA-III was deposited to the DSHB by R. Kemler (DSHB Hybridoma Product TROMA-III).

\section{Mass spectrometry imaging}

$N$-(1-Naphthyl) ethylenediamine dihydrochloride (NEDC) (>98\% purity, no. 222488) was purchased from Sigma Aldrich and used without further purification. Methanol (ULC-MS grade, no.136841), water (LC-MS grade, no. 232178), ethanol (ULC-MS grade, no. 052541), acetone (LC-MS grade, no. 010378) and xylene (AR grade, no. no. 242505) were purchased from Biosolve. Haematoxylin (Merck, no. 104302) and eosin Y (J. T. Baker, no. L088-03) were used under standard laboratory protocols. Entellan was purchased from Merck (no. 107961). Liver tissue was obtained from mice fed a normal diet or CD-HFD for 12 months and sections of $12-\mu \mathrm{m}$ thickness were generated at $-15^{\circ} \mathrm{C}$ with a cryomicrotome (Leica). Samples were thawed and mounted onto clean Intellislides (Bruker). Slides were then spray-coated with matrix using an HTX TM-Sprayer (HTX Technologies) under the following conditions: $7.5 \mathrm{mg} \mathrm{ml}^{-1} \mathrm{NEDC}$ in ethanol/methanol/acetone, (50/49/1) spray temperature $80^{\circ} \mathrm{C}$, spray height $40 \mathrm{~mm}$, velocity $1,200 \mathrm{~mm} \mathrm{~min}^{-1}$, flow rate $0.11 \mathrm{ml} \mathrm{min}^{-1}$, gas flow rate $31 \mathrm{~min}^{-1}, 3 \mathrm{~mm}$ track spacing, 12 passes. Final concentration of NEDC was approximately $2.75 \mu \mathrm{g}$ per $\mathrm{mm}^{2}$. Samples were analysed immediately after spray-coating, using a TimsTOF Flex mass spectrometer (Bruker). Mass spectrometry images (MSI) were generated for both positive and negative ionization modes, with the $\mathrm{m} / z$ window tuned to either $50-150 \mathrm{~m} / z$ (metabolites) or $70-900 \mathrm{~m} / z$ (lipids), with the pixel size set to $10 \mu \mathrm{m}$. All samples were analysed using the post-ionization functionality of the TimsTOF Flex. Individual pixels were gathered with 25 laser shots, with post-ionization laser delay of $9 \mu \mathrm{s}$. TimsTOF data files were imported into SCiLS Lab (Bruker Daltonics). Post-MSI, samples were washed of matrix and H\&E-stained according to standard laboratory protocols. Slides were imaged using an Aperio CS2 (Leica). Box plots of segmented liver tissues were generated, with root mean square normalization between liver tissue from mice fed a normal diet or CD-HFD.

\section{Measurement of acetate}

Mouse and human mouse tissues were weighed, $50 \mu \mathrm{l}$ PBS was added and they were then gently centrifuged at $300 \mathrm{~g}$ for $8 \mathrm{~min}$. Organ supernatants were recovered and acetate contents determined using the acetate assay kit (no. MAK086, Merck) according to the manufacturer's instructions. Organ acetate levels were normalized to organ weight. Concentration of acetate in the supernatant of primary mouse hepatocytes that were treated with palmitate $(250 \mu \mathrm{M})$ or with trimeric FasL (no. ALX-522-001-C010, Enzo) for $24 \mathrm{~h}$ was determined according to the manufacturer's instructions (no. MAK086, Merck).

\section{Measurement of extracellular ATP}

Supernatant of primary mouse hepatocytes that were treated with palmite or trimeric FasL for $24 \mathrm{~h}$ or of $\mathrm{CXCR} 6^{+} \mathrm{CD} 8 \mathrm{~T}$ cells were collected in vitro and the concentration of ATP was measured according to manufacturer's instructions (no. A22066, Thermo Fisher).

\section{Histology, immunohistochemistry, scanning and automated analysis}

Tissues were fixed in $4 \%$ paraformaldehyde, paraffin-embedded and treated as previously reported ${ }^{39}$. Two- $\mu \mathrm{m}$ sections from FFPE or cryopreserved tissues were stained with haematoxylin and eosin or stained with specific antibodies (anti-CXCR6, 1:200, clone PA5-33462, Invitrogen; anti-ICAM 1:1500, clone 3E2B, Linaris; anti-MHC I1:500, clone ER-HR 52) using a Leica Biosystems Bond MAX. Stained tissue slides were scanned using an Aperio System and analysed using Aperio Image Scope software 12.4.0. NAS was performed in a blinded fashion on mouse livers and cross-validated by an expert veterinary pathologist.

For in situ hybridization, freshly non-baked 5- $\mu \mathrm{m}$ FFPE tissue slices were cut and stained according to manufacturer's (ACD biotech) protocol for manual-assay RNAscope, using probes against human CXCR6 (468461) and mouse CXCR6 (no. 871991). For quantification of cells that were positive for $C X C R 6 \mathrm{mRNA}$ per $\mathrm{mm}^{2}$ liver tissue, positive cells of four independent regions of interests in the represented areas were counted and the average number was calculated.

\section{Quantitative real-time PCR}

RNA from liver tissue from mice fed a normal diet or CD-HFD for 12 months was isolated according to the manufacturer's instructions (no. T2010S, NEB). cDNA was generated using SensiFAST cDNA synthesis kit from Bioline (no. BIO-65054). Primers against mouse Il15, Il15ra, Il21, Cxcl16, Tnf, Il6 and Il1b were purchased from Eurofins (Munich); 
the sequences are listed in the Supplementary Information. A mix of primer pairs, double-distilled water and $2 \times$ Takyon Mix SYBR green assay (Eurogentec) was added to the cDNA and amplified copies were quantified by LightCycler 480 (Roche).

RNA from human liver tissue was isolated according to the manufacturer's instructions (no. 740955.250, Macherey Nagel). cDNA was generated using high-capacity cDNA Reverse transcription Kit from Applied Biosystems (no. 4368813). Primers against IL4 (no. Hs00174122_m1), IL15 (no. Hs01003716_m1), IL15RA (no. Hs00542602_g1), IL21 (no. Hs00222327_m1), CXCR6 (Hs01890898_s1), CXCL16 (Hs00222859_ m1), ICAM1 (no.Hs00222859_m1), TNF(no.Hs01113624_g1) and HRPT1 (no.Hs02800695_m1) were purchased from Thermo FisherScientific. A mix of primer pairs, double distilled water and KAPA Probe Fast Universal (no. KK4715, KAP Biosystems) was added to the cDNA and amplified copies were quantified by ViiA7 (Applied Biosystems).

\section{RNA-seq analysis}

Samples for RNA-seq were directly sorted in a semi-skirted 96-well PCR plate including lysis buffer (2× TCL buffer (Qiagen, no. 1070498) + RNase-free water $+\beta$-mercaptoethanol ( $1 \%$ total volume)). Library preparation for bulk 3'-sequencing of poly(A)-RNA was performed as previously described ${ }^{40}$. The barcoded cDNA of each sample was produced with a Maxima RT polymerase (Thermo Fisher) exercising oligo-dT primer containing barcodes, unique molecular identifiers (UMIs) and an adaptor 5 ' ends of the cDNAs were prolonged by a template switch oligo (TSO), and after uniting of all samples full-length cDNA was amplified with primers binding to the TSO site and the adaptor. cDNA was supplemented with the Nextera XT kit (Illumina) and 3 '-end-fragments finally augmented with P5 and P7 Illumina overhangs. We sequenced the library using NextSeq 500 (Illumina). To generate the UMI tables for samples and genes we used Drop-seq pipeline (https://github.com/ broadinstitute/Drop-seq). We used GRCm 38 reference genome for the alignment and ENSEMBL annotation release 75 for annotating genes. The DESeq2 R package ${ }^{41}(\mathrm{v} \cdot 2.1 .28 .1)$ was used to detect the differentially expressed genes (fold change 1.5 and adjusted $P$ value $\leq 0.05$ ). Principal component analysis was performed using the 'prcomp' function in $\mathrm{R}$ and visualized via ggplot $\mathrm{R}$ package (v.3.3.2). Volcano plots and heat maps were plotted using EnhancedVolcanoplot and pheatmap R packages (v.1.0.12).

\section{Identification of transcription factors and network analysis}

Transcription factor analysis was performed using the differentially expressed genes in datasets from $\mathrm{CXCR6}^{+}$and $\mathrm{CXCR}^{-}$mice fed a CD-HFD. To predict the upstream transcription factors that control the differentially expressed genes, we used the 'Binding Analysis for Regulation of Transcription' prediction tool (BART v.1.1) ${ }^{18}$ with default settings. We considered a transcription factor as significant at $P$ value $<$ 0.01 . Transcription factors perturbed within the transcriptome datasets (downstream transcription factors) were identified using the mouse transcription factor atlas ${ }^{42}$. This analysis identified 25 transcription factors in the datasets from $\mathrm{CXCR}^{+}$versus CXCR6 ${ }^{-}$mice fed a CD-HFD. We generated transcription factor-transcription factor network of both upstream transcription factors from BART analysis and downstream transcription factors from the transcriptomes as follows: first, promoter sequences $(-2 \mathrm{~kb})$ of significantly differentially expressed genes from the datasets were downloaded from eukaryotic promoter database $^{43}$. Second, we retrieved the transcription factor binding sites from the JASPAR core and Hocomoco databases ${ }^{44,45}$. Then, we scanned promoter sequences (-2-kb promoters) of differentially expressed genes and transcription factors for binding sites using a custom Python script. We generated transcription factor-transcription factor networks and visualized them in Cytoscape v.3.7.1 (ref. ${ }^{46}$ ). To assess the hierarchy of transcription factor networks, in $(I)$ and out $(O)$ degrees were computed for each transcription factor and its targets using the igraph $\mathrm{R}$ package (https://igraph.org/,v.1.2.6) and hierarchy height $H=(O-I) /(O+I)$ was calculated as previously described ${ }^{47}$. Hierarchy height score defines three levels of transcription-factor network hierarchy.

\section{Human single-cell RNA-seq in patients with NASH}

Sample generation. Single-cell suspensions from human liver were generated by cutting freshly obtained liver tissues into small pieces, followed by enzymatic digestion using the Miltenyi tumour dissociation kit (no. 130-095-929) according to the manufacturer's instructions. Liver pieces were digested for $20 \mathrm{~min}$ at $37^{\circ} \mathrm{C}$ while shaking, and stopped by adding medium (RPMI $+20 \%$ FBS). Digested tissues were passed through a $70-\mu \mathrm{m}$ cell strainer and centrifuged at $350 \mathrm{~g}$ for $10 \mathrm{~min}$. Red blood cell lysis was carried out with ACK lysis buffer (Thermo Fisher Scientific, no. A1049201) and, after washing, the remaining cells with complete medium were strained through a $45-\mu \mathrm{m}$ mesh. $\mathrm{CD} 45^{+}$cells were sorted and subjected to single-cell RNA-seq analysis. Liver cells were stained with anti-CD45-PE (Hl30, no. 12-0459-42) and Live/Dead discrimination (1:1,000, Thermofischer, no. L34973), washed with PBS + $0.05 \mathrm{mM} \mathrm{EDTA}\left(10 \mathrm{~min}, 300 \mathrm{~g}, 4^{\circ} \mathrm{C}\right)$ and sorted into single $\mathrm{CD} 45^{+}$cells using a FACSAria FUSION. Library generation was performed according to the manufacturer's protocol (Chromium Next EM Single Cell 3'GEM, no.10000128). Single-cell sequencing was performed with an Illumina NovaSeq-6000.

Single-cell RNA-seq analysis. To perform downstream analysis, we used filtered gene-barcode matrices generated from the 10X Genomics pipeline cellranger count to serve as input for the R package Seurat $3^{48,49}$ (v.3.2.2). Analysis was initiated by creating Seurat objects from liver samples from patients with steatosis $(n=4)$ or NASH $(n=3)$. We excluded genes that were expressed in fewer than three cells, and also cells with fewer than 200 genes. Datasets were normalized and cell-cycle regression was performed. We executed unsupervised clustering by computing principal components using the RUNPCA function in the Seurat $\mathrm{R}$ package. Cluster analysis was performed using the cluster $\mathrm{R}$ package ${ }^{50}$ with a clustering resolution of 1 , and cell clusters were visualized using uniform manifold approximation and projection (UMAP). Markers were identified using the 'Finding All Markers' function (logfc. threshold $=0.25$ and Wilcoxon rank sum test-adjusted $P$ value $<0.05$ ). Dot plot and feature plots were visualized using the Seurat R package.

To compare mouse bulk RNA-seq dataset $\left(\mathrm{CXCR}^{+}{ }^{+}\right.$versus CXCR6 ${ }^{-}$mice fed a CD-HFD) with human single-cell RNA data from livers of patients with NASH (CD8 RGS1 ${ }^{+}$and CD8 $G N L Y^{+} F G F B P 2^{+}$) we converted mouse genes to human orthologues using an online tool (https://biodbnet-abcc. ncifcrf.gov/db/dbOrtho.php) and computed the Spearman correlation between the $\log _{2}$-transformed fold changes of both datasets. Correlation was considered significant at $P<0.05$, and visualized as a scatter plot using the ggplot2 package (v.0.4). To assess the similarity between CD8 T cell populations from fat tissue (CD8 RGS1 $1^{+}$and CD8 CCL4 $\left.{ }^{+}\right)$and livers of patients with NASH $\left(\mathrm{CD} 8 R G S 1^{+}\right.$and $\left.\mathrm{CD} 8 P L C G 2^{+}\right)$single-cell datasets, we calculated Jaccard similarity co-efficient, $J=\left|P_{\mathrm{i}} \cap P_{\mathrm{j}}\right| / P_{\mathrm{i}} \cup P_{\mathrm{j}} \mid$. $P_{\mathrm{i}}$ and $P_{\mathrm{j}}$ denote genes from the populations. The degree of similarity was visualized as a heat map using yjr pheatmap R package (v.1.0.12) (https:// cran.r-project.org/web/packages/pheatmap/index.html).

\section{GSEA}

To execute GSEA, we downloaded the following gene sets for defined cells or settings in .gmt format from the molecular signature database (MsigDB) (http://software.broadinstitute.org/gsea/msigdb/index.jsp): (1) effector gene set (KAECH_NAIVE_VS_DAY8_EFF_CD8_TCELL_DN); (2) GPCR signalling pathway; (3) TCR signalling pathway; (4) $\mathrm{T}_{\mathrm{H}} 17$ gene set; (5) cell cycle; (6) GSE46025_WT_VS_FOXO1 ${ }^{-1 /}$ KLRG1_LOW_CD8 $_{-}$ EFFECTOR_TCELL up and down gene sets; and (7) apoptosis hallmark gene set. To convert human gene sets into mouse orthologues, we used a shell script (http://crazyhottommy.blogspot.com/2018/02/ convert-human-gmt-file-to-mouse-for-gsea.html) and compared these mouse genes with our RNA-seq dataset. Raw microarray data for the 
transcription factors BATF and TBX21 were from the Gene Expression Omnibus (GEO) database (accession identifiers GSE54215 (BATF knockout versus wild type (day 3)) and GSE122931 (TBX21 knockout versus wild type (H1 cells)) and identified differentially expressed genes using the Limma R package ${ }^{51}$. The following gene sets were retrieved from RNA-seq datasets: mouse genes related to acetate and butyrate were downloaded from ref. ${ }^{23}$ (GEO accession identifier GSE79600) and ref. ${ }^{26}$ (GEO accession identifier GSE132285), gene sets related to RUNX3 knockout and to HOBIT/BLIMP1 double-knockout from GEO (accession identifiers GSE81885 and GSE70813, respectively). The TOX-related gene set (differentially expressed genes in $\operatorname{Tox}^{-/-}$(knockout) versus wild-type P14 cells after 8 days of lymphocytic choriomeningitis virus clone 13 infection) was obtained from ref. ${ }^{13}$. Raw datasets were processed using GREIN DB ${ }^{52}$ and differentially expressed genes were determined using the DESeq2 R package ${ }^{41}$. The calcium-signalling-related gene set was downloaded from Mouse Genome Informatics database (http://www.informatics.jax.org/go/term/GO:0019722). The human liver tissue-resident memory cell gene signatures were procured from ref. ${ }^{33}$ and the IL-15-induced gene set was retrieved from ref. ${ }^{34}$; these were used for GSEA with single T cell datasets from livers of patients with NASH. GSEA of $\log _{2}$-transformed fold changes from differentially expressed genes (CXCR6 ${ }^{+}$mice fed a CD-HFD versus CXCR6 ${ }^{+}$mice fed a normal diet, and $\mathrm{CXCR}^{+}{ }^{+}$versus $\mathrm{CXCR}^{-}{ }^{-}$mice fed a CD-HFD) and from single-cell RNA-seq data from $\mathrm{CD}^{+}$populations of livers from NASH patients were performed using GSEA v.3.0 $\left(\right.$ ref. $^{53}$ ). Fold changes along gene sets were given as an input to the PreRanked tool from GSEA v3.0, which assessed the normalized enrichment score. The normalized enrichment score was considered significant based on an FDR $(q \leq 0.25)$.

\section{Statistics}

All values are shown as mean \pm s.e.m. Statistical analyses were performed with GraphPad Prism software v.9 using unpaired two-tailed Student's $t$-test, two-way ANOVA and one-way ANOVA analysis with Tukey's, Sidak's or Dunnett's post hoc test for multiple comparisons. $P<0.05$ was considered significant. No statistical methods were used to predetermine sample size.

\section{Reporting summary}

Further information on research design is available in the Nature Research Reporting Summary linked to this paper.

\section{Data availability}

All raw gene RNA-seq data from mice have been deposited in the GEO under accession number GSE145104. Single-cell RNA-seq data of fat tissue from patients with NASH can be found in the under accession number EGAS00001004738, and can be accessed at https://ega-archive. org/access/data-access upon request to the corresponding author. Single-cell RNA-seq data from livers of patients with steatosis or NASH can be found under accession number GSE159977. All datasets are available from the corresponding author upon request. Source data are provided with this paper.
35. Lampl, S. et al. Reduced mitochondrial resilience enables non-canonical induction of apoptosis after TNF receptor signaling in virus-infected hepatocytes. J. Hepatol. 73, 1347-1359 (2020).

36. Chen, H. et al. Cytofkit: a Bioconductor package for an integrated mass cytometry data analysis pipeline. PLoS Comput. Biol. 12, e1005112 (2016).

37. Mackay, L. K. et al. T-box transcription factors combine with the cytokines TGF- $\beta$ and IL-15 to control tissue-resident memory T cell fate. Immunity 43, 1101-1111 (2015).

38. Li, M. Z. \& Elledge, S. J. Harnessing homologous recombination in vitro to generate recombinant DNA via SLIC. Nat. Methods 4, 251-256 (2007).

39. Guillot, A. \& Tacke, F. The unexpected role of neutrophils for resolving liver inflammation by transmitting microRNA-223 to macrophages. Hepatology 71, 749-751 (2020).

40. Macosko, E. Z. et al. Highly parallel genome-wide expression profiling of individual cells using nanoliter droplets. Cell 161, 1202-1214 (2015).

41. Love, M. I., Huber, W. \& Anders, S. Moderated estimation of fold change and dispersion for RNA-seq data with DESeq2. Genome Biol. 15, 550 (2014).

42. Zhou, Q. et al. A mouse tissue transcription factor atlas. Nat. Commun. 8, 15089 (2017).

43. Dreos, R., Ambrosini, G., Groux, R., Cavin Périer, R. \& Bucher, P. The eukaryotic promoter database in its 30th year: focus on non-vertebrate organisms. Nucleic Acids Res. $\mathbf{4 5}$ D51-D55 (2017).

44. Khan, A. et al. JASPAR 2018: update of the open-access database of transcription factor binding profiles and its web framework. Nucleic Acids Res. 46, D260-D266 (2018).

45. Kulakovskiy, I. V. et al. HOCOMOCO: towards a complete collection of transcription factor binding models for human and mouse via large-scale ChIP-seq analysis. Nucleic Acids Res. 46, D252-D259 (2018).

46. Shannon, P. et al. Cytoscape: a software environment for integrated models of biomolecular interaction networks. Genome Res. 13, 2498-2504 (2003).

47. Gerstein, M. B. et al. Architecture of the human regulatory network derived from ENCODE data. Nature 489, 91-100 (2012).

48. Butler, A., Hoffman, P., Smibert, P., Papalexi, E. \& Satija, R. Integrating single-cell transcriptomic data across different conditions, technologies, and species. Nat. Biotechnol. 36, 411-420 (2018).

49. Stuart, T. et al. Comprehensive integration of single-cell data. Cell 177, 1888-1902 (2019).

50. Zappia, L. \& Oshlack, A. Clustering trees: a visualization for evaluating clusterings at multiple resolutions. Gigascience 7, (2018).

51. Ritchie, M. E. et al. limma powers differential expression analyses for RNA-sequencing and microarray studies. Nucleic Acids Res. 43, e47 (2015).

52. Mahi, N. A., Najafabadi, M. F., Pilarczyk, M., Kouril, M. \& Medvedovic, M. GREIN: an interactive web platform for re-analyzing GEO RNA-seq data. Sci. Rep. 9, 7580 (2019).

53. Subramanian, A. et al. Gene set enrichment analysis: a knowledge-based approach for interpreting genome-wide expression profiles. Proc. Natl Acad. Sci. USA 102, 15545-15550 (2005)

Acknowledgements We thank S. Yousuf and M. Qui for technical support in preparing samples for single-cell RNA-seq analysis; P. Sinn for technical support; the personnel (particularly J. Maurer) of the Core Facility Flow Cytometry at Biomedical Center Munich (LMU), for providing the imaging cytometry instrument and analysis software; and the personnel of the Core Facility Cell Sorting of the German Cancer Research Center Heidelberg. This work was supported by the DFG, project number 424926990 , to J.P.B., CIBSS EXC-2189 project identifier 390939984 to E.J.P., SFB TRR179 and DZIF Munich site to P.A.K.

Author contributions M.D. and P.A.K. designed the study. M.D., D.P., P.F., A.S., M.L., P.M., F.B., D.I., J.W., S.H., M.A., A.G., A.B., D. Heide, F.M. and S. Reider performed experiments. S.D., R.Ö. and A.M.K. undertook bioinformatics analysis. D. Hartmann, N.H., M.S., C.G.-C., T.G., G.S., J.-P.M., M.E., S. Roth, A.T.B., B.M.-S., F.K.-N., R.K., T.B., P.R., V.L., J.-F.D. and M.H. provided tissue samples, essential reagents or mice. R.R., E.J.P., H.T., F.T., J.-F.D., D. Haller, P.J.M., R.H., R.T., D.Z., J.P.B., M.H. and P.A.K. contributed scientific input. M.D. and P.A.K. wrote the manuscript, and all authors contributed to feedback and proofreading.

Competing interests The authors declare no competing interests.

\section{Additional information}

Supplementary information The online version contains supplementary material available at https://doi.org/10.1038/s41586-021-03233-8.

Correspondence and requests for materials should be addressed to P.A.K.

Peer review information Nature thanks Paul Klenerman, Ignacio Melero, Daniel Peeper and the other, anonymous, reviewer(s) for their contribution to the peer review of this work. Peer reviewer reports are available.

Reprints and permissions information is available at http://www.nature.com/reprints. 


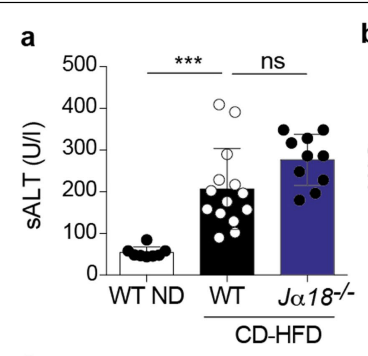

e

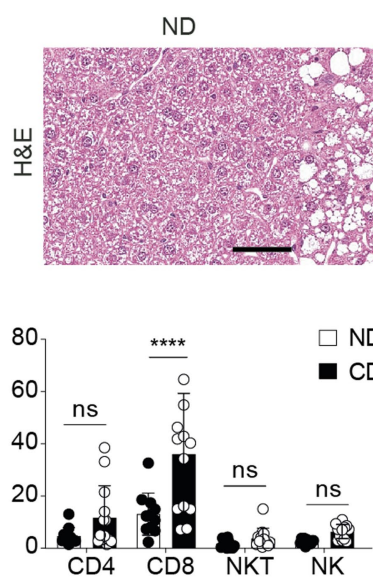

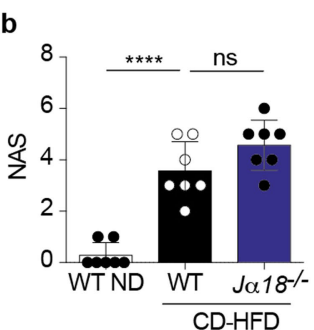

CD-HFD

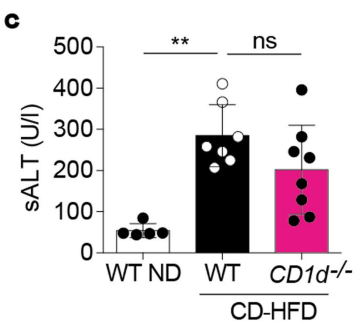

$J_{\alpha 18^{-}}$CD-HFD

CD $1 d^{-\%}$ CD-HFD
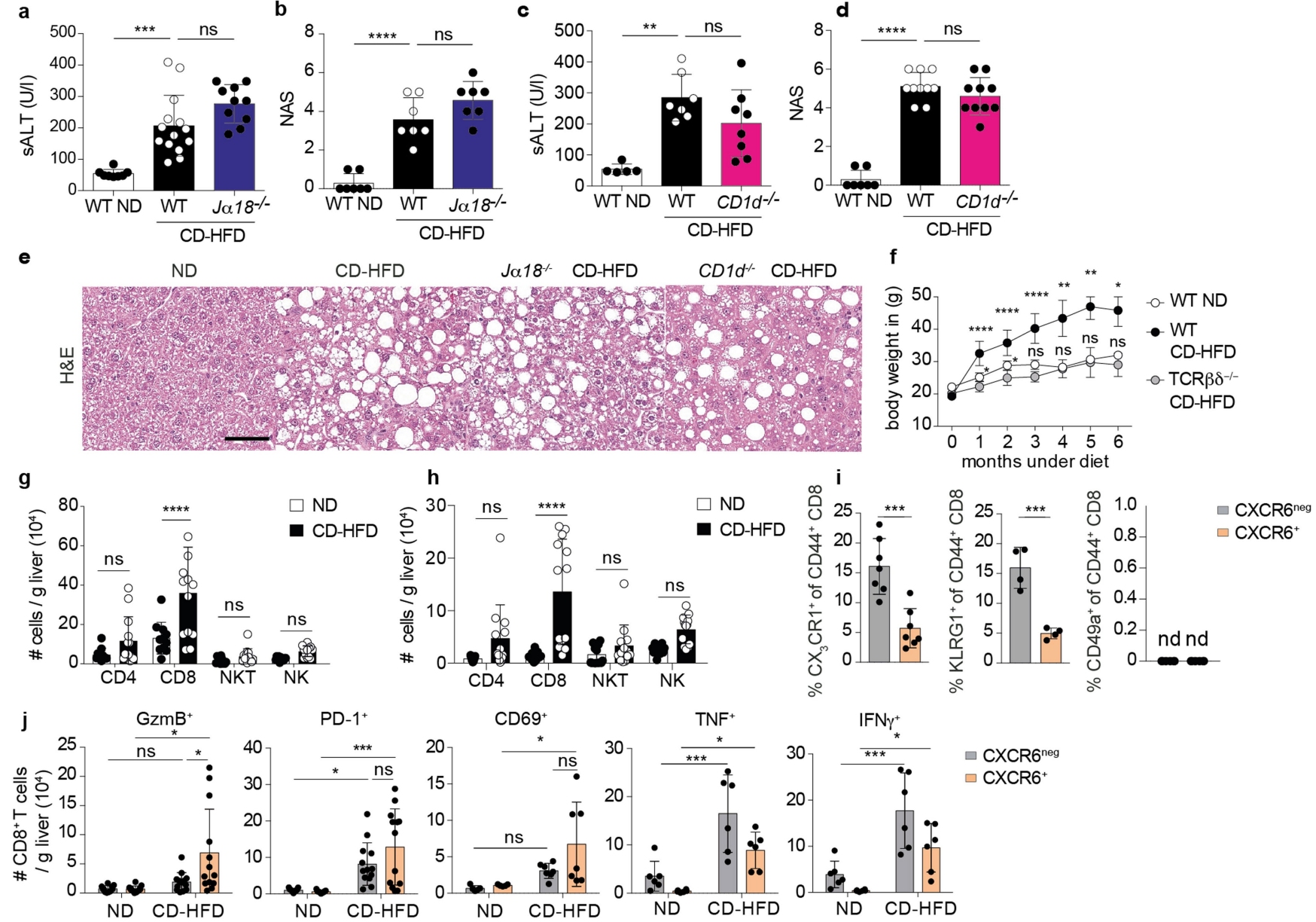

PD-1+
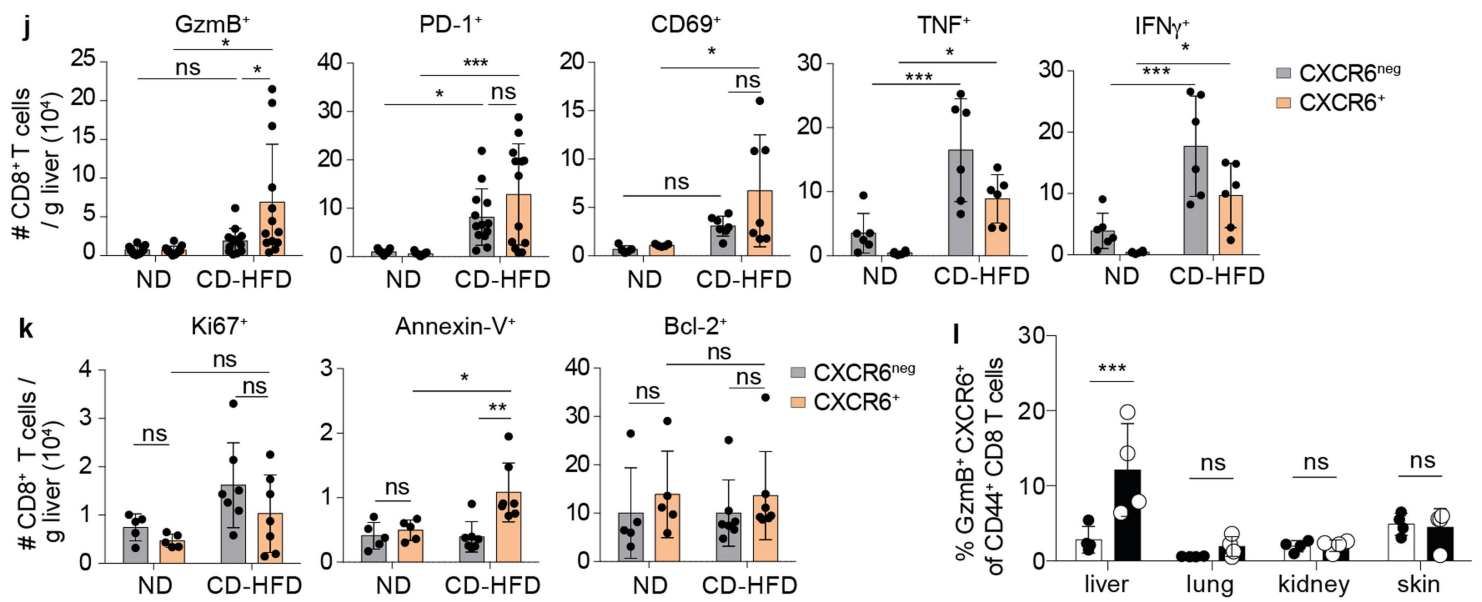

m
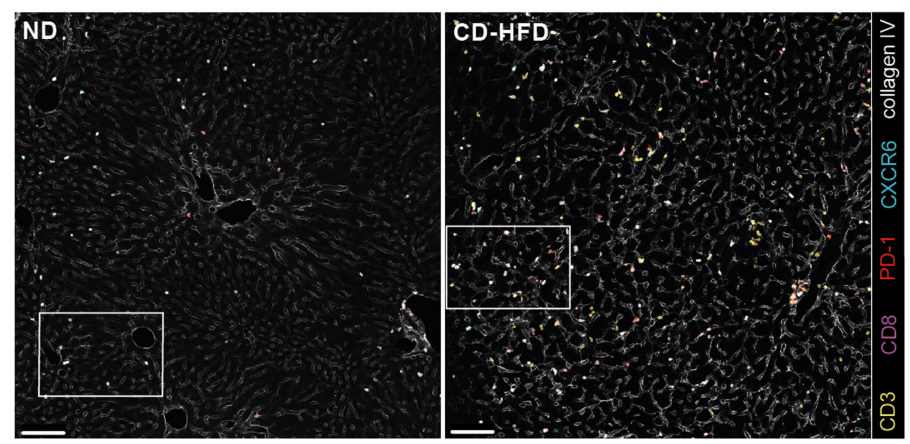

$\square$ ND

CD-HFD
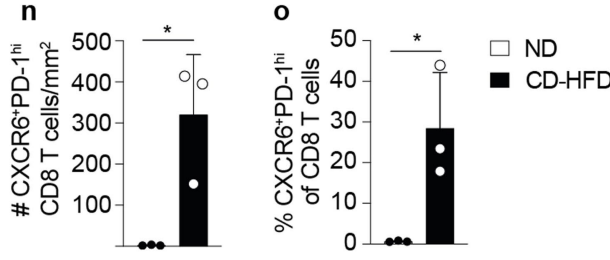

Extended Data Fig. 1 | See next page for caption. 
Extended Data Fig. $1 \mid$ Immune-cell characteristics in livers of mice fed a CD-HFD. a-e, Liver damage after 12 months of feeding a CD-HFD (which induces features of NASH) in $\mathrm{Ca}^{-/} 8^{-/}$and $\mathrm{Cd} 1 \mathrm{~d}^{-/}$mice, determined by sALT and NAS with representative images of H\&E staining (mice fed a normal diet, $n=8$; CD-HFD-fed, wild-type mice, $n \geq 7$; CD-HFD-fed, Ja18 ${ }^{-/}$mice, $n \geq 7$; CD-HFD-fed, Cd1 $^{-1 /}$ mice: $n \geq 8$ ). Scale bar, $100 \mu \mathrm{m}$. Two independent experiments.f, Body weight of mice over the course of six months. $\mathbf{g}$, h, Numbers of hepatic lymphocytes $(\mathbf{g})$ and hepatic $\mathrm{CXCR} \mathbf{6}^{+} \mathrm{T}$ cell populations $(\mathbf{h})$ in mice fed a normal diet $(n=11)$ or CD-HFD $(n=13)$. Two independent experiments. i-k, Numbers and phenotype of hepatic CD $44^{+} \mathrm{CXCR}^{+}$and CXCR6 ${ }^{-} \mathrm{CD} 8 \mathrm{~T}$ cells in NASH mice $(n \geq 5)$. Two independent experiments. I, Frequencies of $\mathrm{CXCR6}^{+} \mathrm{GzmB}^{+} \mathrm{CD} 8 \mathrm{~T}$ cells in different organs in mice fed a normal diet $(n=4)$ and NASH mice $(n=4)$. $\mathbf{m}-\mathbf{o}$, Localization and quantification of hepatic $\mathrm{CXCR}^{+}{ }^{+}$PD $1^{\text {high }}$ CD8 T cells in mice fed a normal diet $(n=3)$ and NASH mice $(n=3)$, by confocal microscopy with representative images. Scale bar, $200 \mu \mathrm{m}$. CD3 (yellow), CD8 (purple), CXCR6 (cyan), PD1 (red) and collagen IV (white). Rectangles highlighted in $\mathbf{m}$ indicate representative zoomed areas shown in Fig.1g. ns, not significant; nd, not determined. Exact $P(\mathbf{a}-\mathbf{d}, \mathbf{f}-\mathbf{I}, \mathbf{n}, \mathbf{o})$ and $n$ $(\mathbf{a}-\mathbf{d}, \mathbf{f}, \mathbf{i}-\mathbf{k})$ values are presented in Source Data. ${ }^{*} P<0.05,{ }^{* *} P<0.01$, ${ }^{* * *} P<0.001,{ }^{* * * *} P<0.0001$. Two-way ANOVA with Sidak's (g, h, l) or with Tukey's multiple comparison test ( $\mathbf{j}, \mathbf{k})$, one-way ANOVA with Tukey's $(\mathbf{a}-\mathbf{d})$ or with

Dunnett's multiple comparison test (f) and unpaired two-tailed $t$-test $(\mathbf{i}, \mathbf{n}, \mathbf{o})$. In $\mathbf{a}-\mathbf{d}, \mathbf{f}-\mathbf{I}, \mathbf{n}, \mathbf{o}$, data are mean \pm s.e.m., error is reported as s.d. 

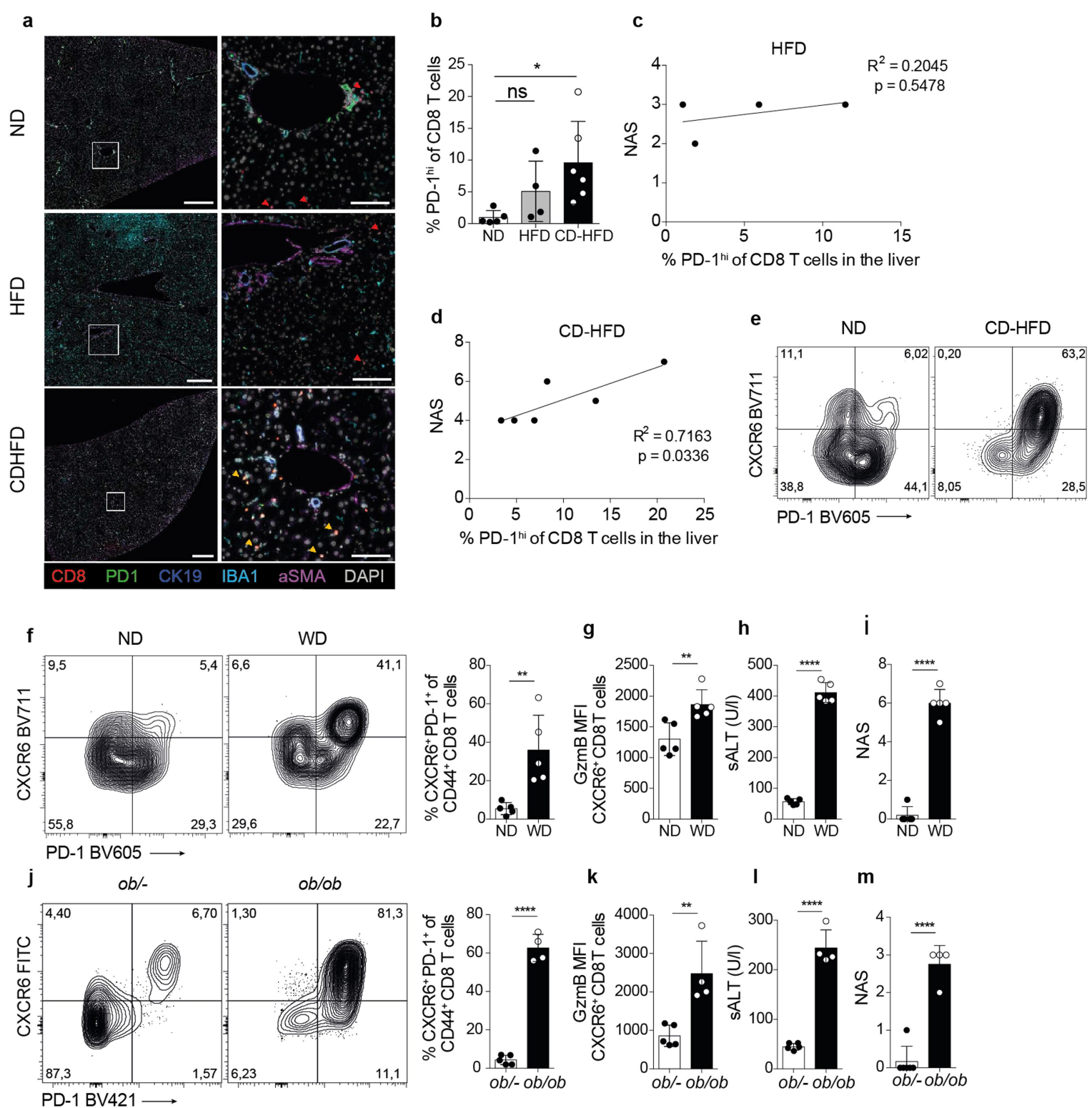

Extended Data Fig. 2 | Increased numbers of hepatic CXCR6 ${ }^{+}$PD1 ${ }^{\text {high }}$ CD8 T cells in different mouse models of obesity-related NASH. a, b, Confocal microscopy of hepatic PD $1^{\text {high }}$ CD8 T cells and IMARIS-based quantification with representative images (normal diet, $n=5$; high-fat diet (HFD), $n=4$; CD-HFD, $n=6$ ). Scale bars, $500 \mu \mathrm{m}$ (left), $100 \mu \mathrm{m}$ (right). CD8 (red), PD1 (green), CK19 (blue), IBA1 (cyan), $\alpha$ SMA (purple) and DAPI (white). Rectangles highlighted in the left panel indicate represent zoomed areas in the right panel. Red arrows indicate $P D 1^{-}$CD8 T cells. Yellow arrows indicate $P D 1^{\text {high }} C D 8 T$ cells. One-way ANOVA with Dunnett's multiple comparison test. c, d, Correlation of liver damage (NAS) with frequencies of hepatic PD ${ }^{\text {high }} \mathrm{CD} 8 \mathrm{~T}$ cells from mice fed a normal diet or CD-HFD. Coefficient of determination $\left(R^{2}\right)$ and statistical significance ( $P$ value) were determined using Pearson's correlation. e, f, CXCR6 and PD1 expression levels in hepatic CD8 T cells in mice fed CD-HFD (e) or a high trans-fat Western diet (WD) (f) $(n=5)$ for 12 months compared to mice fed a normal diet $(n=5)$. h, i, Liver damage (sALT and NAS) in mice from $\mathbf{f . j}, \mathbf{k}$, CXCR6 and PD1 expression levels in hepatic CD8 T cells in $o b /-$ and $o b / o b$ mice after 4 months of chow feeding or mice fed a normal diet $(o b /-, n=6 ; o b / o b, n=4)$. $\mathbf{I}, \mathbf{m}$, Liver damage (sALT and NAS) in mice from $\mathbf{j}$. Exact $P$ values $(\mathbf{b}, \mathbf{f}-\mathbf{m})$ are presented in Source Data. ${ }^{*} P<0.05,{ }^{* *} P<0.01,{ }^{* * * *} P<0.0001$. Unpaired two-tailed $t$-test $(\mathbf{f}-\mathbf{m})$. In $\mathbf{b}, \mathbf{f}-\mathbf{m}$, data are mean \pm s.e.m., errors are shown as s.d. 

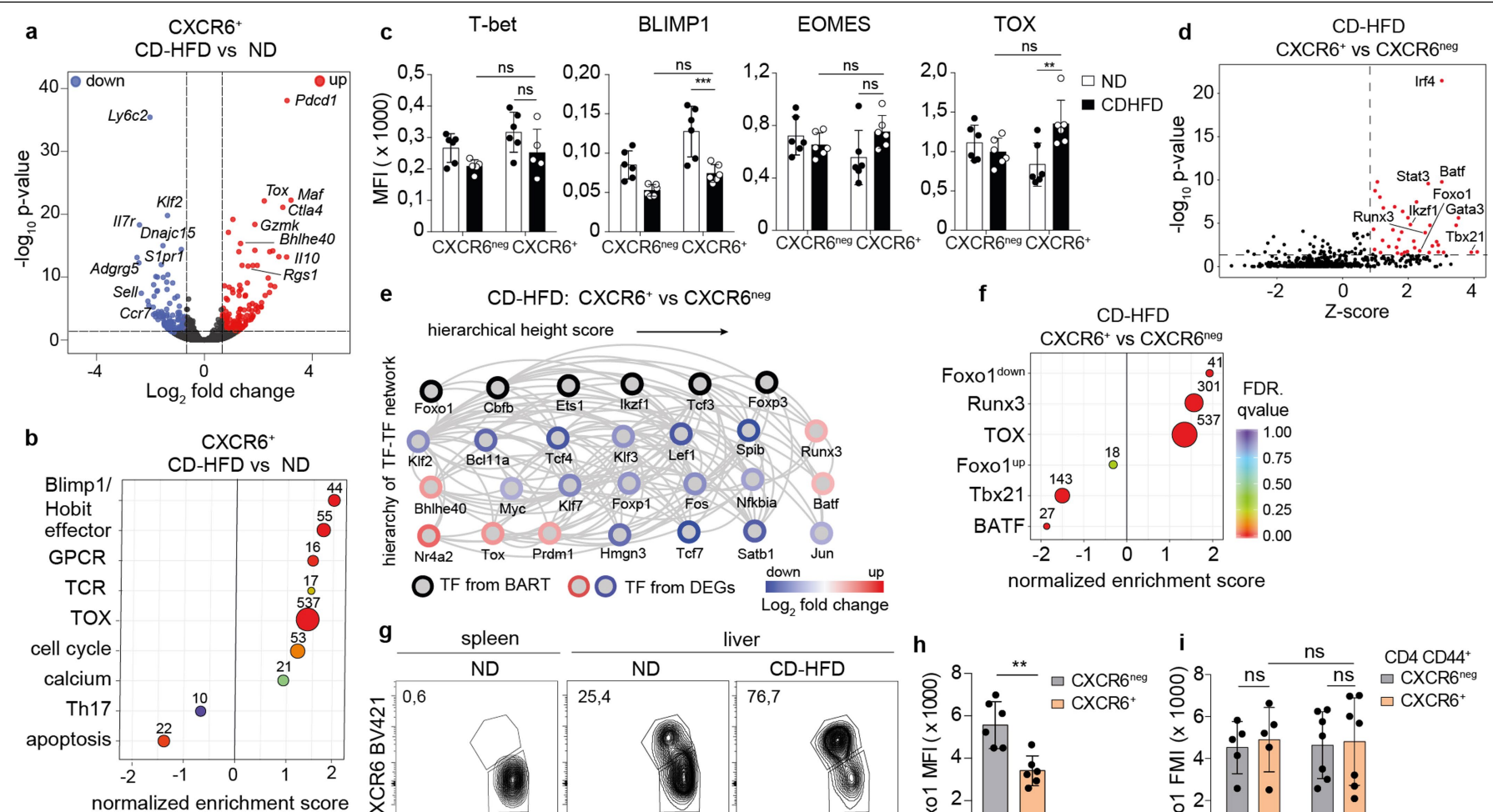

g spleen $\longrightarrow$ liver $\mathbf{h}$
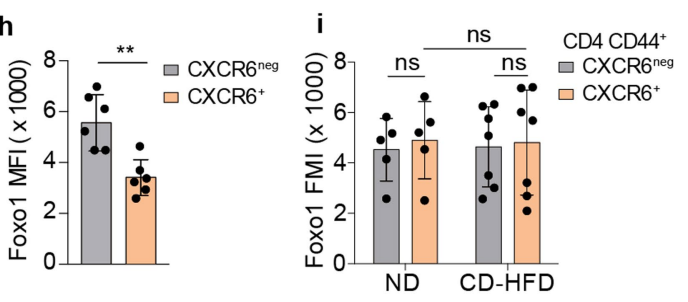

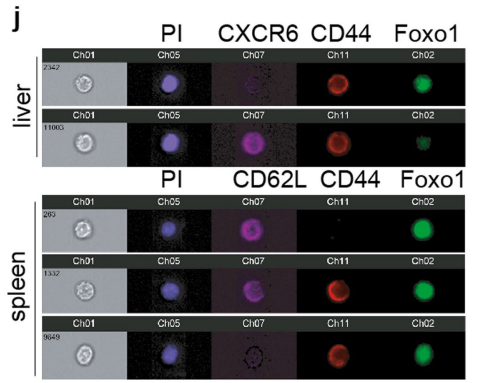

Foxo1 AF647 $\longrightarrow$

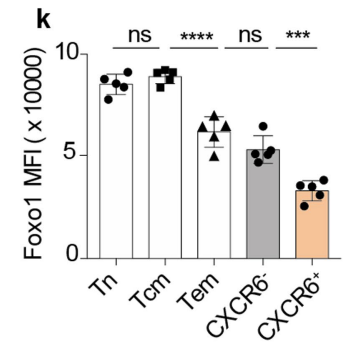

Extended Data Fig. 3 | Transcriptome analysis of hepatic CXCR6 ${ }^{+}$CD8 $\mathrm{T}$ cells from NASH mice. a, Volcano plot showing differentially expressed genes between $\mathrm{CXCR}^{+} \mathrm{CD} 8 \mathrm{~T}$ cells from NASH mice (fed a CD-HFD) compared to healthy mice (fed a normal diet). b, GSEA for distinct pathways from a.c, Flow cytometry analysis of protein levels of transcription factors in hepatic $\mathrm{CXCR6}^{+}$ and CXCR6 ${ }^{-}$CD8 T cells from healthy and NASH mice $(n \geq 5)$.d, Binding analysis for regulation of transcription (BART) to predict transcription-factor activity in hepatic $\mathrm{CXCR6}^{+}$compared to CXCR6 ${ }^{-} \mathrm{CD} 8 \mathrm{~T}$ cells in NASH mice.

e, Transcription-factor network analysis created from differentially expressed genes (a) and BART.f, GSEA for transcription-factor-dependent genes from a. g-i, Flow cytometry analysis of FOXO1 expression in hepatic CXCR6 ${ }^{+}$and
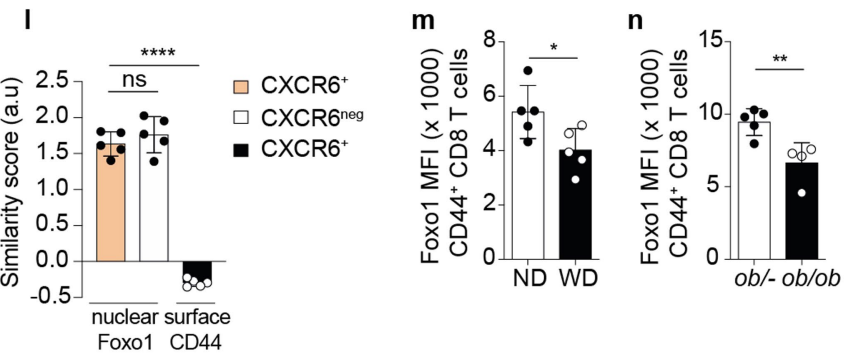

CXCR6 ${ }^{-}$CD8 T cells $(\mathbf{g}, \mathbf{h})$ or CD4 T cells (i) from mice fed a normal diet and NASH mice $(n \geq 6)$. $\mathbf{j}, \mathbf{k}$, Image-stream analysis of expression and localization of FOXO1 in different $\mathrm{T}$ cell populations from spleen and liver of wild-type mice with representative images. Tn, naive T cells; $\mathrm{Tcm}$, central memory T cells; $T e m$, effector memory T cells. I, Similarity score to determine nuclear localization of FOXO1 and surface localization of CD44 $(n=5) . \mathbf{m}, \mathbf{n}$, FOXO1 expression in hepatic $\mathrm{CD} 44^{+} \mathrm{CD} 8 \mathrm{~T}$ cells in mice fed a Western $\operatorname{diet}(n=5)$ and $o b /-$ or $o b / o b$ mice $(n \geq 4)$. PI, propidium iodide. Exact $P$ and $n$ values $(\mathbf{c}, \mathbf{g}$-i) are presented in Source Data. ${ }^{*} P<0.05,{ }^{* *} P<0.01,{ }^{* * * *} P<0.0001$. One-way ANOVA $(\mathbf{k}, \mathbf{l})$, two-way ANOVA with Tukey's multiple comparison test $(\mathbf{c}, \mathbf{i})$ and unpaired two-tailed $t$-test $(\mathbf{h}, \mathbf{m}, \mathbf{n})$. In $\mathbf{c}, \mathbf{h}, \mathbf{i}, \mathbf{k}-\mathbf{n}$, data are mean \pm s.e.m., errors are shown as s.d. 


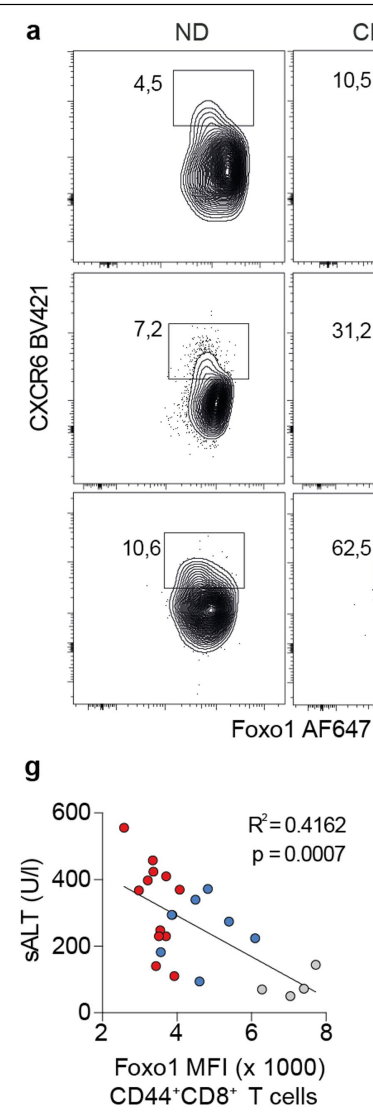

I

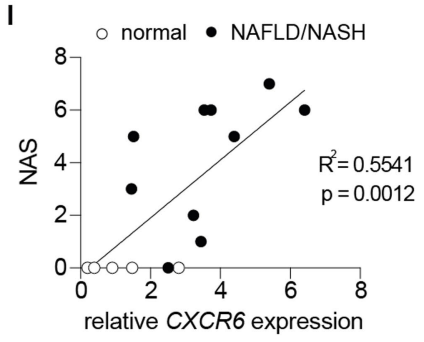

Extended Data Fig. 4 | Hepatic CXCR6 ${ }^{+}$FOXO1 $^{\text {low }}$ CD8 T cell frequency correlates with liver damage in NASH mice and patients with NASH. a-c, Hepatic CXCR6 ${ }^{+}$FOXO1 ${ }^{\text {low }}$ CD8 T cells at 6,9 and 12 months of feeding a CD-HFD, and correlation of FOXO1 expression levels in hepatic CD44 ${ }^{+} \mathrm{CD} 8$ $\mathrm{T}$ cells with frequency of hepatic $\mathrm{CXCR} 6^{+} \mathrm{PD} 1^{\text {high }}$ of CD $44^{+} \mathrm{CD} 8 \mathrm{~T}$ cells from mice fed a CD-HFD, and with NAS. Four independent experiments. d, e, CXCR6 and $\mathrm{CX}_{3} \mathrm{CR} 1$ expression levels in sorted hepatic $\mathrm{CD} 44^{+}{ }^{+}{ } \mathrm{CCR}^{-} \mathrm{CD} 8 \mathrm{~T}$ cells from healthy mice fed a normal diet $(n=5)$ after $18 \mathrm{~h}$ of treatment with the FOXO1 inhibitor AS1842856.f, CXCR6 expression levels after FOXO1 overexpression (transduction with pMP71-Foxo1-eGFP or pMP71-eGFP) in sorted CXCR6 ${ }^{+}$CD8 T cells $(n=3) . \mathbf{g}, \mathbf{h}$, Correlation of sALT and NAS with FOXO1 expression in hepatic $\mathrm{CD} 44^{+} \mathrm{CD} 8 \mathrm{~T}$ cells from $\mathbf{b}$. $\mathbf{i}$, Correlation of FOXO1 expression in liver CD69 ${ }^{+}$CD8 T cells with sALT in patients with NASH $(n=15$ in total: $n=12 \mathrm{NASH}$;

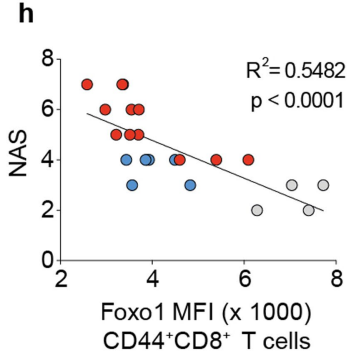

m
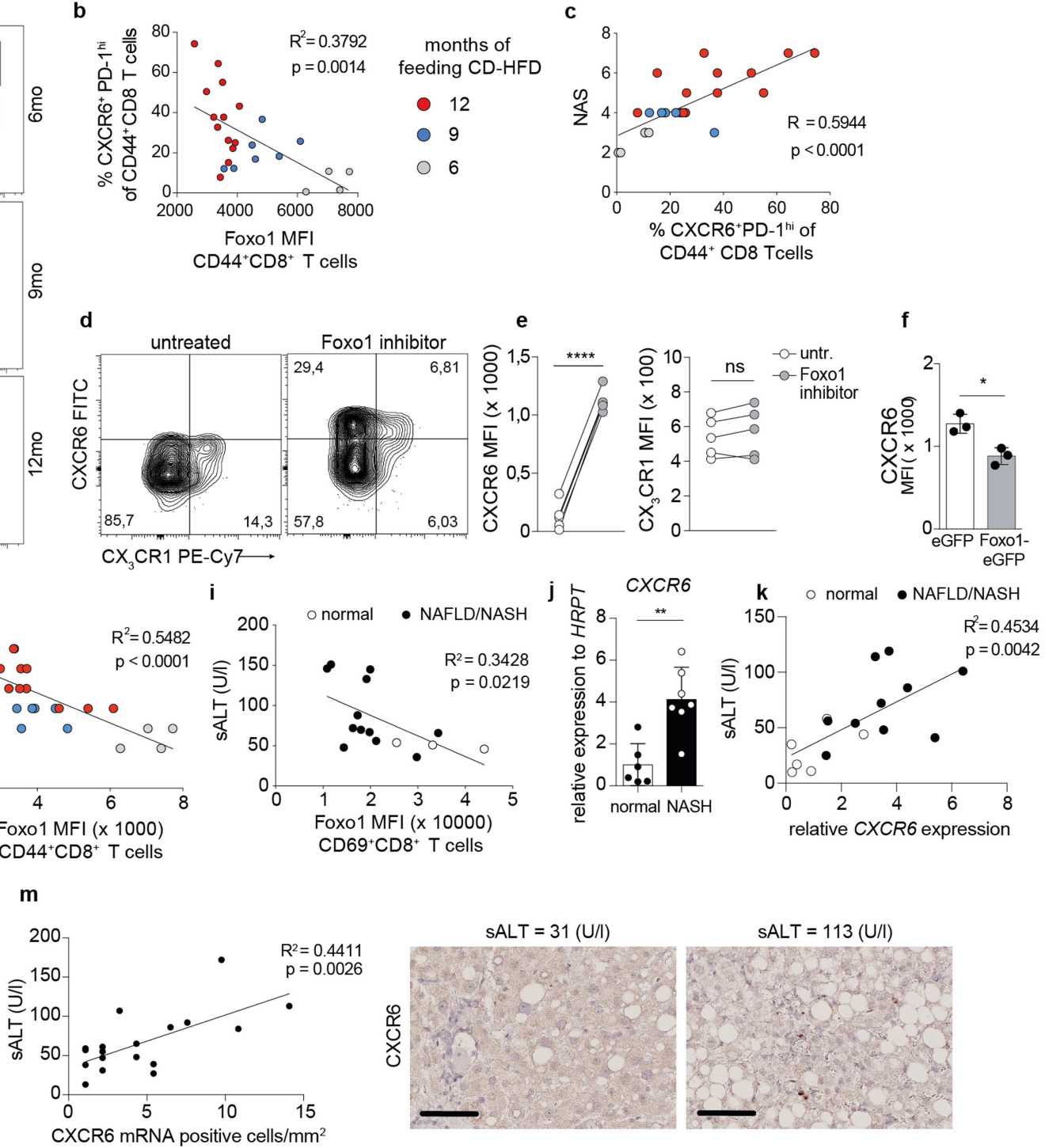

$n=3$ normal liver tissue (NAS $=0)$ ). j, $C X C R 6$ expression quantified by qPCR with reverse transcription (RT-qPCR) in liver tissue of patients with NASH $(N A S \geq 5$ ) (unaffected tissue, $n=6$; tissue from patients with NASH, $n=7$ ). $\mathbf{k}, \mathbf{l}$, Correlation of relative $C X C R 6$ expression with sALT and NAS in patients with NASH (unaffected individuals, $n=6$; patients with NASH, $n=10$ ). $\mathbf{m}$, Correlation of sALT with numbers of cells that are positive for $C X C R 6$ per $\mathrm{mm}^{2}$ of liver tissue in patients with NASH $(n=18)$. Scale bar, $100 \mu \mathrm{m}$. Representative image of in situ hybridization for $C X C R 6 \mathrm{mRNA}$ in liver of patients with low or high sALT. Exact $P$ $(\mathbf{e}, \mathbf{f}, \mathbf{j})$ and $n(\mathbf{b}, \mathbf{c}, \mathbf{g}, \mathbf{h})$ values are presented in Source Data. ${ }^{*} P<0.05,{ }^{* *} P<0.01$, ${ }^{* * * *} P<0.0001$. Coefficient of determination $\left(R^{2}\right)$ and statistical significance $(P$ value) were determined using Pearson's correlation $(\mathbf{b}, \mathbf{c}, \mathbf{g}-\mathbf{i}, \mathbf{k}-\mathbf{m})$. Unpaired two-tailed $(\mathbf{f}, \mathbf{j})$ and paired two-tailed $t$-test $(\mathbf{e})$. In $\mathbf{e}, \mathbf{f}, \mathbf{j}$, data are mean \pm s.e.m., error is reported as s.d. 


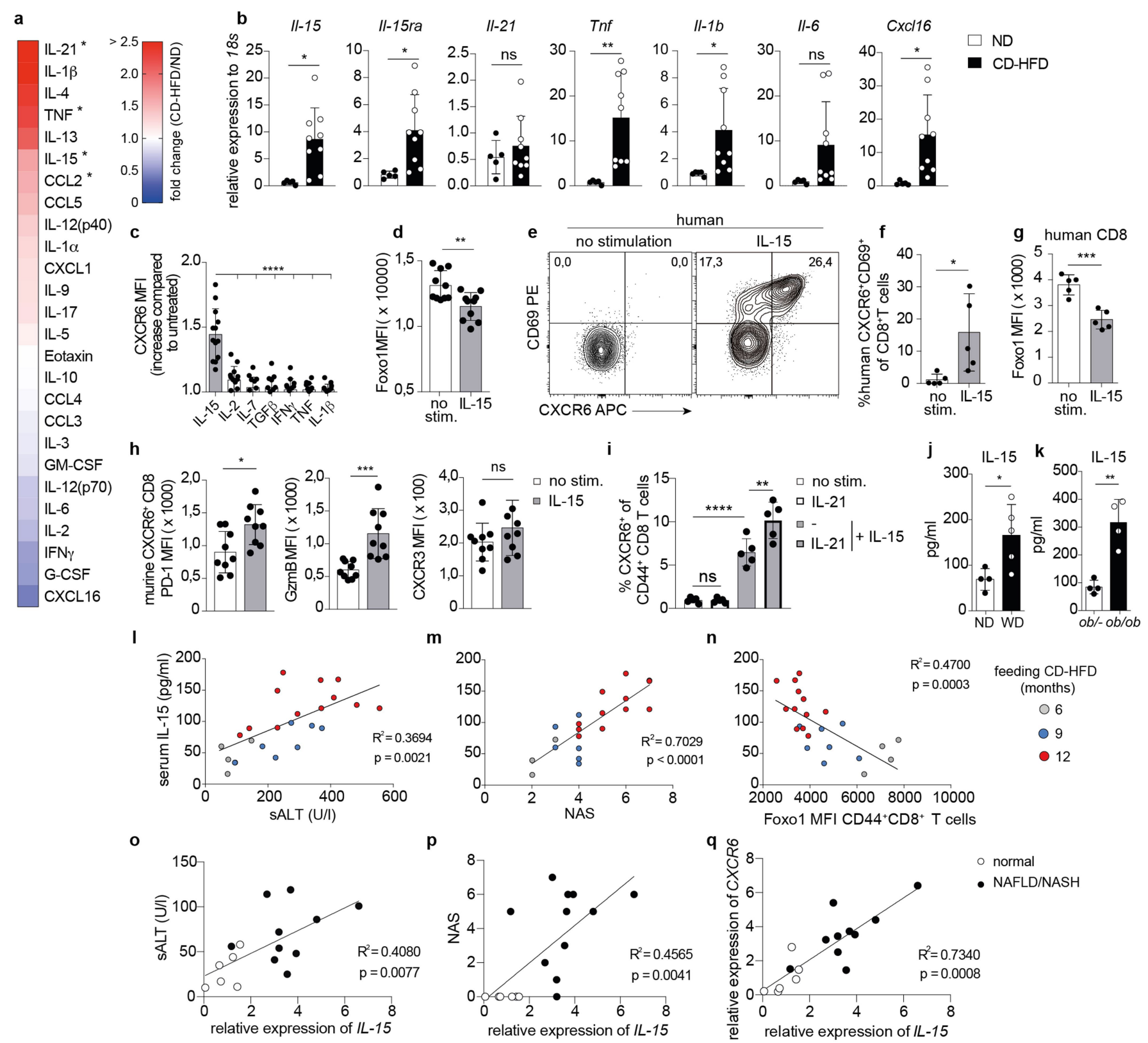

Extended Data Fig. 5 | Increased levels of IL-15 in serum and liver tissue of NASH mice correlate with liver damage and numbers of hepatic CXCR6 ${ }^{+}$ CD8 T cells. a, Heat map of fold changes for cytokine and chemokine serum concentrations in NASH (fed a CD-HFD) $(n \geq 8)$ compared to healthy (fed a normal diet) mice ( $n \geq 6)$ after 12 months of feeding. Values above 2.5 are red. Asterisk denotes values that are significantly different. Exact $P$ and $n$ values are presented in Source Data. Two independent experiments. b, Cytokine and chemokine expression quantified by RT-qPCR in the liver tissue of mice fed a normal diet $(n=5)$ and NASH mice $(n=9)$. c, Flow cytometry analysis of the increase in CXCR6 expression after incubation of sorted hepatic CD44 ${ }^{+} \mathrm{CXCR6}$ CD8 T cells with cytokines for $24 \mathrm{~h}(n=13)$. d, Flow cytometry analysis of FOXO1 expression $24 \mathrm{~h}$ after IL-15 stimulation of hepatic CD44 ${ }^{+} \mathrm{CD} 8 \mathrm{~T}$ cells $(n=10)$. e-g, Flow cytometry analysis of FOXO1 expression in human CD8 T cells at $5 \mathrm{~d}$ after IL-15 stimulation $\left(15 \mathrm{ng} \mathrm{ml}^{-1}\right)$ and frequencies of CXCR6 ${ }^{+} \mathrm{CD} 69^{+}$cells $(n=5)$. h, PD1, GzmB and CXCR3 expression by mouse hepatic CXCR $6^{+}$CD8 T cells $24 \mathrm{~h}$ after IL-15 stimulation ( $n=9)$. i, Percentage of CXCR6-expressing CD8 T cells in sorted, splenic $\mathrm{CD} 44^{+} \mathrm{CD} 8 \mathrm{~T}$ cells $2 \mathrm{~d}$ after stimulation with IL-15 $\left(10 \mathrm{ng} \mathrm{ml}^{-1}\right)$ and/or IL-21 $\left(10 \mathrm{ng} \mathrm{ml}^{-1}\right)(n=5)$. Two independent experiments. j, $\mathbf{k}$, IL-15 serum concentrations in $o b /-(n=4)$ and hyperphagic, leptin-deficient $o b / o b$ mice $(n=4)$ fed a chow diet for 4 months, in mice fed a normal diet $(n=4)$ or a high trans-fat Western diet for 12 months $(n=5)$. $1-\mathbf{n}$, Correlation of IL-15 serum levels with sALT, NAS and FOXO1 expression in hepatic CD44 ${ }^{+} \mathrm{CD} 8 \mathrm{~T}$ cells of NASH mice ( 6 months, $n=4 ; 9$ months, $n=7 ; 12$ months, $n=13$ ). Four independent experiments. $\mathbf{0}-\mathbf{q}$, Correlation of relative hepatic $I L-15$ gene expression levels with sALT, NAS and CXCR6gene expression in patients with NASH and in individuals with normal liver (normal, $n=6$; NASH, $n=10$ ). Exact $P(\mathbf{a}-\mathbf{d}, \mathbf{f}-\mathbf{k})$ and $n(\mathbf{a})$ values are presented in Source Data. ${ }^{*} P<0.05,{ }^{* *} P<0.01$, ${ }^{* * *} P<0.001,{ }^{* * * *} P<0.0001$. Coefficient of determination $\left(R^{2}\right)$ and statistical significance ( $P$ value) was determined using Pearson`s correlation (I-q). One-way ANOVA with Tukey's (i) or Dunnett's multiple comparison test (c), and unpaired two-tailed $t$-test $(\mathbf{a}, \mathbf{b}, \mathbf{d}, \mathbf{f}-\mathbf{h}, \mathbf{j}, \mathbf{k})$. In $\mathbf{a}-\mathbf{d}, \mathbf{f}-\mathbf{k}$, data are mean \pm s.e.m., error is reported as s.d. 

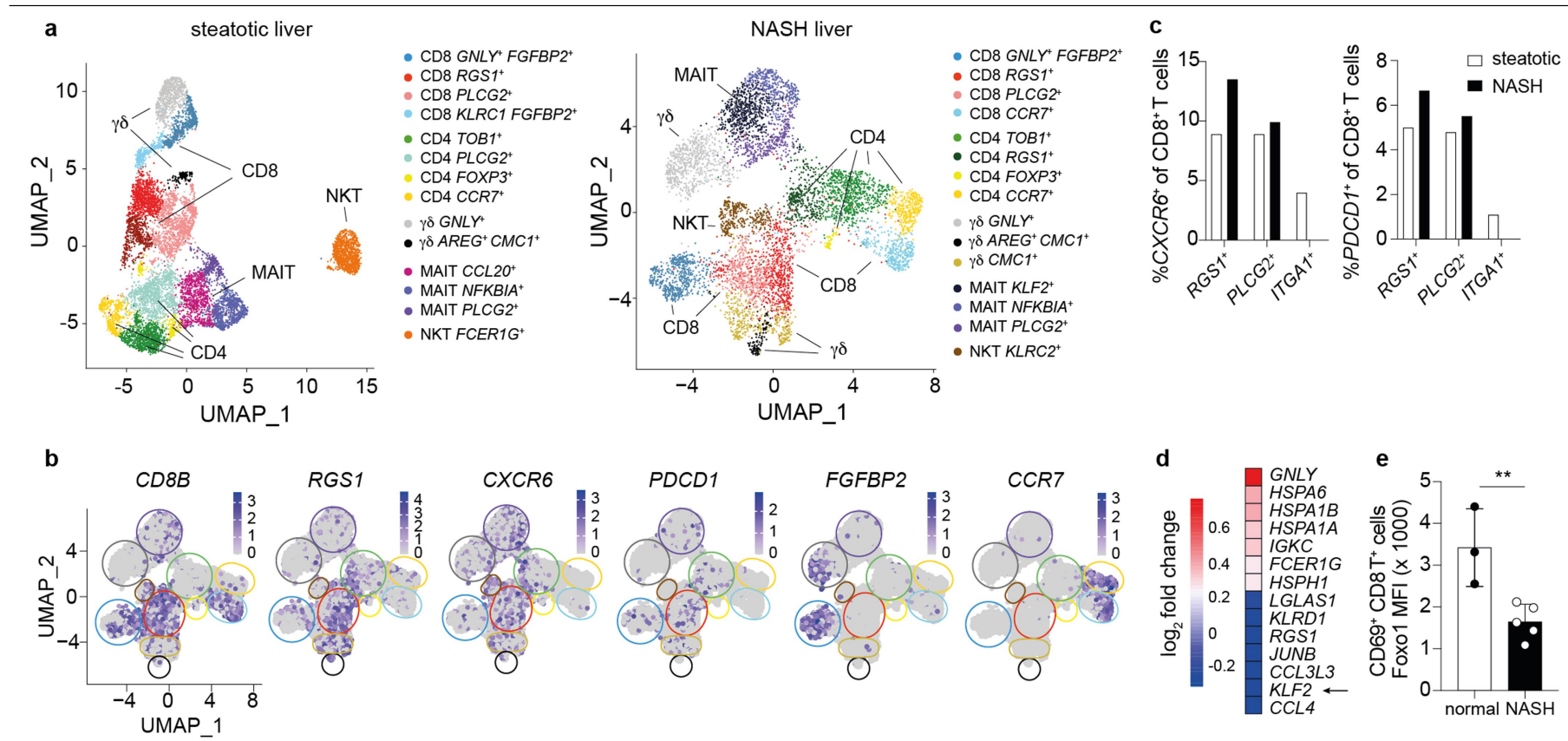

f

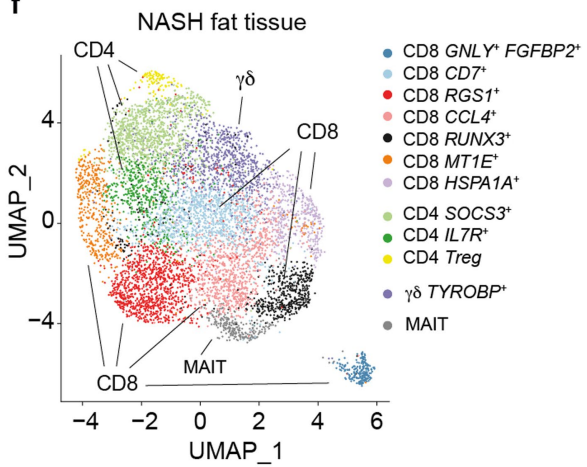

g

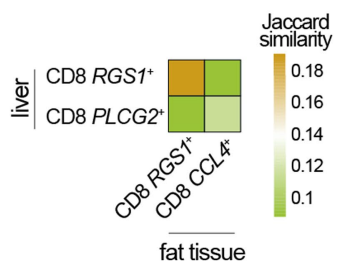

h

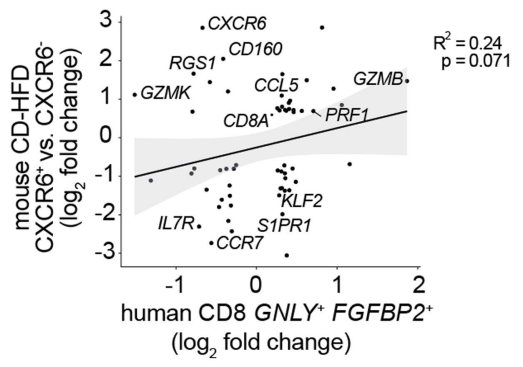

Extended Data Fig. 6 | Single-cell RNA-seq of $\mathrm{CD}^{+}{ }^{+} \mathrm{T}$ cells from livers of patients with steatosis or NASH. a, UMAP plot visualization of hepatic $\mathrm{CD}^{+}$ T cell clusters detected in livers from patients with steatosis $(n=4)$ or NASH $(\mathrm{NAS} \geq 5)(n=3)$. $\mathbf{b}, \mathrm{UMAP}$ plot visualization of hepatic $\mathrm{CD} 3^{+} \mathrm{T}$ cell clusters and of selected genes detected in patients with NASH (NAS $\geq 5)(n=3)$. c, Frequencies of $C X C R 6^{+}$and $P D C D 1^{+}$cells in CD8 T cells in the $R G S 1^{+}, P L C G 2^{+}$and $I T G A 1^{+}$cluster in livers from patients with steatosis or NASH. d, Differentially expressed genes in the $C D 8 R G S 1^{+}$cluster between livers of patients with steatosis or NASH. e, Flow cytometry analysis of FOXO1 expression in $\mathrm{CD} 69^{+} \mathrm{CD} 8 \mathrm{~T}$ cells from livers of unaffected individuals $(n=3)$ and livers of patients with NASH $(n=5)$.
$P=0.0088$, two-tailed $t$-test, data are mean \pm s.e.m.f, UMAP plot visualization of hepatic $\mathrm{CD}^{+} \mathrm{T}$ cell clusters detected in patients with NASH from fat tissue $(n=2)$.g,Jaccard similarity score between tissue-resident CD8 T cell populations in fat and liver of patients with NASH $(n=2)$. h, Correlation of mouse RNA-seq dataset from $\mathrm{CXCR}^{+}$compared to $\mathrm{CXCR6}^{-} \mathrm{CD} 8 \mathrm{~T}$ cells in mice fed a CD-HFD with human single-cell RNA-seq dataset from the CD8 $G N L Y^{+} F G F B P 2^{+}$cluster. The solid line is the linear regression, and the grey area shows the $95 \%$ confidence intervals. Coefficient of determination $\left(R^{2}\right)$ and statistical significance ( $P$ value) were determined using Spearman's correlation. 


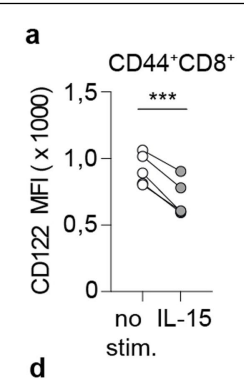

b
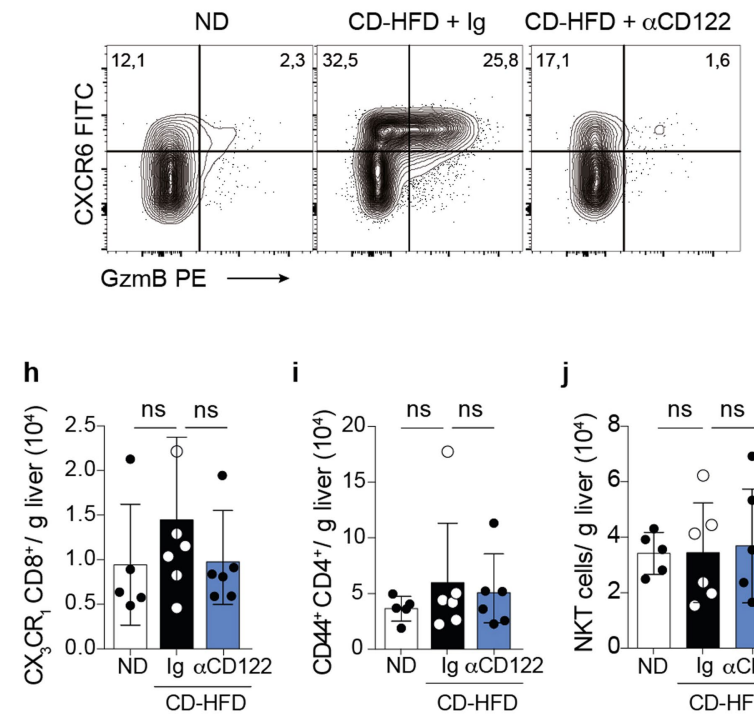

i

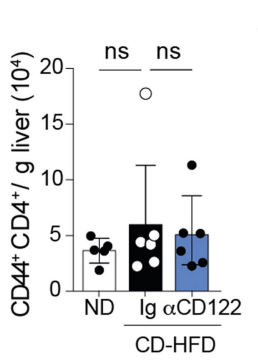

j

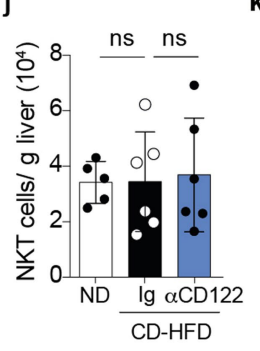

Extended Data Fig. 7 |Anti-CD122 application in NASH mice leads to depletion of $\mathrm{CXCR6}{ }^{+} \mathrm{GzmB}^{+} \mathrm{CD8} \mathrm{T}$ cells and amelioration of liver damage. a, CD122 expression on splenic CD44 ${ }^{+}$CD8 T cells after stimulation with IL-15 $\left(10 \mathrm{ng} \mathrm{ml}^{-1}\right)$ for $24 \mathrm{~h}(n=5) . \mathbf{b}, \mathrm{CD} 122$ expression on hepatic CXCR6 ${ }^{+}$CD8 T cells $(n=8)$. Two independent experiments. $\mathbf{c}-\mathbf{e}$, Frequencies and cell numbers of $\mathrm{CXCR6}^{+} \mathrm{PD}^{+}$and $\mathrm{CXCR6}^{+} \mathrm{GzmB}^{+} \mathrm{CD} 8 \mathrm{~T}$ cells after anti-CD122-treatment for 2 weeks in NASH mice (fed CD-HFD for 12 months) (CD-HFD + immunoglobulin (Ig), $n=6$; CD-HFD + anti-CD122, $n=6$ ). f, sALT in NASH mice from e before and after anti-CD122 treatment for 2 weeks. Unpaired two-tailed $t$-test of sALT
C

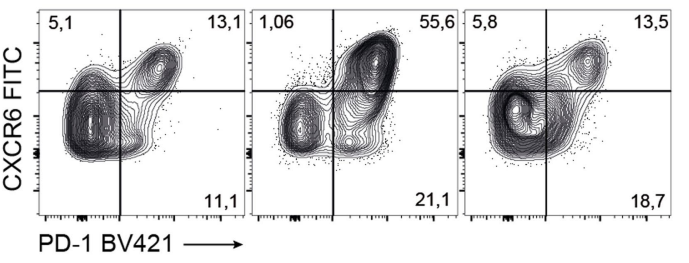

e
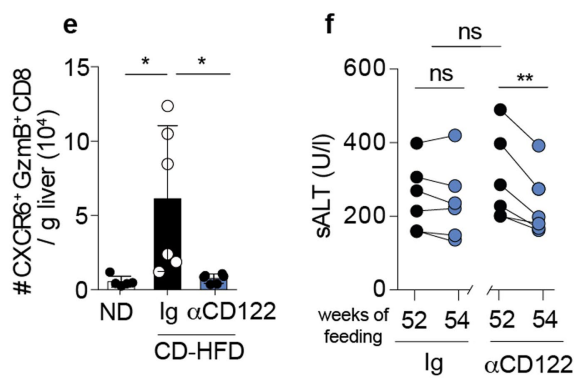

k

I

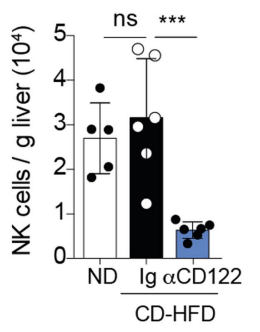

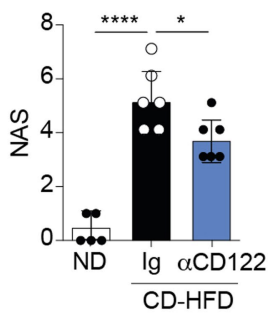

m

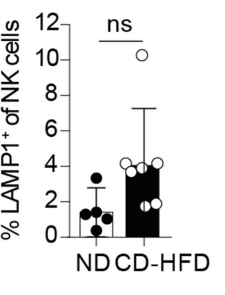

values between groups before treatment, $P=0.7137 . \mathbf{g}-\mathbf{k}$, Numbers of $\mathrm{CX}_{3} \mathrm{CR} 1$ CD8 T cells, $C D 44^{+} \mathrm{CD} 4 \mathrm{~T}$ cells, natural killer T cells and natural killer (NK) cells in the liver after anti-CD122 antibody application from mice in $\mathbf{e . 1}, \mathbf{m}$, No change in phenotype of natural killer cells in NASH mice. Dot plots are representative of $\geq 5$ mice. Exact $P$ values $(\mathbf{a}, \mathbf{b}, \mathbf{e}-\mathbf{m})$ are presented in Source Data. ${ }^{*} P<0.05,{ }^{* *} P<0.01,{ }^{* * *} P<0.001,{ }^{* * * *} P<0.0001$. One-way ANOVA with Tukey's multiple comparison test $(\mathbf{e}, \mathbf{g}-\mathbf{k})$ and paired $(\mathbf{a}, \mathbf{f})$ and unpaired $(\mathbf{b}, \mathbf{l}, \mathbf{m})$ two-tailed $t$-test. In $\mathbf{a}, \mathbf{b}, \mathbf{e}-\mathbf{m}$, data are mean \pm s.e.m., error is reported as s.d. 


\section{Article}
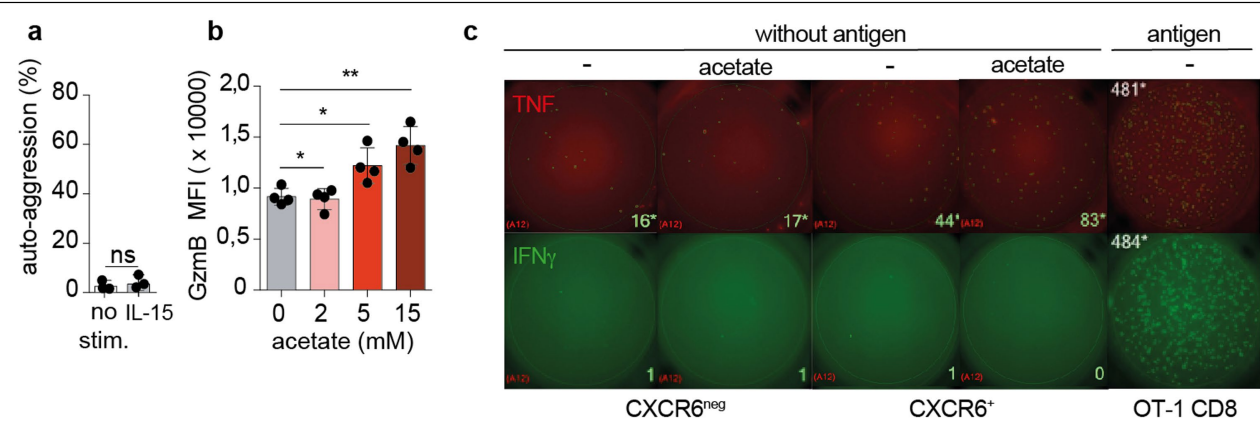

d

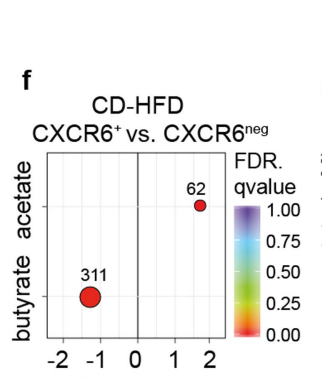

normalized enrichment score
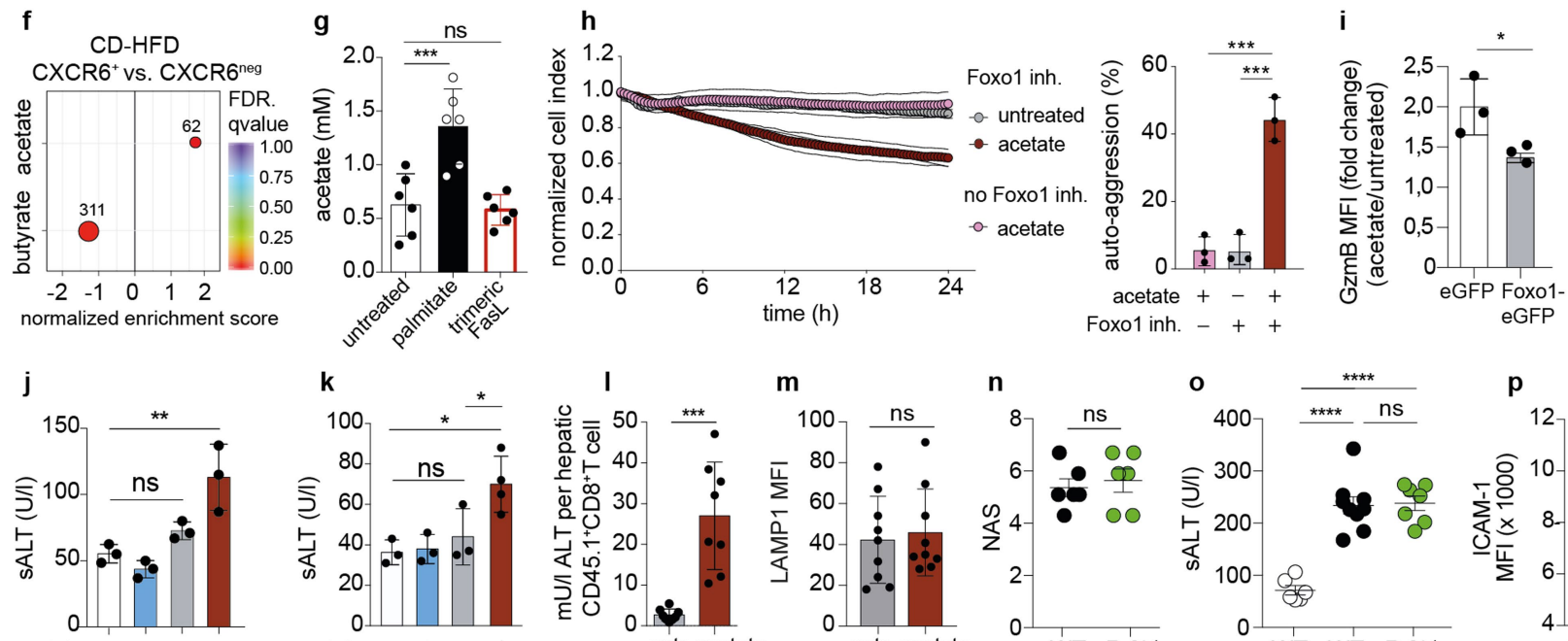

acetate $-+{ }_{-}+$acetate $-+{ }_{-}+$

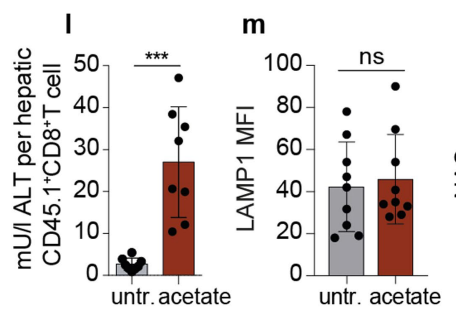

$\frac{\text { WT Prf1- }}{\text { CD-HFD }}$

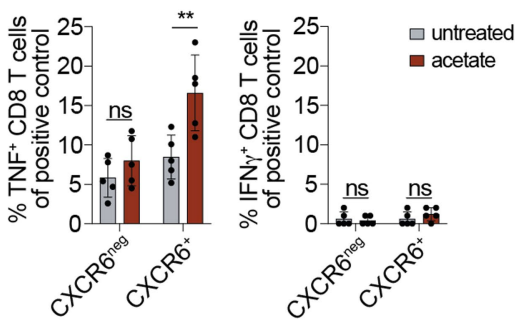

q
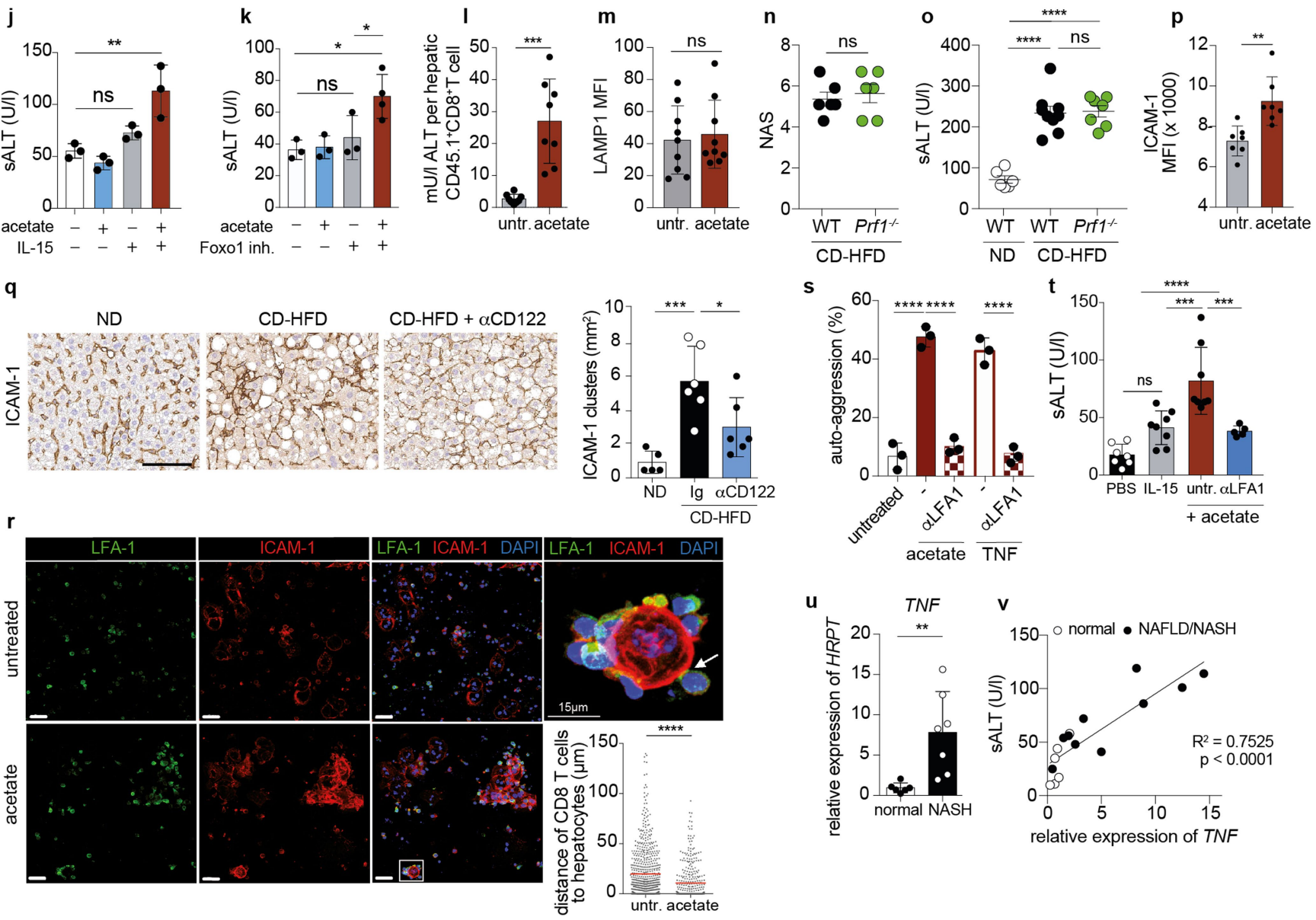

Extended Data Fig. 8 |See next page for caption. 
Extended Data Fig. 8 | IL-15-treated CXCR6 ${ }^{+}$CD8 T cells become autoaggressive after exposure to acetate. a, Auto-aggressive activity of IL-15treated CXCR6 ${ }^{+} \mathrm{FOXO}^{\text {low }} \mathrm{CD} 8 \mathrm{~T}$ cells against hepatocytes $(n=3)$. b, GzmBexpression levels in CXCR6 $6^{+} \mathrm{CD} 8 \mathrm{~T}$ cells exposed for $24 \mathrm{~h}$ to different concentrations of acetate in vitro $(n=4)$. c-e, Fluorospot assay with representative images to quantify TNF and IFN $\gamma$ release from IL-15-stimulated CXCR6 $^{-}$and CXCR6 $^{+}$CD8 1 cells after acetate exposure and from peptidespecific stimulation of OT1CD8 T cells $(n=5)$.f, GSEA for differentially expressed genes from hepatic $\mathrm{CXCR}^{+}$and $\mathrm{CXCR} 6^{-} \mathrm{CD} 8 \mathrm{~T}$ cells of mice fed a CDHFD compared to in vitro-generated memory CD8 T cells exposed to acetate or butyrate. $\mathbf{g}$, Acetate concentrations in supernatants of primary mouse hepatocytes after exposure to palmitate for $24 \mathrm{~h}(250 \mu \mathrm{M})$ or with an agonistic trimeric FasL $\left(25 \mathrm{ng} \mathrm{ml}^{-1}\right)$ to induce cell death $(n=6)$. $\mathbf{h}$, Cytotoxic activity of acetate-exposed polyclonal CD8 T cells after FOXO1 inhibition (AS1842856, $100 \mathrm{nM})$ against hepatocytes $(n=3)$ and quantification. $\mathbf{i}, \mathrm{GzmB}$ expression in acetate-exposed, GFP-expressing CD8 T cells after retroviral transduction with pMP71-GFP-Foxo1 or pMP71-GFP $(n=3)$.j, $\mathbf{k}$, sALT at day 2 after adoptive transfer of IL-15-stimulated or FOXO1-inhibited and acetate-exposed CD8 T cells $(n \geq 3)$. I, Calculation of liver-damage-inducing potential per cell for autoaggressive CD8 T cells $(n=8)$. $\mathbf{m}$, Surface LAMP1 expression on CXCR6 ${ }^{+}$CD8 T cells after a 24 -h exposure to acetate $(15 \mathrm{mM})(n=9) . \mathbf{n}, \mathbf{o}$, Liver damage quantified by NAS and sALT in $\mathrm{Prfl}^{-/}$and littermate control mice after CD-HFD feeding for 1 year. p, ICAM1 expression on hepatocytes in coculture with IL-15-stimulated, acetate-exposed CXCR6 $6^{+}$CD8 T cells $(n=7)$.q, Liver immunohistochemistry with representative images and quantification of ICAM1 clusters per $\mathrm{mm}^{2}$ of liver tissue in mice fed a normal diet $(n=5)$, NASH mice $(n=6)$ and NASH mice treated with anti-CD122 antibody $(n=6)$. Scale bar, $100 \mu \mathrm{m}$. r, Representative microscopic images of IL-15-stimulated, acetateexposed CXCR6 ${ }^{+} \mathrm{CD} 8 \mathrm{~T}$ cells in contact with hepatocytes and quantification of the distance. Arrows indicate polarized LFA1 orientation on T cell interacting with hepatocyte. Scale bars, $30 \mu \mathrm{m}$ (left), $15 \mu \mathrm{m}$ (right).s, Auto-aggressive activity of IL-15-treated $\mathrm{CXCR} 6^{+} \mathrm{CD} 8 \mathrm{~T}$ cells against hepatocytes in presence of acetate $(15 \mathrm{mM})$ or TNF $\left(5 \mathrm{ng} \mathrm{ml}^{-1}\right)$ and anti-LFA1 antibodies $(n=3)$.t, sALT at day 2 after adoptive transfer of auto-aggressive CD8 T cells and injection of anti-LFA1 ( $100 \mu \mathrm{g}$ per mouse) or control immunoglobulin. Two independent experiments. $\mathbf{u}, \mathbf{v}, T N F$ expression in livers from unaffected individuals $(n=6)$ or patients with NASH $(n=7)(\mathbf{u})$ and correlation with SALT (healthy, $n=6$; $\mathrm{NASH}, n=10)(\mathbf{v})$. Cytotoxic activity results are representative of at least three independent experiments. Exact $P(\mathbf{a}, \mathbf{b}, \mathbf{d}, \mathbf{e}, \mathbf{g}-\mathbf{v})$ and $n(\mathbf{n}, \mathbf{o}, \mathbf{t})$ values are presented in Source Data. ${ }^{*} P<0.05,{ }^{* *} P<0.01,{ }^{* * *} P<0.001,{ }^{* * * *} P<0.0001$. Two-way ANOVA with Sidak's multiple comparison test (d, e), one-way ANOVA with Tukey's $(\mathbf{j}, \mathbf{k}, \mathbf{s}, \mathbf{t})$ or with Dunnett's $(\mathbf{b}, \mathbf{g}, \mathbf{h})$ multiple comparison test and unpaired two-tailed $t$-test $(\mathbf{a}, \mathbf{i}, \mathbf{l}-\mathbf{n}, \mathbf{p}, \mathbf{r}, \mathbf{u})$. In $\mathbf{a}, \mathbf{b}, \mathbf{d}, \mathbf{e}, \mathbf{g}-\mathbf{v}$, data are mean \pm s.e.m., error is reported as s.d. 

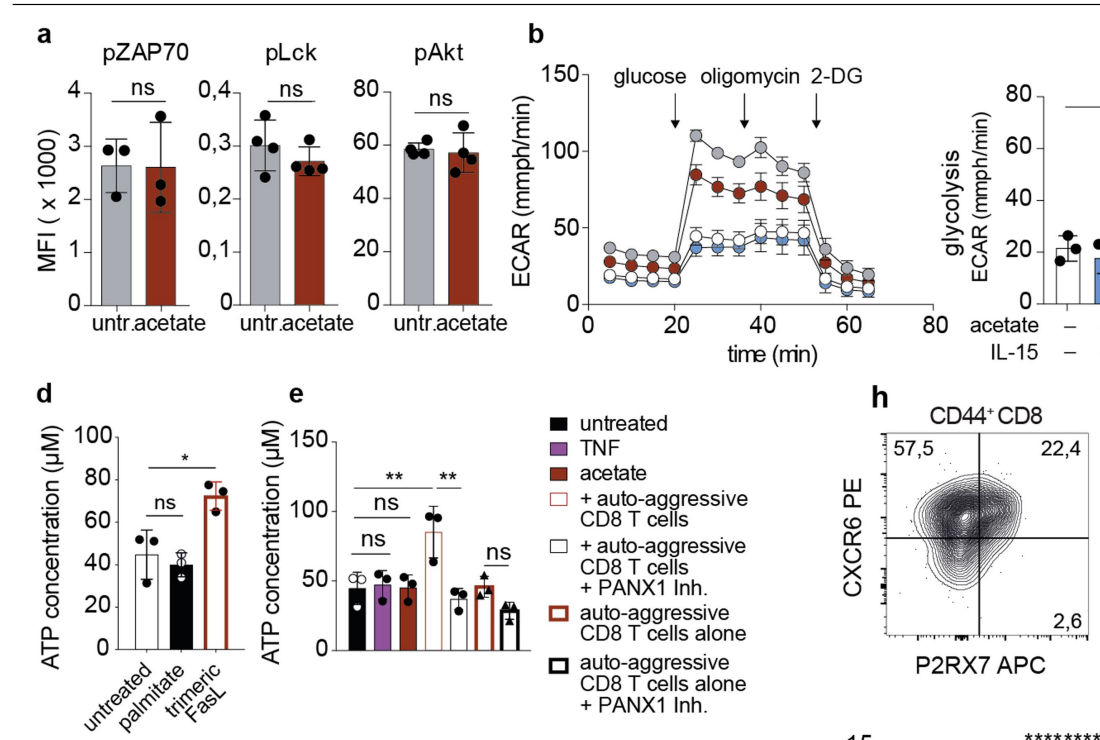$$
\text { i }
$$
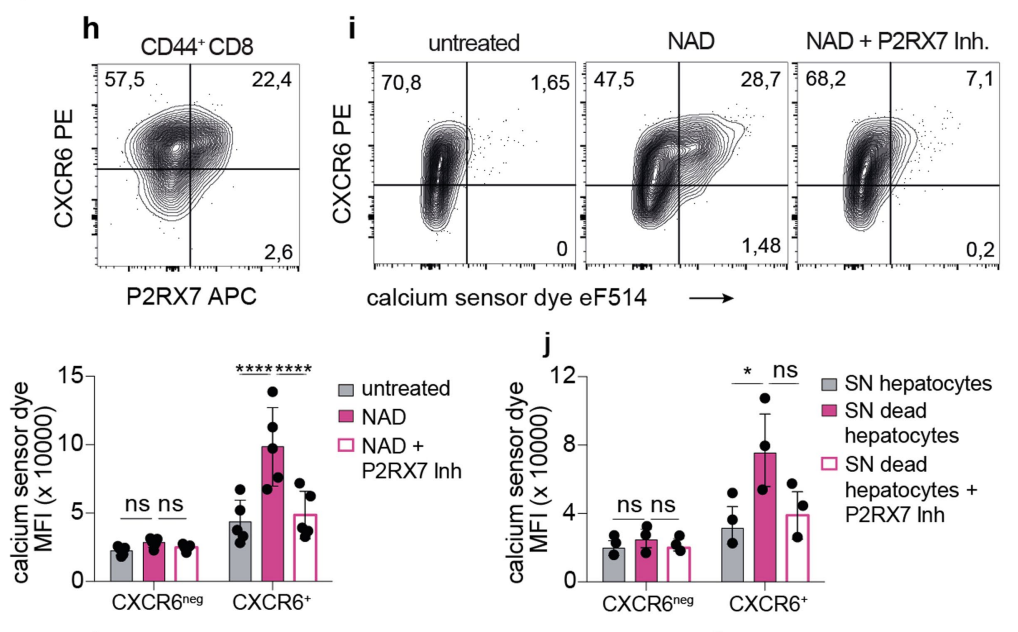

$\mathbf{k}$
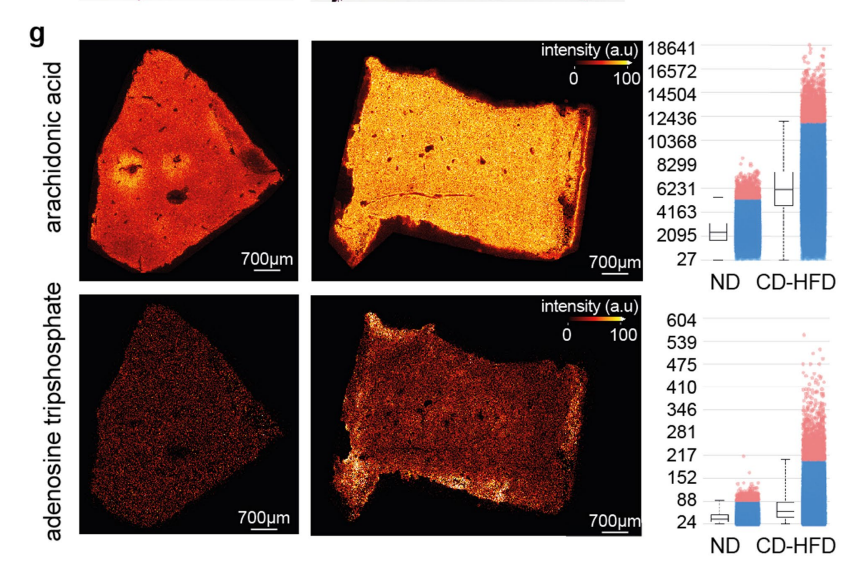

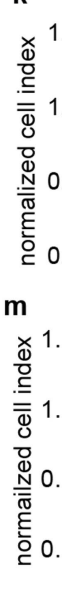
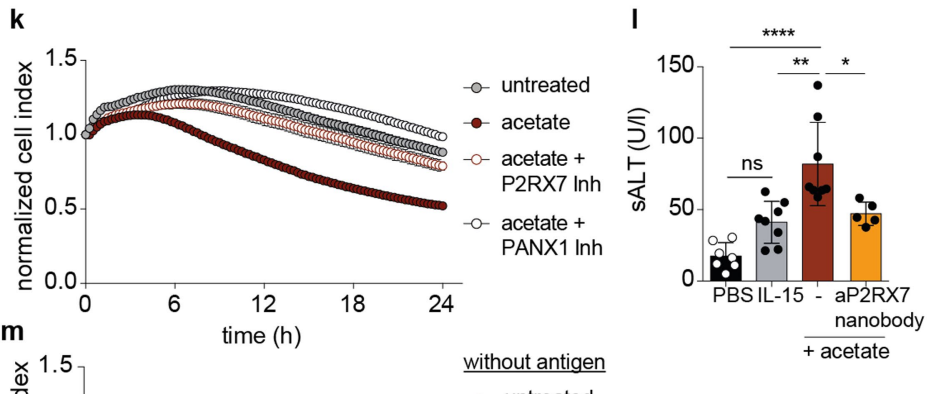

without antigen

-0 untreated

antigen

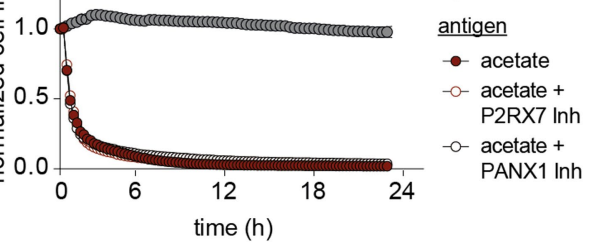

T cells. $\mathbf{i}, \mathbf{j}$, Calcium influx in $\mathrm{CXCR}^{+} \mathrm{CD} 8 \mathrm{~T}$ cells after incubation with NAD $(1 \mu \mathrm{M})(n=5)$ or supernatants from $\mathbf{d}(n=3)$ for $30 \mathrm{~min}$. $\mathbf{k}$, Representative cytotoxicity result of CD8 T cell auto-aggression in the presence of $\mathrm{P} 2 \mathrm{RX} 7$ or PANX1 inhibition $(n=3)$. I, sALT at day 2 after transfer of auto-aggressive CD8 T cells and anti-P2RX7 nanobody ( $50 \mu$ g per mouse). Two independent experiments. $\mathbf{m}$, Representative cytotoxicity result of antigen-specific, IL-15-stimulated and acetate-exposed CXCR6 ${ }^{+} \mathrm{OT} 1 \mathrm{CD} 8 \mathrm{~T}$ cells against S8L-loaded hepatocytes. Exact $P(\mathbf{a}-\mathbf{e}, \mathbf{i}, \mathbf{j}, \mathbf{I})$ and $n(\mathbf{a}, \mathbf{l})$ values are presented in Source Data. ${ }^{*} P<0.05,{ }^{* *} P<0.01,{ }^{* * * *} P<0.0001$. Two-way ANOVA with Tukey's multiple comparison test $(\mathbf{c}, \mathbf{i}, \mathbf{j})$, one-way ANOVA with Tukey's $(\mathbf{b}, \mathbf{e}, \mathbf{l})$ or with Dunnett's (d) multiple comparison test and unpaired two-tailed $t$-test (a). In $\mathbf{a}-\mathbf{e}, \mathbf{i}, \mathbf{j}, \mathbf{I}$ data are mean \pm s.e.m., error is reported as s.d. 

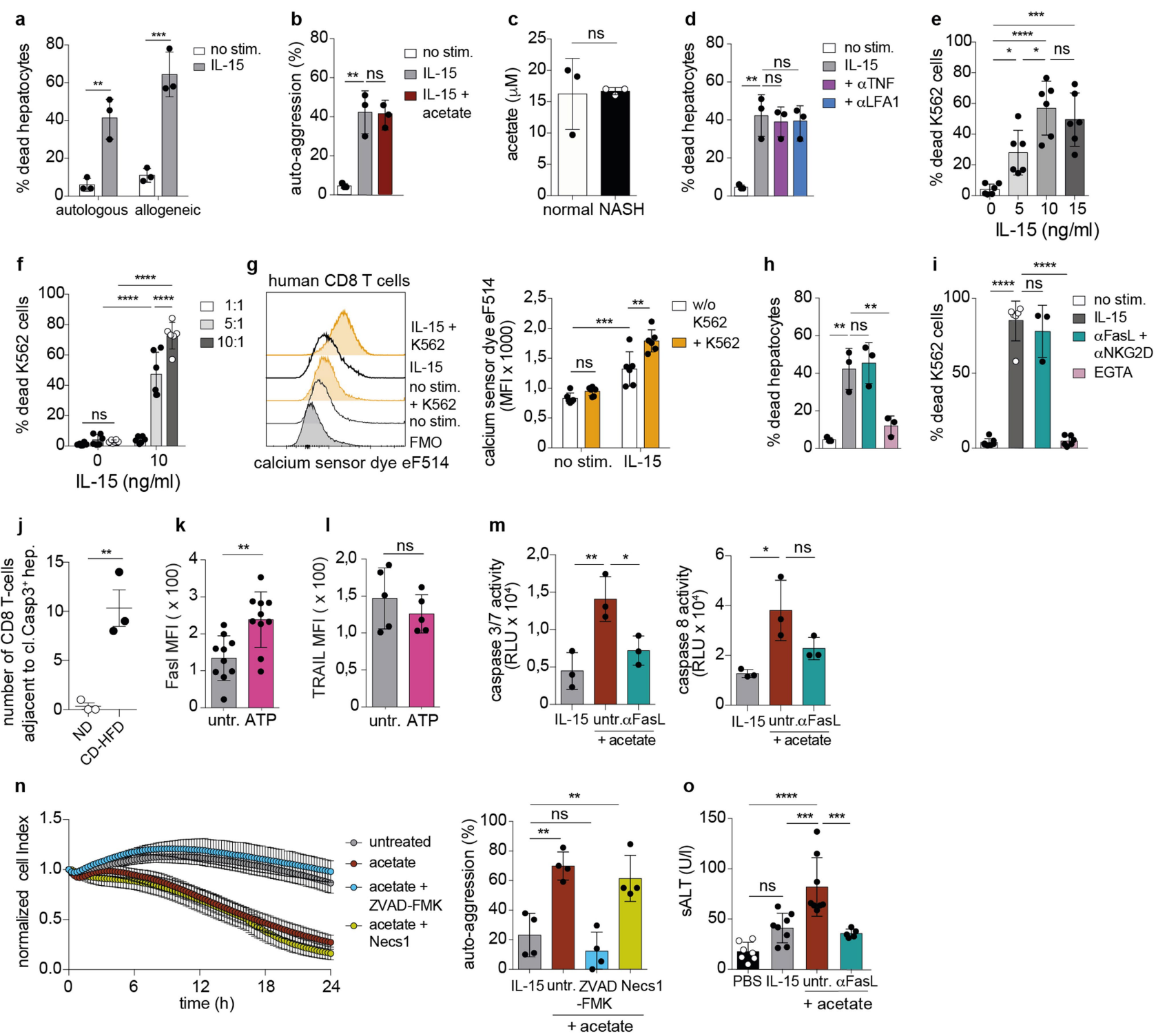

Extended Data Fig. 10 | Auto-aggressive human CD8 T cells. a,

Auto-aggression of allogeneic and autologous CD8 T cells against primary human hepatocytes after incubation with IL-15 (effector-to-target ratio of 3:1 $(n=3))$. b, Auto-aggression by IL-15-treated human CD8 T cells exposed to acetate $(n=3)$.c. Acetate levels in livers from unaffected individuals or patients with NASH $(n=3)$. d, Auto-aggression of human CD8 T cells in presence of anti-TNF $\left(10 \mu \mathrm{g} \mathrm{ml}^{-1}\right)$ or anti-LFA1 $\left(10 \mu \mathrm{g} \mathrm{ml}^{-1}\right)(n=3)$. e, f, Auto-aggression against MHC-I-deficient $\mathrm{K} 562$ cells by human CD8 T cells exposed to IL-15 (e), and at different effector-to-target ratios $(n=6)$. g, Calcium influx in IL15-treated human CXCR6 ${ }^{+} \mathrm{CD} 69^{+} \mathrm{CD} 8 \mathrm{~T}$ cells measured with a calcium sensor dye before or after coculture with $\mathrm{K} 562$ cells and quantification $(n=6)$. $\mathbf{h}, \mathbf{i}$, Auto-aggressive killing of K562 cells by IL-15-treated CD8 T cells in presence of anti-FasL $\left(10 \mu \mathrm{g} \mathrm{ml}^{-1}\right)$, anti-NKG2D $\left(10 \mu \mathrm{g} \mathrm{ml}^{-1}\right)$ or EGTA $(4 \mathrm{mM})$ at effector-to-target ratio of 10:1 $(n=6)$.j, Mean numbers of CD8 T cells adjacent to cleaved CASP $3^{+}$hepatocytes in mice fed a normal diet and NASH mice $(n=3)$. $\mathbf{k}, \mathbf{l}$, Surface FasL and TRAIL expression of mouse CXCR $6^{+}$CD8 T cells after $1 \mathrm{~h}$ exposure to ATP $(200 \mu \mathrm{M})$. m, Caspase activity in primary mouse hepatocytes cocultured with auto-aggressive CD8 T cells and anti-FasL $\left(10 \mu \mathrm{g} \mathrm{m}^{-1}\right)(n=3)$. $\mathbf{n}$, Mouse CD8 T cell auto-aggression in presence of inhibitors against apoptosis (zVAD-FMK, $10 \mu \mathrm{M})$ or necroptosis (Nec-1s, $30 \mu \mathrm{M})(n=4)$. o, sALT at day 2 after adoptive transfer of IL-15-treated, acetate-exposed CD8 $T$ cells and anti-FasL injection (100 $\mu$ g per mouse). Two independent experiments. Exact $P$ $(\mathbf{a}-\mathbf{o})$ and $n(\mathbf{k}, \mathbf{l}, \mathbf{0})$ values are presented in Source Data. ${ }^{*} P<0.05,{ }^{* *} P<0.01$, ${ }^{* * *} P<0.001,{ }^{* * * *} P<0.0001$. Two-way ANOVA with Sidak's (a) and Tukey's (f, $\left.\mathbf{g}\right)$ multiple comparison test, one-way ANOVA with Tukey's multiple comparison test $(\mathbf{b}, \mathbf{d}, \mathbf{e}, \mathbf{h}, \mathbf{i}, \mathbf{m}-\mathbf{o})$ and unpaired two-tailed $t$-test $(\mathbf{c}, \mathbf{j}-\mathbf{l})$. In $\mathbf{a}-\mathbf{o}$, data are mean \pm s.e.m., error is reported as s.d. 


\section{Reporting Summary}

Nature Research wishes to improve the reproducibility of the work that we publish. This form provides structure for consistency and transparency in reporting. For further information on Nature Research policies, see our Editorial Policies and the Editorial Policy Checklist.

\section{Statistics}

For all statistical analyses, confirm that the following items are present in the figure legend, table legend, main text, or Methods section.

n/a Confirmed

$\bigotimes$ The exact sample size $(n)$ for each experimental group/condition, given as a discrete number and unit of measurement

$\bigotimes$ A statement on whether measurements were taken from distinct samples or whether the same sample was measured repeatedly

$\triangle$ The statistical test(s) used AND whether they are one- or two-sided

Only common tests should be described solely by name; describe more complex techniques in the Methods section.

$\bigotimes$ A description of all covariates tested

$\bigotimes$ A description of any assumptions or corrections, such as tests of normality and adjustment for multiple comparisons

$\triangle$ A full description of the statistical parameters including central tendency (e.g. means) or other basic estimates (e.g. regression coefficient)

AND variation (e.g. standard deviation) or associated estimates of uncertainty (e.g. confidence intervals)

$\square$ For null hypothesis testing, the test statistic (e.g. $F, t, r$ ) with confidence intervals, effect sizes, degrees of freedom and $P$ value noted

Give P values as exact values whenever suitable.

\ $\square$ For Bayesian analysis, information on the choice of priors and Markov chain Monte Carlo settings

$\square \bigotimes$ For hierarchical and complex designs, identification of the appropriate level for tests and full reporting of outcomes

$\bigotimes$ Estimates of effect sizes (e.g. Cohen's $d$, Pearson's $r$ ), indicating how they were calculated

Our web collection on statistics for biologists contains articles on many of the points above.

\section{Software and code}

Policy information about availability of computer code

Data collection Data for RNA-seqencing analysis was generated from hepatic CD8 T cells of mice fed a normal diet or choline-deficient high fat diet for 12 months.

Data for single-cell RNA-sequencing analysis was generated from hepatic CD45+ cells of steatotic and NASH patients undergoing bariatric surgery.

Data for single-cell RNA-sequencing analysis was generated from CD45+ CD3+ cells of from fat tissue of NASH patients undergoing bariatric surgery.

Genesets from public available sources used for GSEA are described in the method section.

Following machines for data collection were used: SP6800, SA3800 and SH800 (Sony Biotechnology); Seahorse XF 96 Analyser (Agilent Technologies); Luminex 200 Instrument System (Thermo); xCelligence RTCA MP device (ACEA Biosciences); Leica Biosystems Bond MAX; Tecan Infinite M1000 (Tecan); Leica confocal microscope TCS SP8; TimsTOF Flex mass spectrometer (Bruker); Immunospots ${ }^{\circledR}$ S6 ULTIMATE Analyzer; LightCycler 480 (Roche); ViiA7 (Applied Biosystems); NextSeq 500 (Illumina); HiSeq 3000 and NovaSeq6000 (Illumina); Amnis ImageStream (Millipore); Reflotron ${ }^{\circledR}$ plus system (Roche); Fuji DRI-CHEM NX500i (Fujifilm)

Data analysis Following machines for data analysis were used: Drop-seq 1.12, DESeq2 v2.1.28.1 R package; Seurat v3.2.2 R package; BART v1.1, igraph v1.2.6 R package; Cytofkit v1.11.3 R package; pheatmap v1.0.12 R package; ggpubr v0.4.0 R package; ggplot2 v3.3.2 R package; Graph Pad Prism v9 (Graph-Pad Software); FlowJo v10.8; Arivis Vision 4D (Arivis); Limma v3.44.3 R package; Cytoscape v3.7.1; MSigDB v6.2; GSEA v4.0.3; Sony SP Spectral Analyzer Software 2.0.2.14140 (Sony Biotechnology); Sony SA Software 2.0.2.04040 (Sony Biotechnology); SH Software V1.8.2 (Sony Biotechnology); Imaris software (Version 9.5, Bitplane); SCiLS Lab (Bruker Daltonics); Seahorse XF 96 Analyzer Software v1.4.2 (Agilent Technologies); CTL Immunospot 5.4 Professional DC Software (CTL Europe); IDEAS software v6.2; RTCA Software Pro; Luminex 200 


\section{Data}

Policy information about availability of data

All manuscripts must include a data availability statement. This statement should provide the following information, where applicable:

- Accession codes, unique identifiers, or web links for publicly available datasets

- A list of figures that have associated raw data

- A description of any restrictions on data availability

Data from murine RNAseq are deposited at GEO accession number: GSE145104.

Single-cell RNA-sequencing data of CD45+ cells from liver tissue of steatotic and NASH patients: GSE159977.

Single cell RNA-sequencing data of fat tissue from NASH patients: EGAS00001004738.

All other datasets generated during the current study are available from the corresponding authors on reasonable request.

\section{Field-specific reporting}

Please select the one below that is the best fit for your research. If you are not sure, read the appropriate sections before making your selection.

$\bigotimes$ Life sciences $\quad \square$ Behavioural \& social sciences $\quad \square$ Ecological, evolutionary \& environmental sciences

For a reference copy of the document with all sections, see nature.com/documents/nr-reporting-summary-flat.pdf

\section{Life sciences study design}

All studies must disclose on these points even when the disclosure is negative.

Sample size Pilot experiments and previous published results (Wolf et al, 2014; Malehmir et al., 2019) were used to estimate the sample size such that appropriate statistical tests could yield significant results. The exact $n$ numbers used in the study are indicated in the respective figure legends.

Data exclusions Every mouse fed a normal diet or a choline-deficient high fat diet was included in the analysis. The complete dataset on any individual human or murine sample for flow cytometry was excluded if any obvious problem during sample processing occurred, i.e. more than 70 percent dead cells identified by live dead staining.

Replication All experiments were repeated and validated as stated in the respective figure legends.

Randomization Murine experiments: 6-week-old C57BI/6 mice were randomly allocated into different groups and were fed with appropriated diet or treatment regimens. Human experiments: As described in the figure legends, statistical analysis was corrected for the covariate age.

Blinding Murine experiments were rated in a blinded manner. Further analysis was performed unblinded because the type of diet (ND and CD-HFD could be identified by the researcher on the basis of the colour of the food (ND=brown, CD-HFD=green). Immunohistochemistry, confocal microscopy and serum parameter analysis was performed in a blinded fashion with code-labelling. Every experiment was performed using several control samples and the applied analysis strategy (especially FACS gating strategy) was identical for every single sample. Human experiments: During analysis, patient data underwent pseudonymisation and was blinded to the analyser.

\section{Reporting for specific materials, systems and methods}

We require information from authors about some types of materials, experimental systems and methods used in many studies. Here, indicate whether each material, system or method listed is relevant to your study. If you are not sure if a list item applies to your research, read the appropriate section before selecting a response.

Materials \& experimental systems

n/a
$\square$
$\square$
$\searrow$
$\square$
$\square$
$\square$
$\searrow$

n/a Involved in the study

$\bigotimes$ Antibodies

$\bigotimes$ Eukaryotic cell lines

$\triangle \square$ Palaeontology and archaeology

$\bigotimes$ Animals and other organisms

$\square$ Human research participants

$\bigotimes \square$ Clinical data

$凶$

\begin{tabular}{l|l} 
Methods \\
\hline n/a & Involved in the study \\
$\square$ & $\square$ ChIP-seq \\
$\square$ & $\bigotimes$ Flow cytometry \\
$\square$ & $\square$ MRI-based neuroimaging
\end{tabular}


Antibodies used

Following mouse antibodies for flow cytometry were purchased from BioLegend: anti-CD4 (PM4-5), anti-CD8 (53-6.7), anti-CD44 (IM7), anti-CD69 (H1.2F3), anti-CD178 (FasL, MFL3), anti-CD183 (CXCR3-173), antiCD186 (CXCR6, SA051D1), anti-CD253 (TRALL, N2B2), anti-CD279 (PD-1, 29F.1A12), anti-CX3CR1 (SA011F11), IFNg (XM61.2), anti-KLRG1 (2F1), anti-NK1.1 (PK136), anti-TCRb (H57-597). Following mouse antibodies for flow cytometry were purchased from ThermoFisher. anti-Blimp1 (5E7), anti-BCl-2 (100), anti-CD3 (17A2), anti-CD11a (1217), anti-CD45.1 (A20), anti-CD49a (HMa1), anti-CD54 (ICAM-1, YN1/1.7.4), anti-CD62 作 (eBio4B10), anti-TNF (MP6-XT22), TOX (TXRX10). Anti-Foxo1 (C29H4) was purchased from Cell Signaling.

Following human antibodies for flow cytometry were used: anti-CD3 (SK7, BioLegend), anti-CD8 (HIT8a, BioLegend), anti-CD45 (HI-30, BioLegend), anti-CD69 (FN50, BioLegend), anti-CD186 (K041E5, BioLegend), anti-GzmB (GB11, ThermoFisher), anti-Foxo1 (C29H4, Cell Signaling).

Detection of cytokine concentrations in serum was performed with a 23-plex bead
assay (ELISA) for IL-15 (Peprotech, \#900-K188) or IL-21 (Peprotech, \#900-K368).

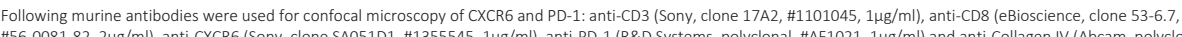

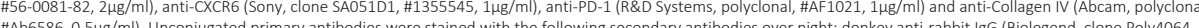

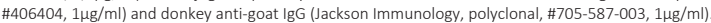
rat anti-mouse CD8 (1:200, 4SM15, ThermoFisher), rabbit anti-mouse cleaved caspase-3 (1:300, D3E9, Cell Signaling Technology), goat anti-mouse collagen IV-a1 (\#nb120-6586, 1:30, polyclonal, Novus Biologicals) Fluor 647 donkey anti-goat IgG $(\mathrm{H}+\mathrm{L})(\# A-21447$, ThermoFisher, $2 \mu \mathrm{g} / \mathrm{ml})$,

Following murine antibodies were used for multiplex immunohistochemistry: anti-PD-1 (1/200, R\&D Systems, \#AF1021), anti-CD8a (1/200, ThermoFisher \#14-0808-82), anti-aSMA (1/200, Agilent \#M085129-2 anti-IBA1 (1/1,000, EMD Millipore \#MABN92), anti-CK19 (1/200, DSHB \#TROMA-III). TROMA-III was deposited to the DSHB by Kemler, R. (DSHB Hybridoma Product TROMA-III).

Following murine antibodies were used for immunohistochemistry: anti-ICAM-1, 1:1500, clone 3E2B, \#MA5405, ThermoFisher

Following murine and human antibodies were used for CD8 T cell cytotoxicity assays: TNF (ThermoFisher, \#PMC3013), IL-6 (Miltenyi Biotec, \#130-094-065), IL-1 (Peprotech, \#211-11B), anti-LFA1 (mouse: BioXcel, M17/4, BE0006, $10 \mu \mathrm{g} / \mathrm{ml}$; human: BioXcell, \#BE0192,R7-1, $10 \mu \mathrm{g} / \mathrm{ml}$ ), anti-mouse MHCI (BioXcell, M1/42.3.9.8, \#BE0077, $10 \mu \mathrm{gg} / \mathrm{mll}$ ), anti-mouse PD-1 (BioXcell, RMP1-14, \#BE0146, $10 \mu \mathrm{g} / \mathrm{ml})$, anti-mouse TNFR1

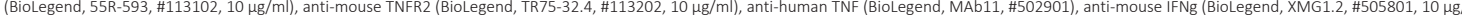

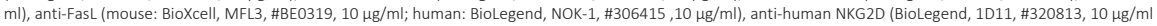

Validation

All antibodies described in the previous section underwent quality control by the companies.

BioLegend tested the quality of their antibodies for flow cytometry by using the following protocols: intracellular (True-Nuclear ${ }^{\text {tw }}$ Transcription Factor Staining Protocol, https://www.biolegend.com/protocols/true NF (A) . Exp. Med. 182:1777) and anti-human NKG2D (G

ThermoFisher: all antibodies for surface and intracellular targets have been tested by flow cytometric analysis of mouse splenocytes or human peripheral blood mononuclear cells (e.g. mouse CD3: https://

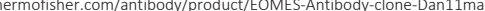
Monoclonal/53-4875-82, e.g. human GzmB: https://www.thermofisher.com/antibody/product/Granzyme-B-Antibody-clone-GB11-Monoclonal/12-8899-41).

Cell Signaling: Foxo1 antibody was tested for flow cytometry by using Jurkat cells and anti-rabbit (H+L), F(ab')2 Fragment (PE Conjugate, \#8885) as a secondary antibody with the following protocol: https:// www.cellsignal.com/products/primary-antibodies/toxo1-c29h4-rabbit-mab/2880

Peprotech: valiation of IL-15 and IL-21 for ELISA application is described here. https://www.peprotech.com/de/anti-mu R\&D: validation of PD-1 for IHC is described here: https://www.rndsystems.com/products/mouse-pd-1-antibody_af1021 BioXcell: validation of binding spefiction for each blocking antibody was performed by western blotting of

Novus biologicals: validation of antibody specificity of anti-mouse collagen IV was performed by genetic strategies: https://www.novusbio.com/products/collagen-iv-antibody nb120-6586

\section{Eukaryotic cell lines}

Policy information about cell lines

Cell line source(s)

K562 cells were obtained from ATCC

https://www.lgcstandards-atcc.org/products/all/CCL-243.aspx)

Retroviral packaging cell line Plat-Eco were optained from Cell Biolabs https://www.cellbiolabs.com/

platinum-e-plat-e-retroviral-packaging-cell-line

Authentication

The cells were authenticated by the vendor and no further authentication was performed in the laboratory

Mycoplasma contamination

All cell lines were routinely tested negative for mycoplasma contamination

Commonly misidentified lines

(See ICLAC register)

No commonly misidentified cell lines were used

\section{Palaeontology and Archaeology}

Specimen provenance Provide provenance information for specimens and describe permits that were obtained for the work (including the name of the issuing authority, the date of issue, and any identifying information).

Specimen deposition Indicate where the specimens have been deposited to permit free access by other researchers.

Dating methods

If new dates are provided, describe how they were obtained (e.g. collection, storage, sample pretreatment and measurement), where they were obtained (i.e. lab name), the calibration program and the protocol for quality assurance OR state that no new dates are provided.

Tick this box to confirm that the raw and calibrated dates are available in the paper or in Supplementary Information.

Ethics oversight

Identify the organization(s) that approved or provided guidance on the study protocol, OR state that no ethical approval or guidance was required and explain why not.

Note that full information on the approval of the study protocol must also be provided in the manuscript. 


\section{Animals and other organisms}

Policy information about studies involving animals; ARRIVE guidelines recommended for reporting animal research

Laboratory animals

- C57BI/6 mice were purchased from Charles River (Sulzfeld, Germany). H-2Kb-restricted T-cell receptor (TCR) transgenic CD45.1+ OT1 mice were bred and maintained under specific pathogen-free (SPF) conditions in the centre for preclinical research, School of Medicine, TUM, according to the guidelines of the Federation of Laboratory Animal Science Association. Male mice between the ages of 6 and 10 weeks were used in experiments. All experiments with these mice were approved by Regierung Oberbayern (55.2-1-54-2532-60-14)

- 6-week-old male C57BI/6, Prf1-/-, Cd1d-/-, Ja18-/- and Tcrb-/-, Tcrd-/- mice were fed with a normal diet, a choline-deficient high fat diet or western diet with trans fat ad libitum and housed at the at German Cancer Research Center (DKFZ) according to the guidelines of the Federation of Laboratory Animal Science Association. All experiments with these mice including interventional studies were performed in accordance to German Law (g129/16).

Wild animals

No wild animals were used in this study

Field-collected samples No field-collected samples were used in this study

Ethics oversight

All mice were kept according to the guidelines of the Federation of Laboratory Animal Science Association and experiments were authorized by permission of the Regierung of Oberbayern and the animal reserach committee at the DKFZ g129/16 and

55.2-1-54-2532-60-14.

Note that full information on the approval of the study protocol must also be provided in the manuscript.

\section{Human research participants}

Policy information about studies involving human research participants

Population characteristics

Patients with NAFLD/NASH were admitted for minilaroscopy-guided liver biopsy or bariatric surgery at the University Hospital Hamburg Eppendorf, at the University Clinic for Visceral Surgery and Medicine (Inselspital), at the Medical University Innsbruck, at the Department of General and Visceral Surgery (University of Freiburg) or at the Heidelberg University Hospital. The patients were recruited into the study after they gave written and informed consent.

Recruitment

Consecutive patients presenting to the outpatient's department at the University hospitals of Heidelberg, Freiburg, München, Hamburg, Bern and Innsbruck were included into the study after they gave written informed consent.

Ethics oversight

All experiments with human liver samples were approved by the ethics committee of Hamburg, Germany (PV5184 and PV5187), Innsbruck, Austria (AN2017-0016 369/4.21) and Bern, Switzerland (2020-00852). Single cell RNAseq-analysis of CD3 + lymphocytes from human liver tissue and mesenterial fat tissue was approved by the Medical Ethics Committee of Heidelberg University (S-629/2013) and the Ethics Committee of Freiburg University (544/17). Experiments with normal human liver samples for isolating primary human hepatocytes were approved by the ethics committee at TUM (232/19S).

\section{Clinical data}

Policy information about clinical studies

All manuscripts should comply with the ICMJE guidelines for publication of clinical research and a completed CONSORT checklist must be included with all submissions.

Clinical trial registration

Provide the trial registration number from ClinicalTrials.gov or an equivalent agency.

Study protocol

Note where the full trial protocol can be accessed OR if not available, explain why.

Data collection

Describe the settings and locales of data collection, noting the time periods of recruitment and data collection.

Outcomes

Describe how you pre-defined primary and secondary outcome measures and how you assessed these measures.

\section{Dual use research of concern}

Policy information about dual use research of concern

Hazards

Could the accidental, deliberate or reckless misuse of agents or technologies generated in the work, or the application of information presented in the manuscript, pose a threat to: 

No $\mid$ Yes
$\square$ Public health
$\square \square$ National security
$\square$ Crops and/or livestock
$\square \square$ Ecosystems
$\square(\square$ Any other significant area

\section{Experiments of concern}

Does the work involve any of these experiments of concern:

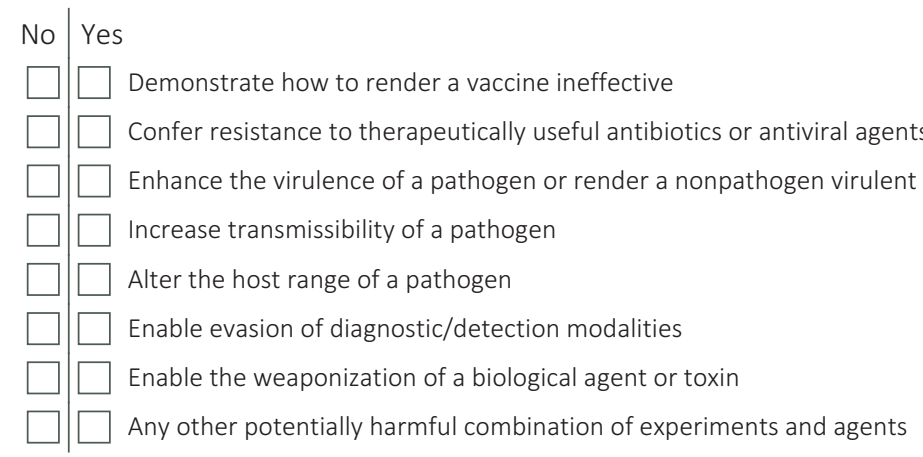

ChIP-seq

\section{Data deposition}

$\square$ Confirm that both raw and final processed data have been deposited in a public database such as GEO.

$\square$ Confirm that you have deposited or provided access to graph files (e.g. BED files) for the called peaks.

Data access links

May remain private before publication

Files in database submission

Genome browser session (e.g. UCSC)

\section{Methodology}

Replicates

Sequencing depth

Antibodies

Peak calling parameters

Data quality

Software
For "Initial submission" or "Revised version" documents, provide reviewer access links. For your "Final submission" document, provide a link to the deposited data.

Provide a list of all files available in the database submission.

Provide a link to an anonymized genome browser session for "Initial submission" and "Revised version" documents only, to enable peer review. Write "no longer applicable" for "Final submission" documents. 


\section{Plots}

Confirm that:

$\bigotimes$ The axis labels state the marker and fluorochrome used (e.g. CD4-FITC).

$\bigotimes$ The axis scales are clearly visible. Include numbers along axes only for bottom left plot of group (a 'group' is an analysis of identical markers). $\bigotimes$ All plots are contour plots with outliers or pseudocolor plots.

$\bigotimes$ A numerical value for number of cells or percentage (with statistics) is provided.

\section{Methodology}

Sample preparation

Instrument

Software

Cell population abundance

Gating strategy

\begin{abstract}
For isolation of splenic immune cells, the spleen was removed and mechanically disrupted, filtered through a $70-\mu m$ strainer, and red blood cells were lysed with 2 minutes incubation with ammonium chloride potassium buffer. Spleen cells were washed twice with cold PBS. For isolation of hepatic immune cells, murine liver was perfused via the portal vein for a minute and subsequently passed through a $100 \mu \mathrm{m}$ mesh sieve, washed and the cell pellet was resuspended in $8 \mathrm{ml}$ of GBSS containing collagenase IV (1:400, Worthington, \#LS004189) and digested in a rotatory shaker (240 rpm) for $15 \mathrm{~min}$ at $37^{\circ} \mathrm{C}$. The cell suspension was washed and lymphocytes were isolated through Percoll (40/80, GE Healthcare, \#10607095) density centrifugation (7 acceleration, 1 deceleration, 1440?? g, for $25 \mathrm{~min}$ ). For stimulation of lymphocytes, cells were stimulated with IL-15R?/IL-15 (10 ng/ml, ThermoFisher, \#14-8152-80), IL-21 (10 ng/ml, Peprotech, \# 210-21), IL-7 (10 ng/ml, Peprotech, \# 217-17), IL-2 (10 ng/ml), TGF? (10 ng/ml, Peprotech, \#100-21), IFN? (10 ng/ml, Peprotech, \#315-05), IL-1 (10 ng/ml, Peprotech, \#211-11B) or TNF (5 ng/ml, ThermoFisher, \#PMC3013) for 18 hours followed by flow cytometry analysis. For isolation of lymphocytes from kidney, the renal capsula was removed and kidneys were digested by injecting $1 \mathrm{ml}$ PBS containing type IV collagenase (1 mg/ml, Worthington, \#LS004189) and DNAse I (50 U/ml, Roche, \#04716728001). After mechanical dissection, tissue was incubated for $60 \mathrm{~min}$ at $37^{\circ} \mathrm{C}$, the cell suspension was filtered through a $70-\mu \mathrm{m}$ mesh strainer, washed and subjected to Percoll (40\%/80\%) density centrifugation ( $1440 \mathrm{xg}$, for $25 \mathrm{~min}$ ). For isolation of lymphocytes from murine skin, ears were cut and the dorsal side was removed from the ventral side. After cutting in small pieces, the tissue suspension was digested with $3 \mathrm{mI}$ PBS solution containing type IV collagenase $(2 \mathrm{mg} / \mathrm{ml}$ ) and DNAse I (50 $\mathrm{U} / \mathrm{ml}$ ) for $60 \mathrm{~min}$ at $37^{\circ} \mathrm{C}$. Finally, the cell suspension was filtered through a $70-\mu \mathrm{m}$ mesh strainer, washed and were ready for subsequent analysis. For isolation lymphocytes from the lung, both lobes were removed and digested by injecting $1 \mathrm{ml} \mathrm{PBS}$ solution containing type IV collagenase $(1 \mathrm{mg} / \mathrm{ml})$ and DNAse I $(50 \mathrm{U} / \mathrm{ml})$. After tearing the lobes apart and removing remaining air by pipetting, tissue suspension was digested for $30 \mathrm{~min}$ at $37^{\circ} \mathrm{C}$. Finally, tissue suspension was filtered through a $70-\mu \mathrm{m}$ strainer, washed and subjected to Percoll (40\%/80\%)-density centrifugation (1440 x g, $25 \mathrm{~min}$ ).

To generate cell suspension from human liver tissue for flow cytometric analysis, tissue was mashed through a $100 \mu \mathrm{m}$ strainer and centrifuged $(400 \times \mathrm{g}, 5 \mathrm{~min})$. After cautiously decanting the supernatant, cell pellet was resuspended in medium (RPMI $1640+10 \% \mathrm{FCS}+1 \% \mathrm{P} / \mathrm{S}$ ) and centrifuged again before proceeding with flow cytometric analysis.
\end{abstract}

PBMCs were generated from blood of healthy, voluntary donors which was approved by a vote from the ethics committee of the University Hospital München rechts der Isar. Blood was mixed with PBS (1:1) and loaded on Pancoll (PAN Biotech, \#P04-601000) to isolate PBMCs through centrifugation (1400 g, $25 \mathrm{~min}$ ).

Sony SP6800 Spectral Analyser, Sony SA3800 Spectral Analyser, Sony SH800 Cell sorter

FlowJo software, Tree Star, Ashland, USA v10

All samples were sorted using "high-purity" mode and every sample underwent a post-sort purity check. If sort purity was < $95.0 \%$ of the FSC/SSC gate of starting cell population

FSC-A/SSC-A -> FSC-H/FSC-A -> FSC-A/Live-Dead -> cells of interest defined as "alive cells", folllowed by staining for T cells.

$\bigotimes$ Tick this box to confirm that a figure exemplifying the gating strategy is provided in the Supplementary Information.

\section{Magnetic resonance imaging}

\section{Experimental design}

Design type

Design specifications

Behavioral performance measures
Indicate task or resting state; event-related or block design.

Specify the number of blocks, trials or experimental units per session and/or subject, and specify the length of each trial or block (if trials are blocked) and interval between trials.

State number and/or type of variables recorded (e.g. correct button press, response time) and what statistics were used to establish that the subjects were performing the task as expected (e.g. mean, range, and/or standard deviation across subjects). 
Acquisition

Imaging type(s)

Specify: functional, structural, diffusion, perfusion.

Field strength

Specify in Tesla

Sequence \& imaging parameters

Specify the pulse sequence type (gradient echo, spin echo, etc.), imaging type (EPI, spiral, etc.), field of view, matrix size, slice thickness, orientation and TE/TR/flip angle.

Area of acquisition

State whether a whole brain scan was used OR define the area of acquisition, describing how the region was determined.

Diffusion MRI

Used

Not used

Preprocessing

Preprocessing software

Provide detail on software version and revision number and on specific parameters (model/functions, brain extraction, segmentation, smoothing kernel size, etc.).

Normalization

If data were normalized/standardized, describe the approach(es): specify linear or non-linear and define image types used for transformation OR indicate that data were not normalized and explain rationale for lack of normalization.

Normalization template

Describe the template used for normalization/transformation, specifying subject space or group standardized space (e.g. original Talairach, MNI305, ICBM152) OR indicate that the data were not normalized.

Noise and artifact removal

Describe your procedure(s) for artifact and structured noise removal, specifying motion parameters, tissue signals and physiological signals (heart rate, respiration).

Volume censoring

Define your software and/or method and criteria for volume censoring, and state the extent of such censoring.

Statistical modeling \& inference

Model type and settings Specify type (mass univariate, multivariate, RSA, predictive, etc.) and describe essential details of the model at the first and second levels (e.g. fixed, random or mixed effects; drift or auto-correlation).

Effect(s) tested

Define precise effect in terms of the task or stimulus conditions instead of psychological concepts and indicate whether ANOVA or factorial designs were used.

Specify type of analysis:

$\square$ Whole brain $\square$ ROI-based $\square$ Both

Statistic type for inference (See Eklund et al. 2016)

Correction

Specify voxel-wise or cluster-wise and report all relevant parameters for cluster-wise methods.

Describe the type of correction and how it is obtained for multiple comparisons (e.g. FWE, FDR, permutation or Monte Carlo)

Models \& analysis

$\mathrm{n} / \mathrm{a}$ | Involved in the study

$\square$ Functional and/or effective connectivity

$\square$ Graph analysis

$\square$ Multivariate modeling or predictive analysis

Functional and/or effective connectivity

Report the measures of dependence used and the model details (e.g. Pearson correlation, partial correlation, mutual information).

Graph analysis

Report the dependent variable and connectivity measure, specifying weighted graph or binarized graph, subject-or group-level, and the global and/or node summaries used (e.g. clustering coefficient, efficiency, etc.).

Multivariate modeling and predictive analysis

Specify independent variables, features extraction and dimension reduction, model, training and evaluation metrics. 